Luís Fabiano Assaf Bastos

\title{
A INFLUENNCIA DE EFEITOS DE ALTA FREQUÊNCIA DO REGIME DE VENTOS NA RESSURGÊNCIA DE CABO FRIO
}

Dissertação apresentada à Comissão de Pós-Graduação do Instituto Oceanográfico da Universidade de São Paulo, como parte dos requisitos para obtenção do Título de Mestre em Ciências, área de Oceanografia Física.

Orientador: Prof. Dr. Edmo José Dias Campos 


\title{
UNIVERSIDADE DE SÃO PAULO \\ INSTITUTO OCEANOGRÁFICO
}

\section{A influência de efeitos de alta frequência do regime de ventos na ressurgência de cabo frio}

\author{
Luís Fabiano Assaf Bastos
}

Dissertação apresentada ao Instituto Oceanográfico da Universidade de São Paulo, como parte dos requisitos para obtenção do Título de Mestre em Ciências; área: Oceanografia Física.
Julgada em
/ $/$ por:

Prof. Dr. Edmo José Dias Campos

Conceito

Prof. Dr. do Instituto Oceanográfico da Universidade de São Paulo

Prof. Dr. Belmiro Mendes de Castro Filho

Conceito

Prof. Dr. do Instituto Oceanográfico da Universidade de São Paulo

Prof. Dr. Ricardo Camargo

Conceito

Prof. Dr. do Instituto de Astronomia, Geofísica e Ciências Atmosféricas da Universidade de São Paulo 


\section{Sumário}

Agradecimentos $\quad$ iii

Resumo iv

Abstract $\quad$ v

Lista de Figuras viii

1 Introdução 1

1.1 O fenômeno da Ressurgência . . . . . . . . . . . . . . . . . . . . 1

1.2 Embasamento teórico da Dinâmica de Ekman . . . . . . . . . . . 5

1.2.1 Camada de Superfície. . . . . . . . . . . . . . 5

1.2.2 A velocidade no topo da Camada de Ekman . . . . . . . . 8

1.2.3 O Transporte de Ekman . . . . . . . . . . . . . . . . . . 9

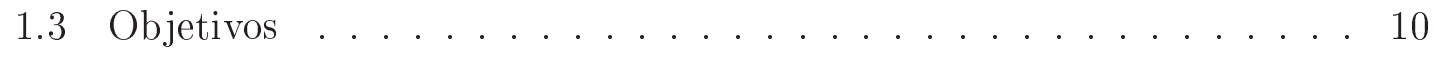

1.4 Estrutura do Trabalho . . . . . . . . . . . . . . . . 10

2 Descrição da Região de Estudo $\quad 11$

2.1 Área de Estudo . . . . . . . . . . . . . . . . . . . . 11

2.2 Batimetria da Região de Estudo . . . . . . . . . . . . . . . . . 12

2.3 Climatologia da Região de Estudo . . . . . . . . . . . . . . 15

3 Material e Métodos 20

3.1 Dados Hidrográficos . . . . . . . . . . . . . . . 20

3.2 Dados de ventos . . . . . . . . . . . . . . . . . . . . . 21

3.3 O Modelo Numérico . . . . . . . . . . . . . . . . . . 31 
4 Discussão dos resultados $\quad 34$

4.1 Análise dos Dados Hidrográficos de verão e inverno . . . . . . . . . . 34

4.2 O Modelo Numérico . . . . . . . . . . . . . . . . . . . 57

4.2.1 Experimento Forçado com Output do RAMS . . . . . . . . . . 57

4.2.2 Experimento forçado com vento sintético . . . . . . . . 66

5 Conclusão e sugestões para trabalhos futuros $\quad 73$

5.1 Sumário e Conclusões . . . . . . . . . . . . . . . . . 73

5.2 Sugestão para trabalhos futuros . . . . . . . . . . . . . . 74

$\begin{array}{ll}\text { Referências Bibliográficas } & 74\end{array}$ 


\section{Agradecimentos}

Agradeço a todos aqueles que de certa forma colaboraram para que este trabalho chegasse ao fim. Inicialmente a minha esposa Keler Cristina e minhas filhas Fabiane Cristina e Tatiane Cristina agradeço pela compreensão e apoio nos últimos dois anos que estive longe delas me dedicando ao mestrado. Aos meus pais, Jairo de Araújo Bastos e Salima Assaf Bastos que sempre me apoiaram e incetivaram na vida. Às minhas irmãs, Helena Assaf Bastos e Cláudia Assaf Bastos pelo incentivo que sempre me deram em relação aos estudos. Ao Prof. Dr. Edmo Campos, meu orientador, pela paciência e orientação neste trabalho de dissertação, principalmente nos momentos em que tive grandes dificuldades de ordem pessoal bem como pelas aulas ministradas durante o curso e conhecimentos transmitidos, sem os quais, não seria possível o término deste trabalho. Ao Prof. Dr. Ilson Carlos Almeida Silveira pelas aulas ministradas durante o curso colaborando de maneira significativa para o meu entendimento da dinâmica dos oceanos bem como pelo apoio prestado durante o curso. Ao Prof. Dr. Ricardo Camargo do Instituto de Astronomia, Geofísica e Ciências Atmosféricas da Universidade de São Paulo pela cessão dos dados de ventos provenientes do modelo atmosféricos que muito contribuíram para condução dos trabalhos desta dissertação. Aos meus colegas da turma de mestrado, em especial, Carlos Teixeira e Renato Cecílio pelo convívio e pelas noites perdidas que passamos estudando para as provas do curso de mestrado. Aos meus amigos e companheiros do Laboratório de Modelagem dos Oceanos, Enrique Huaringa, Carlos Teixeira, Carlos Lentini, Roberto de Almeida, Ana Carolina, Ana Luiza e Rosio que sempre tiveram extrema boa vontade para me ensinar, principalmente, no início quando as dificuldades são sempre maiores. À Marinha do Brasil pela oportunidade que me deu de fazer esta pós-graduação numa das melhores instituição de ensino superior do país. E por último agradeço à Deus pela minha vida. 


\section{Resumo}

O trabalho tem o objetivo geral de estudar os efeitos transientes de alta frequência do regime de ventos na ressurgência de Cabo Frio, utilizando para este fim dados oceanográficos e saídas do modelo oceanográfico HYCOM. Para atingir este objetivo utilizou-se um conjunto de dados oceanográficos bem como de ventos obtidos junto ao Banco Nacional de Dados Oceanográficos (BNDO) do Centro de Hidrografia da Marinha (CHM). Estes dados são provenientes de duas comissões realizadas pelo ex-Navio Oceanográfico Almirante Saldanha, uma no período de 16 a 23 de janeiro de 1986 e outra no período de 09 a 22 de setembro de 1972. Os dados mostram uma flutuação na estrutura termohalina da região de Cabo Frio, presumivelmente, associada aos eventos de ressurgência ocorridos devido à variação no campo de ventos predominantes na região, mais especificamente, pertubações de alta frequência como a brisa do mar (BM) e a passagem de sistemas frontais na região. Com os resultados preliminares do presente trabalho podemos inferir a existência de uma correlação entre a atuação da BM no regime de ventos com uma intensificação da ressurgência em Cabo Frio já que a circulação local tem o efeito de alterar tanto a intensidade quanto a direção dos ventos predominantes naquela região fazendo com que o vento resultante se torne mais intenso e com uma tendência de ficar paralelo à costa o que favorece à ocorrência do fenômeno da ressurgência. Com os dados de setembro de 1972 observamos também um comportamento interessante da profundidade da isoterma de $16^{\circ} \mathrm{C}$, que é um bom indicador da intensidade da ressurgência, quando a mesma altera sua profundidade em torno de $50 \mathrm{~m}$, passando de $70 \mathrm{~m}$ para $20 \mathrm{~m}$, fato este visivelmente associado à alteração no campo de ventos devido à passagem de um sistema frontal na região. 


\section{Abstract}

The overall objective of this work is to study the transient hight-frequency effects of the wind regime on the Cabo Frio upwelling. For this, oceanography data and outputs of the oceanographic model HYCOM were used. In order to obtain this objective, a set of oceanographic and wind data, obtained by means of the National Bank of Oceanographic Data (BNDO) of the Hydrographic Center of the Navy (CHM), was used. This data is a result of two commissions carried out by the exoceanographic vessel Almirante Saldanha, one between January 16th and 23rd, 1986, and the other from September 9th to 22rd, 1972. The data showed a fluctuation in the thermohaline structure in the Cabo Frio region, presumably associated to the upwelling events which occur due to variations in the predominant wind fields in the region, specifically high frequency disturbances such as the sea breeze (SB) and the passing of frontal systems in the region. Based on preliminary results of this work, we may infer the existence of a correlation between the role of the SB on the wind regime and an intensification of the Cabo Frio upwelling since the local circulation has the effect of altering the intensity as well as the direction of the predominant winds in the region. Consequently, the resulting wind is intensified and has a tendency of becoming parallel to the coast which, in turn, favors the occurance of the upwelling phenomenon. Based on the September 1972 data, we observed an interesting behavior of the depth of the $16^{\circ} \mathrm{C}$ isotherm, which is a good indicator of the intensity of the upwelling process. The depth of this isotherm is altered in approximately $50 \mathrm{~m}$ going from $70 \mathrm{~m}$ to $20 \mathrm{~m}$, which in noticeably associated to the alteration in the wind field due to the passing of a frontal system in the region. 


\section{Lista de Figuras}

1.1 Ressurgência de quebra de plataforma causada por meandramentos ciclônicos. . . . . . . . . . . . . . . . . . . . . 4 4

1.2 Representação esquemática do transporte integrado na camada de Ekman . . . . . . . . . . . . . . . . . . . . . . 9

2.1 Região de Estudo com as estações de verão (vermelho) e inverno(azul) e a seção a leste de Cabo Frio. . . . . . . . . . . . . . . . . . . . . . . 12

2.2 Topografia de fundo da Região da SBB . . . . . . . . . . . . . . . 13

2.3 Isóbatas na Região de Cabo Frio extraída da carta náutica $N^{\circ} 70$ da Marinha do Brasil. . . . . . . . . . . . . . . . . . . . . . . . . . . . . 14

2.4 Climatologia COADS da média de TSM no período de 1949-1989 para os meses de fevereiro e agosto. . . . . . . . . . . . . . . . 17

2.5 Climatologia COADS da média de vento na superfície e TSM no período de 1949-1989 para os meses de janeiro e julho. . . . . . . . . 19

3.1 Vento 09Z de 16JAN86 . . . . . . . . . . . . . . . . 23

3.2 Vento $12 \mathrm{Z}$ de $16 \mathrm{JAN} 86 \ldots \ldots \ldots \ldots \ldots \ldots$

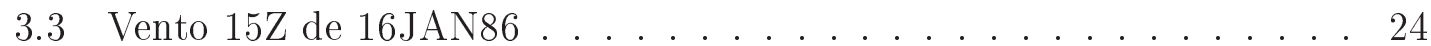

3.4 Vento $18 \mathrm{Z}$ de $16 \mathrm{JAN} 86 \ldots \ldots \ldots \ldots \ldots \ldots$

3.5 Vento 09Z de 17JAN86 . . . . . . . . . . . . . . . 25

3.6 Vento $12 \mathrm{Z}$ de $17 \mathrm{JAN} 86 \ldots \ldots \ldots \ldots \ldots \ldots$

3.7 Vento $15 \mathrm{Z}$ de $17 \mathrm{JAN} 86 \ldots \ldots \ldots \ldots \ldots \ldots$

3.8 Vento $18 \mathrm{Z}$ de $17 \mathrm{JAN} 86 \ldots \ldots \ldots \ldots \ldots \ldots$

3.9 Vento 09Z de 18JAN86 . . . . . . . . . . . . . 27

3.10 Vento $12 \mathrm{Z}$ de $18 \mathrm{JAN} 86 \ldots \ldots \ldots \ldots \ldots . \ldots \ldots$ 
3.11 Vento $15 \mathrm{Z}$ de $18 \mathrm{JAN} 86 \ldots \ldots \ldots$. . . . . . . . . . . . 28

3.12 Vento $18 \mathrm{Z}$ de $18 \mathrm{JAN} 86 \ldots \ldots$. . . . . . . . . . . . . . 28

3.13 Série temporal do vetor de vento na superfície . . . . . . . . . . . 29

3.14 Vento zonal . . . . . . . . . . . . . . . . . . . . . 30

3.15 Vento meridional . . . . . . . . . . . . . . . . . 30

4.1 Séries temporais de T e S no verão . . . . . . . . . . . . . . 35

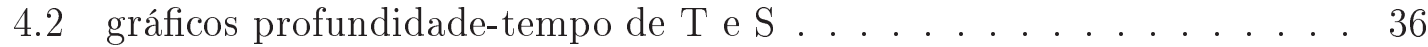

4.3 Diagrama T-S verão . . . . . . . . . . . . . . . . . . . . 37

4.4 Séries temporais de $\mathrm{T}$ e $\mathrm{S}$ no inverno . . . . . . . . . . . . 38

4.5 Gráficos profundidade-tempo de $\mathrm{T}$ e $\mathrm{S}$. . . . . . . . . . . . 39

4.6 Diagrama T-S inverno . . . . . . . . . . . . . . . . 40

4.7 Seção zonal de T e S . . . . . . . . . . . . . . . . . . . . . . . 41

4.8 Topografia de fundo extraída da carta náutica No.70 da Marinha do Brasil ........................ . . 43

4.9 Vista de topo das seções I e II de T . . . . . . . . . . . . . . . . 44

4.10 Seções I e II de T . . . . . . . . . . . . . . . . . . . . . . . 45

4.11 Isoterma de $16^{\circ} \mathrm{C} \ldots \ldots . \ldots . \ldots 46$

4.12 Carta Sinótica para $1200 \mathrm{Z}$ de 09SET72 . . . . . . . . . . . . 48

4.13 Carta Sinótica para 1200Z de 10SET72 . . . . . . . . . . . . 49

4.14 Carta Sinótica para 1200Z de 11SET72 . . . . . . . . . . . 50

4.15 Carta Sinótica para 1200Z de 12SET72 . . . . . . . . . . . . 51

4.16 Carta Sinótica para $1200 \mathrm{Z}$ de $13 \mathrm{SET} 72$. . . . . . . . . . . . . . 52

4.17 Carta Sinótica para $1200 \mathrm{Z}$ de 14 SET72 . . . . . . . . . . . . . 53

4.18 Carta Sinótica para 1200Z de 15SET72 . . . . . . . . . . . . . 54

4.19 Carta Sinótica para 1200Z de 16SET72 . . . . . . . . . . . . 55

4.20 Carta Sinótica para $1200 \mathrm{Z}$ de $17 \mathrm{SET} 72 \ldots$. . . . . . . . . 56

4.21 Vetores do vento do modelo atmosférico . . . . . . . . . . . . 58

4.22 Anomalias das componentes do tensor de cisalhamento do vento . . . 59

4.23 Temperatura em quatro diferentes instantes: $t=0, t=1$ dia, $t=2$ dias e $t=3$ dias. 
4.24 Temperatura em quatro diferentes instantes: $t=0$ horas, $t=6$ horas , $t=12$ horas e $t=18$ horas. . . . . . . . . . . . . . . . 61

4.25 Seção zonal na latitude $23^{\circ} \mathrm{S}$ em quatro diferentes instantes: $t=0, t=1$ dia, $t=2$ dias e $t=3$ dias. . . . . . . . . . . . . . . . . 62

4.26 Seção zonal na latitude $23^{\circ} \mathrm{S}$ em quatro diferentes instantes: $t=0$ horas, $t=6$ horas,$t=12$ horas e $t=18$ horas. . . . . . . . . . 63

4.27 Seção meridional na longitude $41^{\circ} \mathrm{W}$ em quatro diferentes instantes: $t=0$, $t=1$ dia, $t=2$ dias e $t=3$ dias. . . . . . . . . . . . . . . . . 64

4.28 Seção meridional na longitude $41^{\circ} \mathrm{W}$ em quatro diferentes instantes: $t=0$ horas, $t=6$ horas , $t=12$ horas e $t=18$ horas. . . . . . . . . . . . 65

4.29 Anomalia da tensão de cisalhamento do vento para um período de 20 dias de um arquivo de vento teórico contendo transientes de alta freqüência .................... 66

4.30 Seção zonal de temperatura na latitude $23^{\circ} \mathrm{S} 03 \mathrm{Z}$ dia $24 \mathrm{JAN}$. As linhas sólidas nesssas figuras representam superfícies coordenadas: isopicnais no interior; camadas " $\mathrm{z}$ ", na camada de mistura; e coordenadas sigma nas regiões mais rasas da plataforma continental. A linha mais grossa representa aproximadamente o fundo da camada de Ekman. . 68

4.31 Seção zonal de temperatura na latitude $23^{\circ} \mathrm{S} 03 \mathrm{Z}$ dia $28 \mathrm{JAN}$. . . . . . 68

4.32 Seção zonal de salinidade na latitude $23^{\circ} \mathrm{S} 03 \mathrm{Z}$ dia $24 \mathrm{JAN} \quad$. . . . . . 69

4.33 Seção zonal de salinidade na latitude $23^{\circ} \mathrm{S} 03 \mathrm{Z}$ dia $28 \mathrm{JAN}$. . . . . . 69

4.34 Seção meridional de temperatura na longitude $41.6^{\circ} \mathrm{W} 03 \mathrm{Z}$. . . . . . 71

4.35 Seção meridional de temperatura na longitude $41.6^{\circ} \mathrm{W} 18 \mathrm{Z}$. . . . . . 71

4.36 Seção meridional de salinidade na longitude $41.6^{\circ} \mathrm{W} 03 \mathrm{Z}$. . . . . . . 72

4.37 Seção meridional de salinidade na longitude $41.6^{\circ} \mathrm{W} 18 \mathrm{Z}$. . . . . . . 72 


\section{Capítulo 1}

\section{Introdução}

\subsection{O fenômeno da Ressurgência}

Apesar das regiões características de ressurgência costeira ocorrerem na margem leste dos oceanos como por exemplo no Peru, Equador, Califórnia e Oregon na costa do Oceano Pacífico e noroeste da África e ao sul da corrente de Benguela no Oceano Atlântico, ressurgência costeira também está presente, em menor intensidade, na margem oeste dos oceanos como ocorre ao longo da plataforma continental brasileira, particularmente, próximo a Cabo Frio $\left(22^{\circ} \mathrm{S}, 42^{\circ} \mathrm{W}\right)$. Nessa região ocorre uma ressurgência com forte modulação sazonal. Maiores intensidades ocorrem durante as estações de primavera e verão. Nas estações de outono e inverno há um relaxamento natural do fenômeno. Considerando que as águas quentes de origem tropical nas camadas superficiais têm uma baixa produtividade, a ocorrência da ressurgência tem uma importância significativa no enriquecimento biológico da região, incentivando assim, a atividade pesqueira da área. A compreensão dos efeitos geradores do fenômeno da ressurgência e suas consequências são de extrema importância por ter um impacto considerável na atividade econômica da pesca em Cabo Frio e adjacências.

O fenômeno da ressurgência é um problema dinâmico que tem sido investigado por muitos pesquisadores. O fenômeno é caracterizado por um movimento ascendente, pelo qual as águas subsuperficiais, geralmente mais frias e ricas em nutrientes, são trazidas para a superfície. Ele é gerado quando a tensão de cisalhamento do vento 
provoca divergência horizontal à superfície, fazendo com que águas subsuperficiais, mais profundas, movam-se para cima por conservação de massa (continuidade). O cisalhamento $(\tau)$ exercido pelo vento na superfície do oceano pode ser calculado em função da velocidade do vento $\left(\vec{u}_{w}\right)$, densidade da atmosfera $\left(\rho_{a}\right)$ e pelo coeficiente de arrasto $\left(c_{d}\right)$, de acordo com a fórmula abaixo:

$$
\tau=\rho_{a} c_{d} \vec{u}_{w}\left|\vec{u}_{w}\right|
$$

O cisalhamento é a força por unidade de área exercida na superfície do oceano e que é responsável pela transferência de momento verticalmente pela coluna d'água através das forças de atrito, isto é, o momento horizontal devido à ação do vento é tranferido verticalmente para o oceano através da camada limite chamada "camada de Ekman".

Existem dois tipos principais de ressurgência, a costeira e a de quebra de plataforma. A costeira ocorre principalmente na plataforma interna sendo causada preferencialmente pelos ventos enquanto que a de quebra de plataforma ocorre na região do talude superior e é causada pelos vórtices e meandros ciclônicos emitidos pelas correntes. Um exemplo típico de ocorrência desses dois tipos de ressurgência ocorre na região de Cabo Frio. A ressurgência costeira existente em Cabo Frio é causada pelos ventos de NE, enquanto que na plataforma e no talude superior a causa é atribuída aos meandramentos ciclônicos da Corrente do Brasil (Campos et al. (1995); Campos et al. (2000); Castelão et al. (2004)). Na latitude de Cabo Frio, região caracterizada pela ação da Corrente do Brasil, que é a corrente de contorno oeste associada ao giro subtropical do Atlântico Sul (Silveira et al., 2000) ocorre uma mudança brusca de orientação da linha de costa induzindo o surgimento de vórtices ciclônicos que favorecem a ocorrência do fenômeno. Naquela região, Castro and Miranda (1998) reportam a existência de Águas Centrais do Átlântico Sul (ACAS) bem próximo à costa.

O fenômeno da ressurgência na região de Cabo Frio é afetado por três principais agentes que são o regime de ventos, os meandramentos ciclônicos da Corrente do Brasil e a brisa do mar (BM). A batimetria local também é um fator que afeta a ressurgência tendo em vista que a plataforma acompanha a mudança brusca da 
orientação da linha de costa e há um intenso gradiente batimétrico próximo à Ilha de Cabo Frio. O regime de ventos atua como agente já que os ventos predominantes de NE na região favorecem à ocorrência da ressurgência tendo em vista que, pela teoria do transporte de Ekman, as águas superficiais são transportadas para esquerda do vento no HS e por continuidade águas mais frias e profundas afloram na superfície.

Em relação aos meandramentos ciclônicos da Corrente do Brasil, segundo Campos et al. (2000), baseado em análises de dados hidrográficos e nas idéias de Osgood et al. (1987), o papel dos meandros das correntes de contorno oeste pode ser explicado considerando os meandramentos como uma circulação ciclônica de um núcleo de água fria entre a corrente e o talude continental. Nos meandros ocorre uma ressurgência na parte frontal e subsidência na parte de trás como se observa na figura 1.1, que é uma representação esquemática do meandramento da Corrente do Brasil nas proximidades da costa. Devido à circulação ciclônica, a água na parte frontal do vórtice que aflorou devido à ressurgência é advectada na direção da plataforma continental e o oposto ocorre na parte de trás do vórtice. Em Campos et al. (2000) são mostradas algumas evidências de ressurgência de quebra de plataforma devido aos meandramentos ciclônicos da Corrente do Brasil ao longo da costa sudeste do Brasil fundamentadas na análise de dados hidrográficos e em resultados de modelagem numérica.

As frentes frias, que são fenômenos atmosféricos freqüentes na região de Cabo Frio, e a brisa do mar (BM), também um fenômeno característico da região, constituem os principais efeitos de alta freqüência do regime de ventos que influenciam a ressurgência em Cabo Frio. Franchito et al. (1998) apresentam um estudo numérico que avalia o efeito da ressurgência costeira na circulação local e o feedback do efeito da BM no sinal de ressurgência. Para estudar esta interação entre o oceano e a atmosfera foi utilizado no estudo um modelo atmosférico a fim de verificar o efeito da ressurgência na brisa do mar e um modelo oceanográfico de duas camadas para verificar o efeito da circulação local na ressurgência. O experimento numérico foi conduzido utilizando médias de três meses com a finalidade de investigar a variação sazonal da circulação: Janeiro-Fevereiro-Março (JFM), Abril-Maio-Junho (AMJ), Julho-Agosto-Setembro (JAS) e Outubro-Novembro-Dezembro (OND). O resultado 


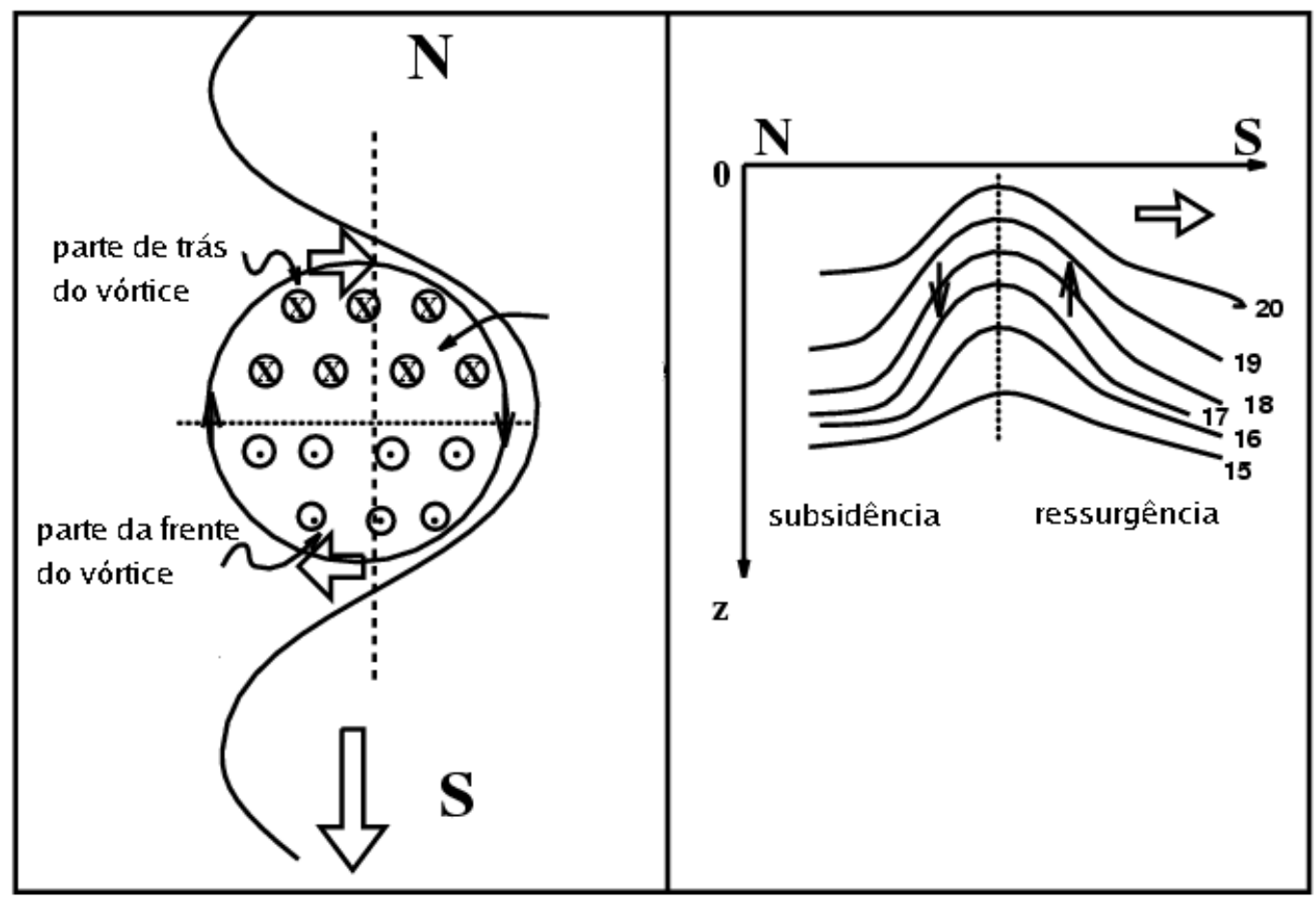

Figura 1.1: Ressurgência de quebra de plataforma causada por meandramentos ciclônicos.

do estudo numérico mostrou que a BM é mais intensa nos períodos de OND e JFM, quando ocorre ressurgência, e mais fraca em AMJ e JAS, quando ocorre um enfraquecimento na ressurgência. De acordo com estes autores a brisa do mar (BM) em Cabo Frio intensifica a ressurgência pois tem o efeito principal de aumentar a intensidade dos ventos na região e por outro lado a ressurgência tem o efeito de intensificar a circulação local o que demonstra que há um feedback positivo entre a brisa do mar e a ressurgência costeira. Uma segunda razão para o aumento da ressurgência na parte da costa da região de Cabo Frio com orientação E-W é a mudança na direção do vento resultante causada pela BM que faz com que o mesmo fique mais zonal e com isso paralelo à costa. Ainda devido à mudança brusca na orientação da linha de costa para direção E-W, a BM naquela região não é totalmente perpendicular à costa fato este que propicia as duas vantagens citadas acima para ocorrência da ressurgência, ou seja, altera dois itens da resultante do vento seu modulo e direção. A mudança na direção resultante dos ventos devido à atuação da BM, ao norte de Cabo Frio, e próximo ao Cabo de São Tomé, onde a linha de costa tem uma direção NE-SW, já tem um efeito contrário e não favorece a intensificação do fenômeno. 


\subsection{Embasamento teórico da Dinâmica de Ekman}

\subsubsection{Camada de Superfície}

Pela teoria dinâmica do transporte de Ekman as águas superficiais na camada de Ekman movem-se para esquerda do vento no hemisfério sul (HS) e, desta forma, devido a ascenção de águas mais frias, as regiões de ressurgência apresentam a temperatura da supérficie do mar (TSM) mais baixa em relação à média da temperatura das águas adjacentes.

As equações do movimento utilizadas para o estudo de Ekman são:

componentes horizontais:

$$
\begin{gathered}
-f v=-\frac{1}{\rho} \frac{\partial p}{\partial x}+\frac{A_{v}}{\rho} \frac{\partial^{2} u}{\partial z^{2}} \\
f u=-\frac{1}{\rho} \frac{\partial p}{\partial y}+\frac{A_{v}}{\rho} \frac{\partial^{2} v}{\partial z^{2}}
\end{gathered}
$$

componente vertical:

$$
0=-g-\frac{1}{\rho} \frac{\partial p}{\partial z}
$$

e a equação da continuidade:

$$
\frac{\partial u}{\partial x}+\frac{\partial v}{\partial y}+\frac{\partial w}{\partial z}=0
$$

Considerando o oceano incompressível e homogêneo, os gradientes de pressão existentes são aqueles gerados pela inclinação da superfície livre (componente barotrópica). Esta situação difere da geostrofia porque, com adição dos termos de atrito, as forças do gradiente de pressão e coriolis deixam de ser diretamente opostas. Um novo equilíbrio é atingido, diferente do geostrófico. A teoria de Ekman foi desenvolvida para explicar um movimento de larga escala que ocorre no meio do oceano, longe das margens continentais, uma região onde os contornos laterais estão suficientemente longes para que seus efeitos possam ser desprezados. Considerando o movimento de uma massa homogênea de fluido limitada inferiormente por um fundo plano 
e horizontal, e que apresenta-se em rotação com velocidade angular constante de maneira que sob tais condições podemos considerar que a densidade do oceano é constante (oceano homogêneo) e que o movimento é essencialmente horizontal, pois estando os contornos laterais muito longe, os cisalhamentos horizontais de corrente são nulos:

$$
\frac{\partial u}{\partial x}=\frac{\partial u}{\partial y}=\frac{\partial v}{\partial x}=\frac{\partial v}{\partial y}=0
$$

Neste caso a equação da continuidade resume-se a:

$$
\frac{\partial w}{\partial z}=0
$$

ou seja, a velocidade vertical w é constante ao longo do eixo z. Como o fundo é plano, w deve ser nulo bem próximo do fundo, então sendo w constante na coluna d'água e sendo w nulo em um ponto da coluna, w deve ser nulo em toda a coluna d'água. Assim ficamos apenas com u e v, e estes são constantes horizontalmente. Isto significa um movimento horizontal e estacionário, que se apresenta em equilibrio hidrostático na vertical. Neste caso os termos de atrito, nas equações horizontais do movimento resumem-se as derivadas de segunda ordem de u e v em relação à z e torna-se nulo na componente vertical como se observa nas equações (1.2), (1.3) e (1.4). Nessas equações o coeficiente de viscosidade aparece com o índice v pois tratase da componente vertical do termo de atrito, já que a parte horizontal do laplaciano de u e v é nula. Como o movimento é na camada de Ekman e que nesta região o fluxo resultante é a soma do fluxo geostrófico e do fluxo gerado pelo atrito do vento, vamos separar as componentes u e v do fluxo em suas componentes geostrófica e não-geostrófica:

$$
\begin{aligned}
& u=u_{g}+u_{e} \\
& v=v_{g}+v_{e}
\end{aligned}
$$

onde o índice e indica o fluxo de ekman e o $\mathbf{g}$ indica a geostrofia. Substituindo estas variáveis nas equações horizontais do movimento, lembrando que a componente 
geostrófica do fluxo é constante ao longo do eixo z pois trata-se da parte barotrópica que não cisalha na vertical, ficamos com:

$$
\begin{aligned}
-f\left(v_{g}+v_{e}\right) & =-\frac{1}{\rho} \frac{\partial p}{\partial x}+\frac{A_{v}}{\rho} \frac{\partial^{2} u}{\partial z^{2}} \\
f\left(u_{g}+u_{e}\right) & =-\frac{1}{\rho} \frac{\partial p}{\partial y}+\frac{A_{v}}{\rho} \frac{\partial^{2} v}{\partial z^{2}}
\end{aligned}
$$

Parte da solução é o fluxo geostrófico e, a outra parte, é o fluxo de ekman. Como o fluxo geostrófico está associado ao gradiente de pressão e o fluxo de Ekman ao atrito, podemos separar as soluções da seguinte forma:

$$
\begin{gathered}
-f v_{g}=-\frac{1}{\rho} \frac{\partial p}{\partial x} \\
f u_{g}=-\frac{1}{\rho} \frac{\partial p}{\partial y} \\
-f v_{e}=\frac{A_{v}}{\rho} \frac{\partial^{2} u}{\partial z^{2}} \\
-f u_{e}=\frac{A_{v}}{\rho} \frac{\partial^{2} v}{\partial z^{2}}
\end{gathered}
$$

Na vertical continuamos com o equilíbrio hidrostático:

$$
\frac{\partial p}{\partial z}=-\rho g
$$

As equações (1.12) e (1.13) representam o fluxo geostrófico e as equações (1.14) e (1.15) representam o fluxo de ekman. Derivando a equação (1.14) e substituindo na (1.15), obtem-se a equação diferencial de quarta ordem abaixo:

$$
\frac{\partial^{4} u_{e}}{\partial z^{4}}+\left(\frac{f}{A_{v}}\right)^{2} u_{e}=0
$$

cuja solução geral é:

$$
u_{e}(z)=A_{1}^{\frac{(1+i) z}{\delta_{E}}}+A_{2}^{\frac{-(1+i) z}{\delta_{E}}}+A_{3}^{\frac{(1-i) z}{\delta_{E}}}+A_{4}^{\frac{-(1-i) z}{\delta_{E}}}
$$


As constantes $A_{1}-A_{4}$ podem ser obtidas através das condições de contorno:

Em $\mathrm{z}=0$ (superfície):

$$
\begin{gathered}
\tau_{z x}=-\rho A_{v} \frac{\partial u_{e}}{\partial z} \\
\tau_{z y}=-\rho A_{v} \frac{\partial v_{e}}{\partial z}
\end{gathered}
$$

Para $z \rightarrow-\infty$ (abaixo da camada de ekman):

$\mathrm{u}(\mathrm{z} \rightarrow-\infty) \rightarrow 0$

$\mathrm{v}(\mathrm{z} \rightarrow-\infty) \rightarrow 0$

Usando as condições de contorno e assumindo $\tau_{z y}=0$ temos $A_{2}=A_{4}=0$ e $A_{3}$ $=\mathrm{i} A_{1}$, sendo o valor da constante $A_{1}$ :

$$
A_{1}=\frac{\tau_{z x} \delta_{E}}{2 \rho A_{v}}\left(\frac{1-i}{2}\right)
$$

Substituindo os valores das constantes $A_{1}-A_{4}$ na solução geral (1.18) e após cálculo idêntico para a componente meridional v, tem-se:

$$
\begin{gathered}
u(z)=\frac{\tau_{z x} \delta_{E}}{\sqrt{2} \rho A_{v}} e^{\frac{z}{\delta_{E}}} \sin \left(\frac{z}{\delta_{E}}+\frac{\pi}{4}\right) \\
v(z)=-\frac{\tau_{z x} \delta_{E}}{\sqrt{2} \rho A_{v}} e^{\frac{z}{\delta_{E}}} \sin \left(\frac{z}{\delta_{E}}+\frac{\pi}{4}\right)
\end{gathered}
$$

\subsubsection{A velocidade no topo da Camada de Ekman}

Na superfície $(\mathrm{z}=0)$ temos os seguintes valores para u e v:

$$
\begin{gathered}
u(z=0)=\frac{\sqrt{2}}{2} V_{0} \\
v(z=0)=-\frac{\sqrt{2}}{2} V_{0}
\end{gathered}
$$

onde, 


$$
V_{0}(z=0)=\left(u^{2}+v^{2}\right)^{\frac{1}{2}}=\frac{\tau_{z x} \delta_{E}}{\sqrt{2} \rho A_{V}}
$$

Observa-se que o vetor $V_{0}$ isto é a velocidade gerada pelo vento no topo da camada de Ekman (superfície do oceano) orienta-se segundo um ângulo de $45^{\circ}$, à direita (esquerda) da direção do vento no hemisfério norte (sul).

\subsubsection{O Transporte de Ekman}

O transporte de volume integrado na camada de Ekman de superície é dado por:

$$
\vec{M}=\frac{\vec{\tau} X \vec{k}}{f}
$$

Ou seja, $\vec{M}$ é proporcional à intensidade de $\vec{\tau}$ e orientado em ângulo reto com a direção do vento: à direita no hemisfério norte, e à esquerda no hemisfério sul, onde $\mathrm{f}<0$. O fluxo de massa devido aos efeitos não-geostróficos da fricção, integrado em toda a coluna do fluido é para a direita (esquerda) da tensão de cisalhamento do vento no hemisfério norte (sul). A figura 1.2 mostra uma representação esquemática do produto vetorial envolvido no cálculo do transporte de Ekman.
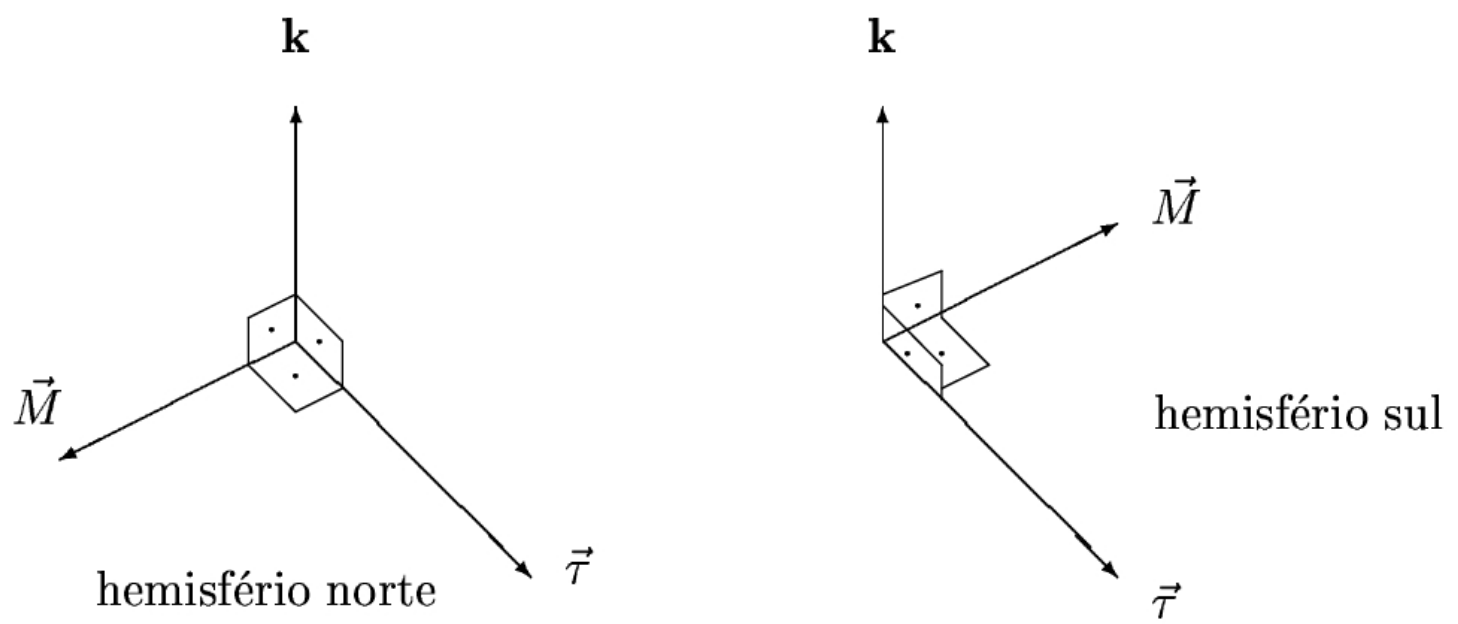

Figura 1.2: Representação esquemática do transporte integrado na camada de Ekman 


\subsection{Objetivos}

O objetivo geral do presente trabalho consiste em estudar os efeitos de transientes de alta frequência do regime de ventos na ressurgência de Cabo Frio, utilizando dados oceanográficos e saídas de modelo numérico. São identificados os seguintes objetivos específicos:

- Identificar, classificar e quantificar as variações da ressurgência de acordo com as diversas forçantes existentes.

- Comparar os resultados do modelo numérico com os dados observados

- Identificar possíveis "feedbacks"da ressurgência no sistema atmosférico local.

\subsection{Estrutura do Trabalho}

Neste trabalho de dissertação será abordada a flutuação observada na estrutura termohalina da região de Cabo Frio, presumivelmente, associada aos eventos de ressurgência ocorridos devido à variação no campo de ventos. Inicialmente apresentamos as diferenças sazonais no campo de vento climatológico que explica, em parte, o aparente decréscimo da ressurgência durante o inverno austral e em seguida é mostrado o campo de ventos para o período de estudo onde se constata mudanças significativas nas direções e intensidades dos mesmos. Posteriormente é analisado o conjunto de dados hidrogáficos com as informações de vento do período de estudo.

No presente capítulo foi colocado a importância da ressurgência e os objetivos a serem atingidos. Na seqüência deste trabalho, no capítulo 2, é feita uma descrição da área de estudo, incluindo os aspectos da batimetria e ventos predominantes. No capítulo 3 apresenta-se uma descrição dos dados que foram utilizados, assim como a metodologia empregada. No capítulo 4 são analisados os dados hidrográficos

juntamente com uma discussão dos resultados obtidos incluindo os resultados do modelo numérico e no capítulo 5 apresenta-se a conclusão com as sugestões para trabalhos futuros. 


\section{Capítulo 2}

\section{Descrição da Região de Estudo}

\section{1 Área de Estudo}

A área de estudo compreende a região definida pelos paralelos $22^{\circ} \mathrm{S}$ e $25^{\circ} \mathrm{S}$ e pelos meridianos $040^{\circ} \mathrm{W}$ e $044^{\circ} \mathrm{W}$ de acordo com figura 2.1, onde os vetores Amax e Bmax indicam as direções de vento mais favoráveis à ocorrência de ressurgência nas regiões A e B respectivamente. Nesta figura também consta as estações de verão (vermelho) e inverno(azul) bem como a seção feita a leste de Cabo Frio. Esta área de estudo está inserida na Plataforma Continental Sudeste, definida como "South Brazil Bight (SBB)"por Castro and Miranda (1998). A SBB está compreendida entre Cabo Frio (RJ), na latitude de $23^{\circ} \mathrm{S}$, e Cabo de Santa Marta (SC), na latitude de $20^{\circ} 40^{\prime} \mathrm{S}$. A largura da plataforma nessa região é variável, desde $50 \mathrm{~km}$ na parte norte até $230 \mathrm{~km}$ ao centro diminuindo novamente em direção ao sul. A batimetria é suave com as isóbatas acompanhando a linha de costa, porém vale ressaltar a ocorrência de uma mudança brusca na orientação NE-SW da linha de costa, ao norte de Cabo Frio, para E-W, ao sul de Cabo Frio, bem como a existência de um intenso gradiente batimétrico próximo à ilha de Cabo Frio. Esta mudança está associada à ocorrência de ressurgência de quebra de plataforma em virtude dos vórtices ciclônicos gerados a partir da Corrente do Brasil (CB) (Campos et al. (1995); Campos et al. (1996)). A ressurgência costeira existente na área de Cabo Frio é causada, principalmente, devido aos ventos, enquanto que na quebra de plataforma e no talude o principal mecanismo de bombeamento da Água Central do Atlântico 
Sul (ACAS) são os meandramentos ciclônicos da corrente do Brasil (Campos et al. (1995); Campos et al. (2000); Castelão et al. (2004)). Na região de Cabo Frio ocorre uma predominância dos ventos de NE devido à presença do Anticiclone Subtropical do Atlântico Sul (ASAS) e de acordo com a teoria de Ekman ocorre um transporte "offshore" das águas superficiais próxima à costa causando, assim, a divergência superficial que propicia a ocorrência do fenômeno da ressurgência.

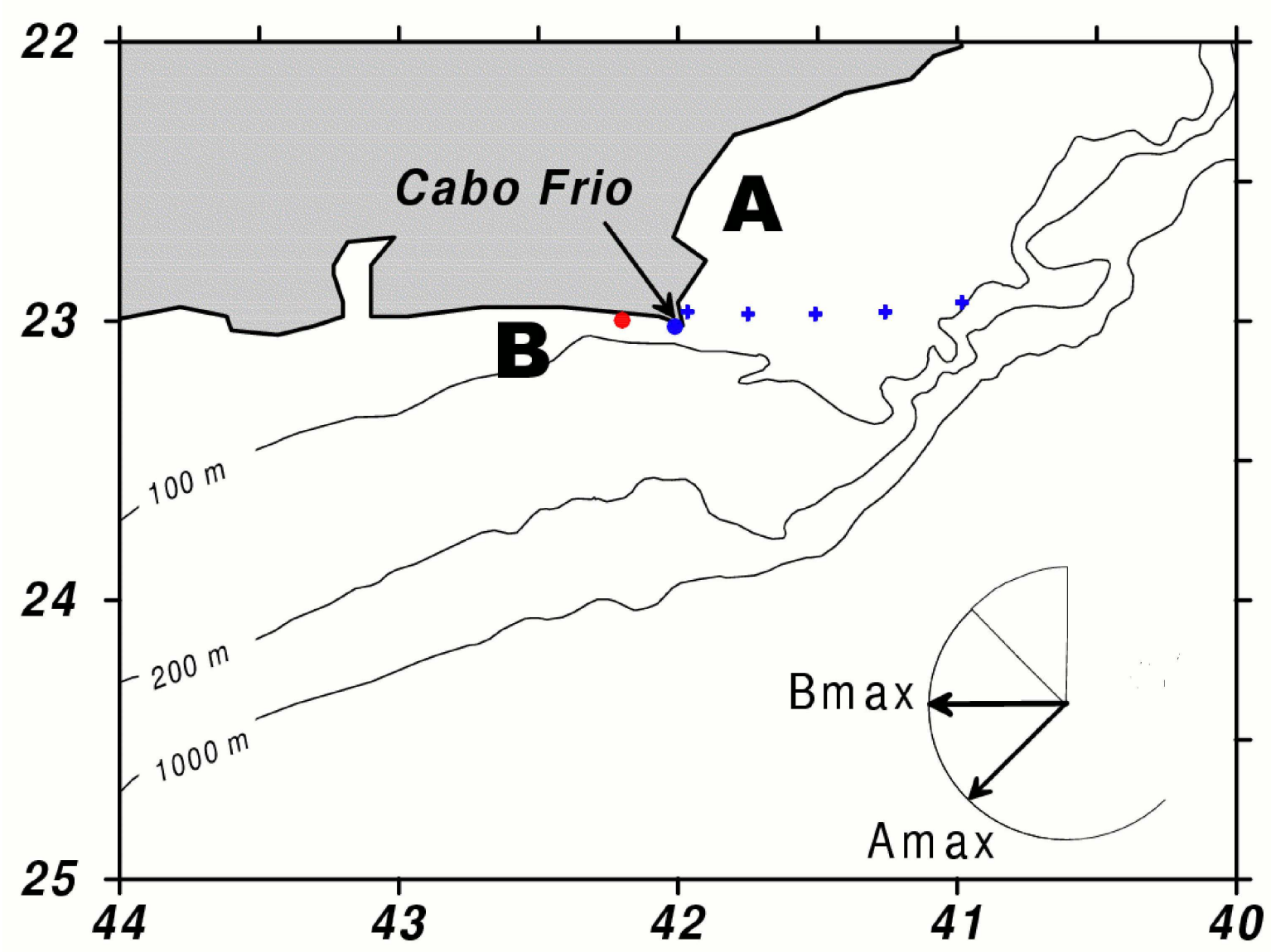

Figura 2.1: Região de Estudo com as estações de verão (vermelho) e inverno(azul) e a seção a leste de Cabo Frio.

\subsection{Batimetria da Região de Estudo}

Na figura 2.2 podemos observar, através de uma visão tridimensional, a topografia de fundo da SBB onde se constata a mudança na orientação da linha de costa. Embora a ressurgência seja um fenômeno marcante dessa região, uma variação significativa do fenômeno ocorre ao longo da costa. Áreas de ressurgência são freqüentemente observadas em Cabo Frio, Cabo de São Tomé e próximo à Vitória. Um sinal forte 
de ressurgência com temperatura da superfície do mar (TSM) baixa ocorre próximo à Cabo Frio e por esta razão a maior parte dos estudos do fenômeno ocorre nesta região. Como ocorre uma ressurgência intensa em Cabo Frio, muitos trabalhos na literatura associam uma forte influência da topografia de fundo na contribuição da intensificação do fenômeno (Valentim et al. (1987); Mascarenhas et al. (1971)). Na figura 2.3 podemos visualizar o comportamento das isóbatas de Vitória à Cabo Frio. Exatamente em Cabo Frio observamos um adensamento acentuado das isolinhas de mesma profundidade, com as isóbatas bem juntas e próximas à costa, onde a isóbata de $100 \mathrm{~m}$ encontra-se numa distância de apenas $7 \mathrm{~km}$ da costa o que caracteriza um significativo gradiente topográfico local. A mesma isóbata de $100 \mathrm{~m}$ encontra-se à $42 \mathrm{~km}$ da costa nas proximidades do Rio de Janeiro, à $88 \mathrm{~km}$ no Cabo de São Tomé e à 33 km em Rio Doce.

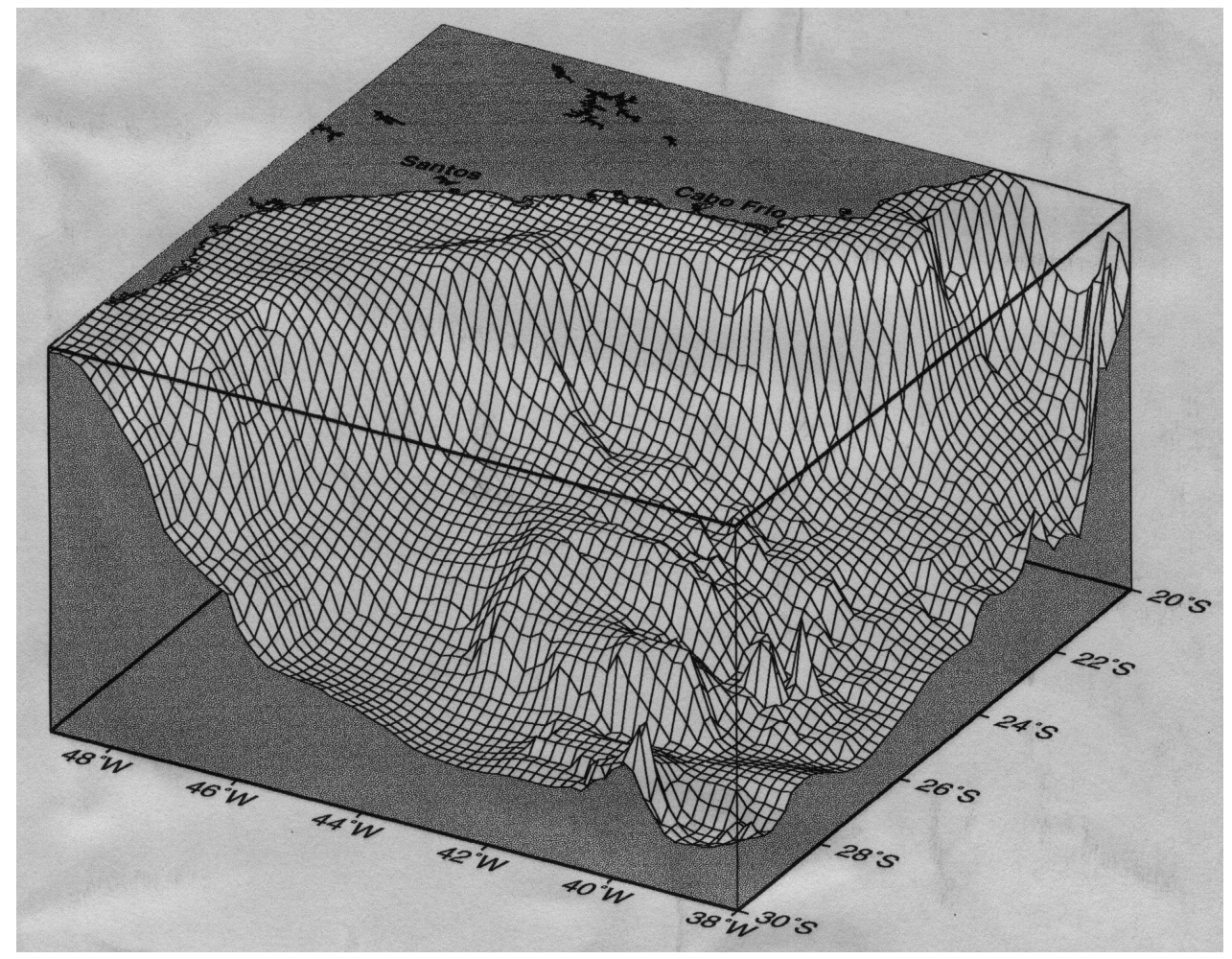

Figura 2.2: Topografia de fundo da Região da SBB 


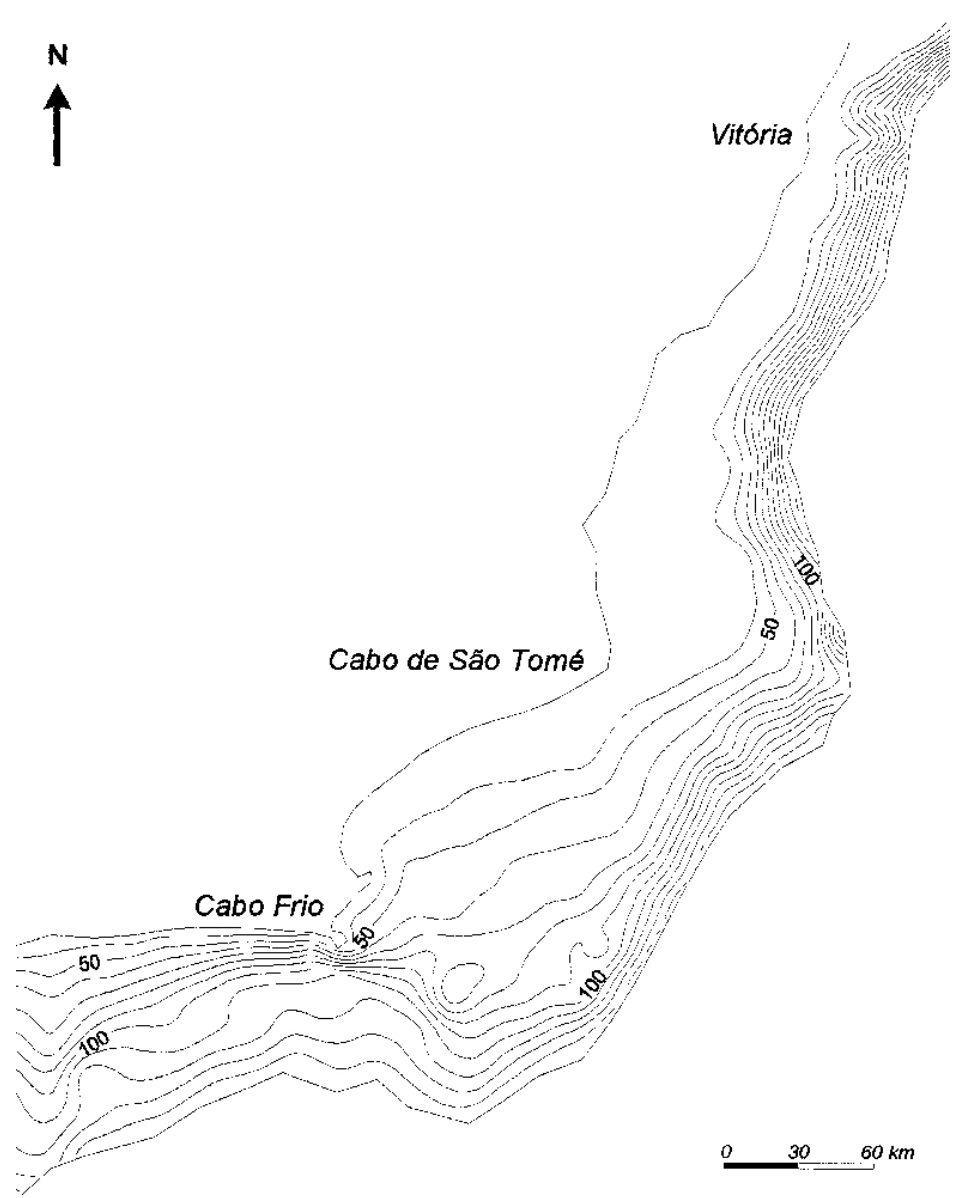

Figura 2.3: Isóbatas na Região de Cabo Frio extraída da carta náutica $N^{\circ} 70$ da Marinha do Brasil.

Rodrigues and Lorenzzetti (2001) fizeram um estudo numérico dos efeitos da topografia de fundo e da geometria da linha de costa na ressurgência da costa sudeste do Brasil e concluiram que ambos os mecanismos têm um papel importante na ressurgência costeira da região, particularmente em Cabo Frio. Nesta região ocorre uma grande variação na largura da Plataforma Continental. No Rio de Janeiro a largura é, aproximadamente, de $150 \mathrm{~km}$, caindo para $80 \mathrm{~km}$ nas imediações de Cabo Frio, aumentando novamente para 110 km no Cabo de São Tomé e reduzindo para apenas $35 \mathrm{~km}$ em Rio Doce. Vários estudos anteriores sugerem que a variação da ressurgência costeira observada ao longo da costa está relacionada com a topografia de fundo.Peffley and O'Brien (1976) estudou o efeito da topografia de fundo e da geometria da linha de costa na ressurgência costeira de Oregon. Seus resultados indicaram que a variação da topografia de fundo prevalece em relação à geometria da linha de costa na determinação da distribuição da ressurgência ao longo da costa. Um estudo similar foi desenvolvido para a costa do Peru porPreller and 
O'Brien (1980). Este estudo também concluiu que a variação da ressurgência costeira ao longo da costa está relacionada à topografia de fundo. Entretanto, alguns estudos mostram que as irregularidades da linha de costa podem afetar também a ressurgência costeira. Arthur (1965) e Yoshida (1967) concluíram que uma ressurgência intensa pode ocorrer à sotavento dos cabos. Estudos mais recentes, desenvolvidos por Crépon and Richez (1982) e Hua and Thomasset (1983), mostram que centros de ressurgência costeira localizados em posições fixas no Golfo de Lions aconteceram, exclusivamente, devido à geometria da costa.

Considerando que esta parte da costa brasileira apresenta variações importantes tanto na geometria da costa quanto na topografia de fundo, o estudo de Rodrigues and Lorenzzetti (2001) foi de extrema relevância já que verificou o papel que cada um desses dois mecanismos têm na ressurgência.

\subsection{Climatologia da Região de Estudo}

A baixa temperatura da superfície do mar nas proximidades de Cabo Frio é particularmente evidente no verão. No período de dezembro a março, mesmo com uma resolução pouco detalhada do banco de dados climatológico COADS (Comprehensive Ocean-Atmosphere Data Set), a temperatura da superfície do mar revela uma TSM mínima local bem definida nas imediações de Cabo Frio. Em contraste uma TSM mínima local não está aparente na climatologia de abril a outubro. Na figura 2.4 podemos observar a climatologia COADS da temperatura de superfície do mar (1949-1989) para os meses de fevereiro e agosto. No mês de fevereiro, verão no hemisfério sul, a TSM local mínima é por volta de $1,2^{\circ} \mathrm{C}$ mais baixa quando comparada com as águas adjacentes, porém não é possível dimensionar a extensão espacial da ressurgência devido a baixa resolução espacial da climatologia COADS. No entanto, na média, para o mês de agosto essa diferença na TSM não é observada.

A estrutura termohalina na região constitui na mistura de três massas d'águas: Água Costeira (AC), Água Tropical (AT) e Água Central do Átlântico Sul (ACAS), sendo a AT e ACAS de origem oceânica, transportadas pela Corrente do Brasil (CB) (Emilsson, 1961). A AT localiza-se na parte superior da coluna d'água, na 
plataforma externa e possui índices termohalinos $\mathrm{T}>20^{\circ} \mathrm{C}$ e S $>36,4$ enquanto que a ACAS, localizada na parte inferior da coluna d'água, possui índices termohalinos $\mathrm{T}<20^{\circ}$ C e S $<36,4$ (Miranda, 1982). 

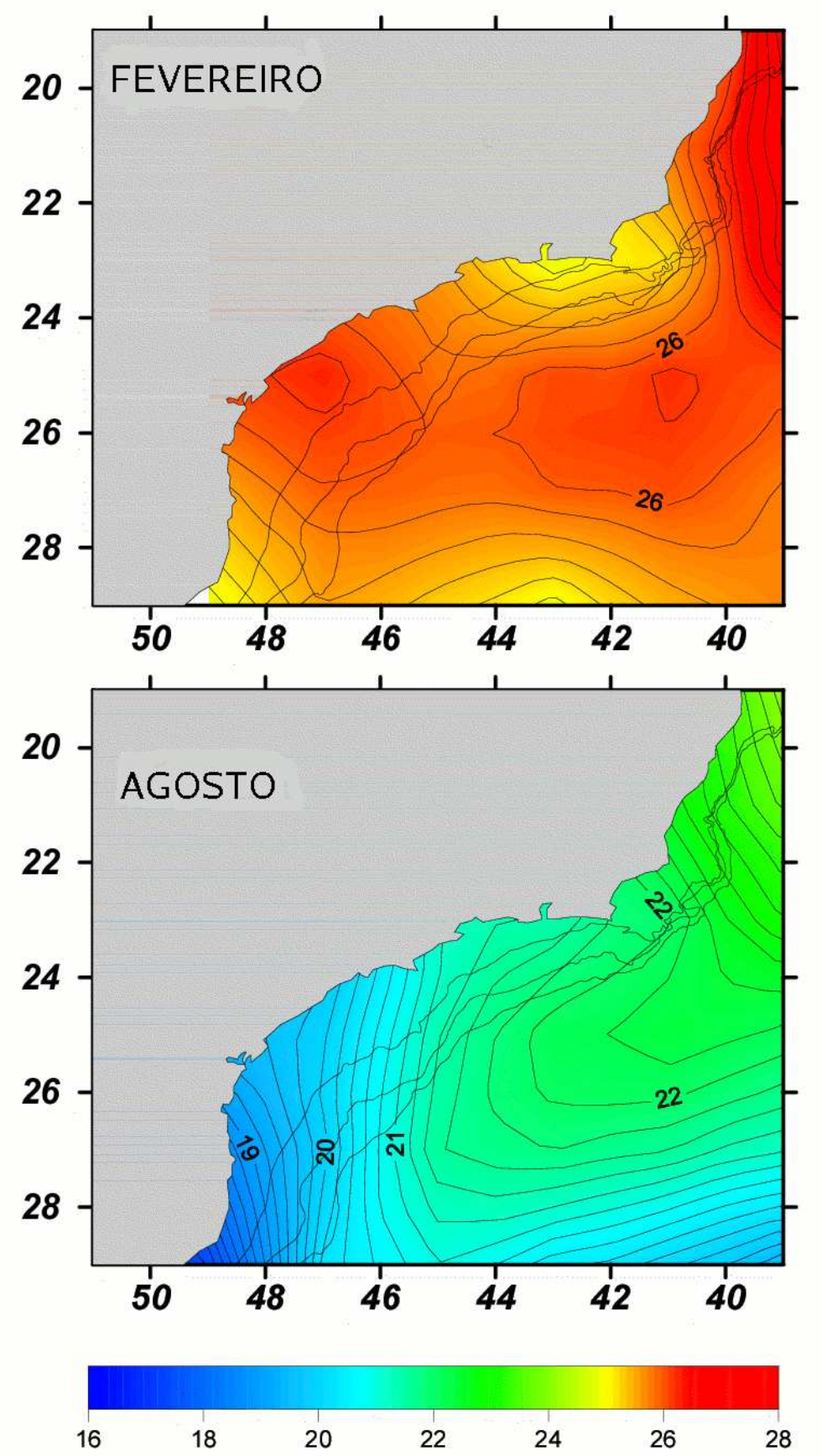

Figura 2.4: Climatologia COADS da média de TSM no período de 1949-1989 para os meses de fevereiro e agosto. 
Dados climatológicos de ventos existentes são insuficientes para que se tenha uma boa resolução espacial. Para descrever a climatologia do cisalhamento do vento Castro and Miranda (1998) usaram os dados tabelados por Samuel e Cox (1987) originados a partir de Hellerman and Rosenstein (1983). O Anticiclone Subtropical do Atlântico Sul (ASAS) e os ventos alíseos na região equatorial são as feições principais do Atlântico Sul. A posição e a força do giro subtropical nos mostra oscilações sazonais afetando diretamente a intensidade e direção dos ventos sobre a plataforma. Entre os paralelos $15^{\circ} \mathrm{S}$ e $35^{\circ} \mathrm{S}$, no verão, prevalecem os ventos de NE enquanto que no inverno, em resposta ao deslocamento do Anticiclone do Atlântico Sul e a influência dos transientes atmosféricos, os ventos médios são menos intensos e sua direção predominante é de E. Os ventos de NE, predominantes no verão, são favoráveis a ocorrência de ressurgência ao norte de Cabo Frio e os ventos de E, predominantes no inverno, são favoráveis à ocorrência de ressurgência a oeste de Cabo Frio (Castro and Miranda, 1998). As frentes frias são fenômenos freqüentes na região de Cabo Frio. A forçante principal da circulação em grande parte da plataforma é o vento (Castro, 1982). Na plataforma continental Sudeste a variabilidade na circulação no inverno é dominada pela passagem de sistemas frontais (Stech and Lorenzzetti, 1992). As frentes frias ocorrem com uma freqüência anual média de 5-10 dias mas possuindo ocorrências mínimas, na média, de três por mês em fevereiro e máxima de cinco por mês em outubro (Castro and Miranda, 1998). A figura 2.5, obtida a partir dos dados climatológicos de vento e de TSM do banco de dados COADS, nos mostra a distribuição média do vento na superfície na parte oeste do Atlântico Sul para os meses de Janeiro e Julho. Podemos observar diferenças sazonais significativas no padrão dos ventos. Devemos também considerar que este regime sazonal se altera com as pertubações de alta frequência como a aproximação de sistemas frontais e a circulação local do tipo brisa marinha. 

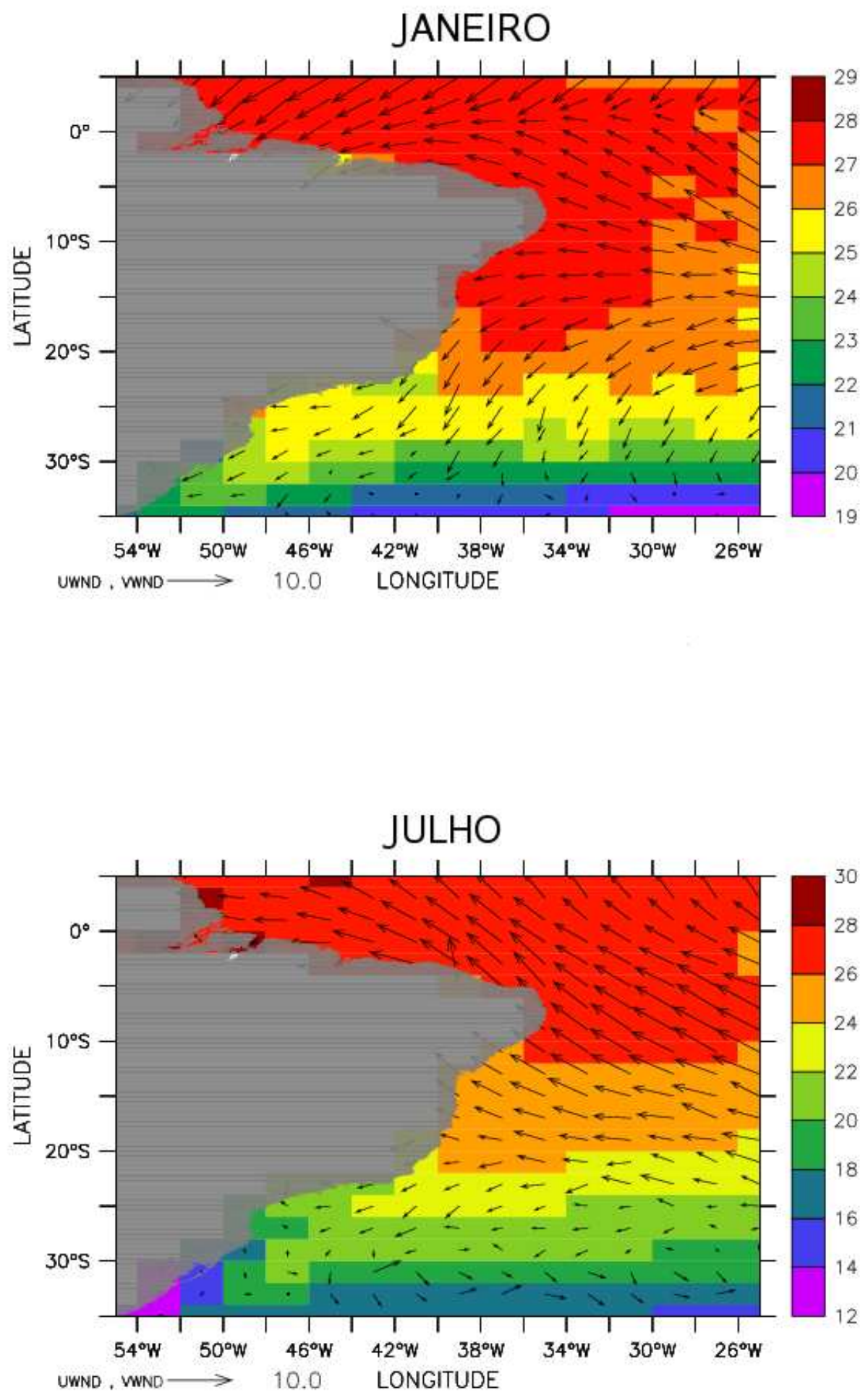

Figura 2.5: Climatologia COADS da média de vento na superfície e TSM no período de 1949-1989 para os meses de janeiro e julho. 


\section{Capítulo 3}

\section{Material e Métodos}

\subsection{Dados Hidrográficos}

A metodologia utilizada para este trabalho consiste em interpretar e analisar séries temporais de dados de temperatura e salinidade coletados na região de estudo, análise de arquivo de ventos proveniente de modelo atmosférico e também observados, além da utilização de saídas do modelo HYCOM para comparação com dados coletados bem como o uso de dados climatológicos. O conjunto de dados hidrográficos utilizados neste trabalho foram obtidos junto ao Banco Nacional de Dados Oceanográficos (BNDO) do Centro de Hidrografia da Marinha (CHM) localizado em Niterói-RJ. Em 1986 foram realizadas coletas no período de 16 a 23JAN pelo então navio Oceanográfico Almirante Saldanha numa estação situada na posição $23^{\circ}$ S e $42,22^{\circ} \mathrm{W}$, localizada $22 \mathrm{~km}$ a oeste da Ilha de Cabo Frio e numa distância de $4 \mathrm{~km}$ da costa, onde a profundidade local é 55m. Um total de 155 perfis verticais foram obtidos, num intervalo médio de 1 hora, com amostras sendo coletadas nas profundidades nominais de 0, 5, 10, 20, 30 e 48 metros. Em 1972 foram realizadas coletas no período de 09 a 22SET numa estação localizada 1 km ao sul de Cabo Frio, onde a profundidade local é $80 \mathrm{~m}$. Um total de 93 perfis verticais foram obtidos, num intervalo médio de 3 horas, com amostras sendo coletadas nas profundidades nominais de 0, 10, 20, 30, 40, 50, 60 e 75 metros e após os perfis foi feita uma seção. Na figura 2.1, do capítulo 2 podemos observar a localização das estações de verão (vermelho) e inverno (azul) bem como a seção feita a leste da ilha de Cabo Frio. 
Para melhor visualização de como a batimetria na região influencia a penetração da ACAS na plataforma interna, duas outras seções, que podem ser vistas na figura 4.9 do capítulo 4, com dados de março de 1967, foram também analisadas.

\subsection{Dados de ventos}

Para realização do trabalho utilizou-se dados de ventos provenientes do modelo atmosférico RAMS (Regional Atmospheric Modeling System) com resultados a cada três horas de 00Z de 14JAN até $12 \mathrm{Z}$ de 25JAN86. Utilizou-se também dados coletados pelo navio Alte. Saldanha no período de 16-22JAN86 que estão em conformidade com os dados provenientes do modelo atmosférico. A visualização e análise desses dados de vento estão feitas a seguir no qual, juntamente com os dados hidrográficos, pode-se verificar a clara interação entre a circulação atmosférica local e a ressurgência. A climatologia dos ventos da região foi abordada no capítulo 2 quando se descreveu a região de estudo. De acordo com Franchito et al.,1998, à medida que a temperatura em terra vai ficando maior que a TSM, a circulação da BM se inicia próximo à costa por volta das 11:00 horas local para esta época do ano (Janeiro) tendo seu valor máximo entre 14:00 - 16:00 hora local. Com o surgimento da BM ao longo da tarde ocorre uma composição vetorial da circulação local com os ventos predominantes da região e isto faz com que a resultante fique mais zonal na linha de costa E-W e com isso paralelo à costa, o que favorece à ressurgência. Isso consequentemente causa uma flutuação de alta frequência na estrutura termohalina da região. Devido à mudança brusca na orientação da linha de costa para EW em Cabo Frio, a BM naquela região não é totalmente perpendicular à costa o que favorece na composição vetorial o surgimento do vento resultante paralelo à costa. Nessa parte da costa o aumento da intensidade dos ventos provocado pela BM, aliado ao fato de gerar uma mudança de direção favorável, intensifica a ressurgência. Mesmo quando a temperatura em terra se torna menor que sobre o mar, o fluxo de ar continua no sentido do mar para terra porém com intensidades menores. A reversão da brisa ocorre apenas nas primeiras horas da manhã do dia seguinte com o surgimento de uma fraca brisa no sentido terra-mar. Com a utilização 
do MATLAB, como ferramenta de visualização, e, utilizando o arquivo de ventos, foi feita a plotagem dos ventos no período de 16JAN86 a 20JAN86 para a grade do modelo atmosférico. Nas figuras 3.1 a 3.12 podemos observar a variação nas intensidades e direções dos ventos. Nos gráficos de $15 \mathrm{Z}$ e $18 \mathrm{Z}$ para os dias 16, 17 e 18JAN podemos observar mudanças, tanto nas direções quanto nas intensidades dos ventos, o que, presumivelmente, estão associadas à atuação da BM. O arquivo de ventos utilizado é proveniente do modelo atmosférico RAMS e nele há dados de ventos a cada 3 horas no período de 00Z de 14JAN86 à 12Z de 25JAN86. 


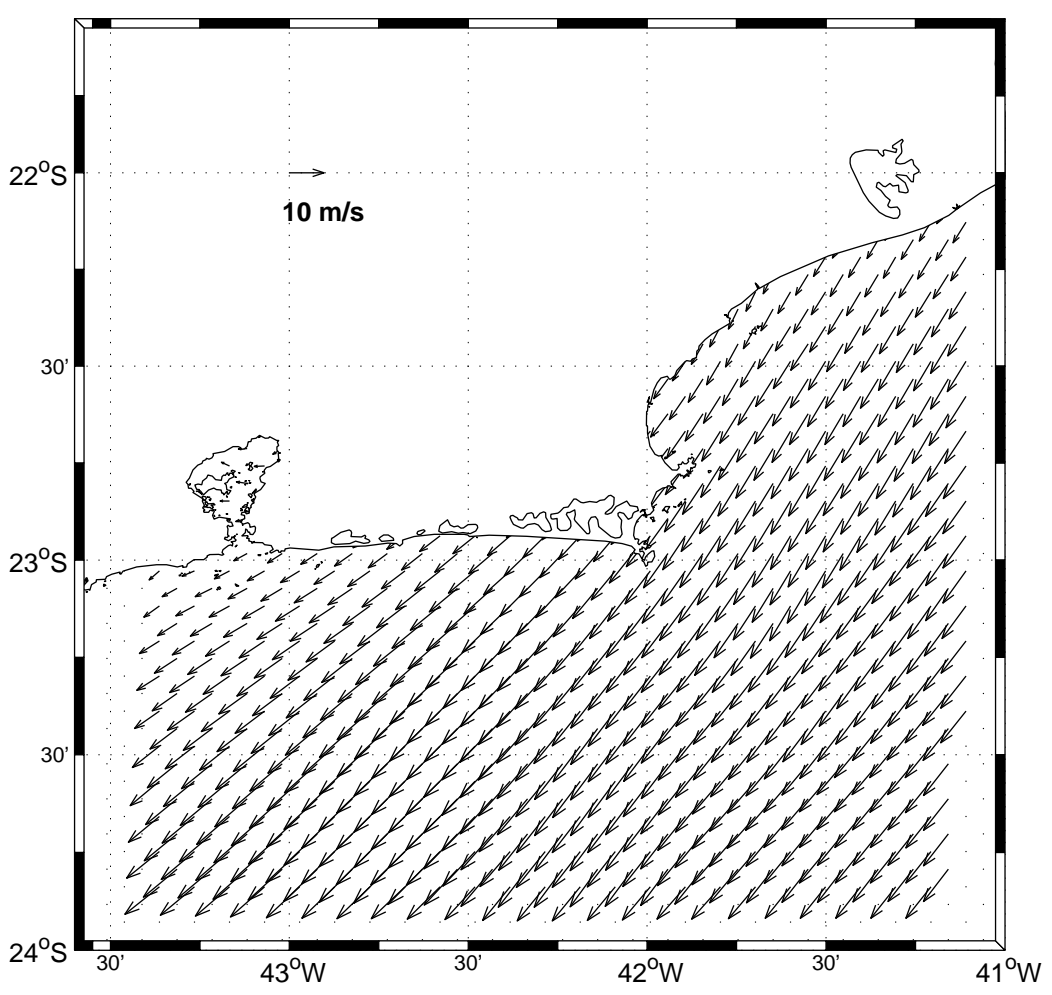

Figura 3.1: Vento $09 Z$ de 16JAN86

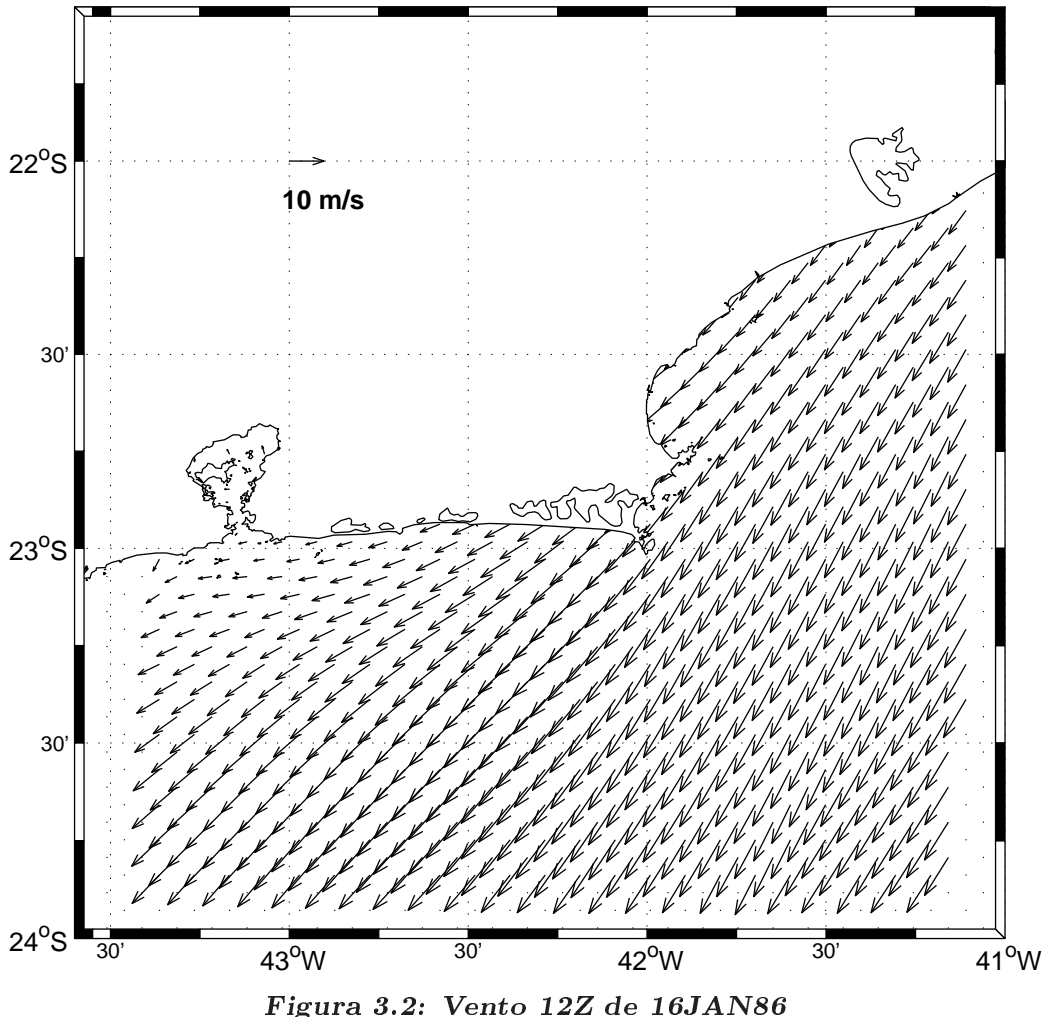




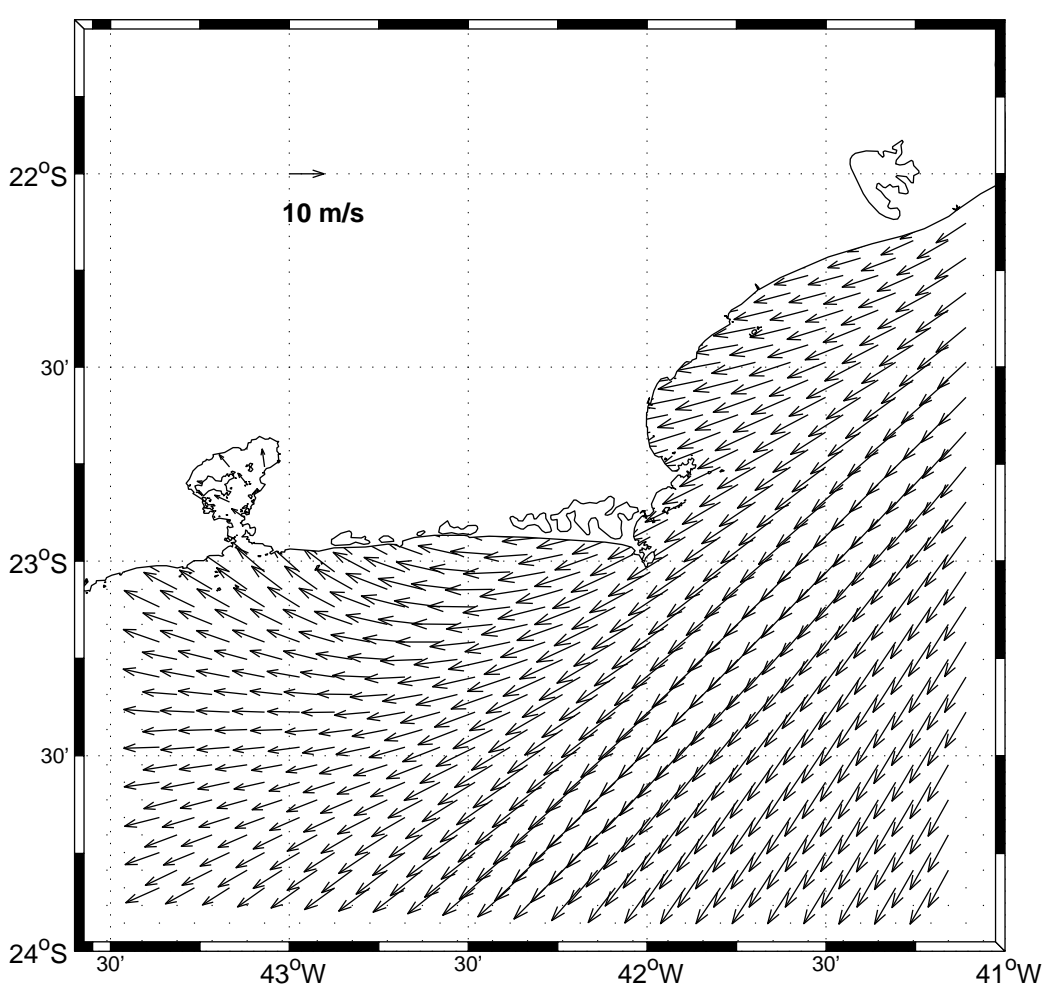

Figura 3.3: Vento $15 Z$ de 16JAN86

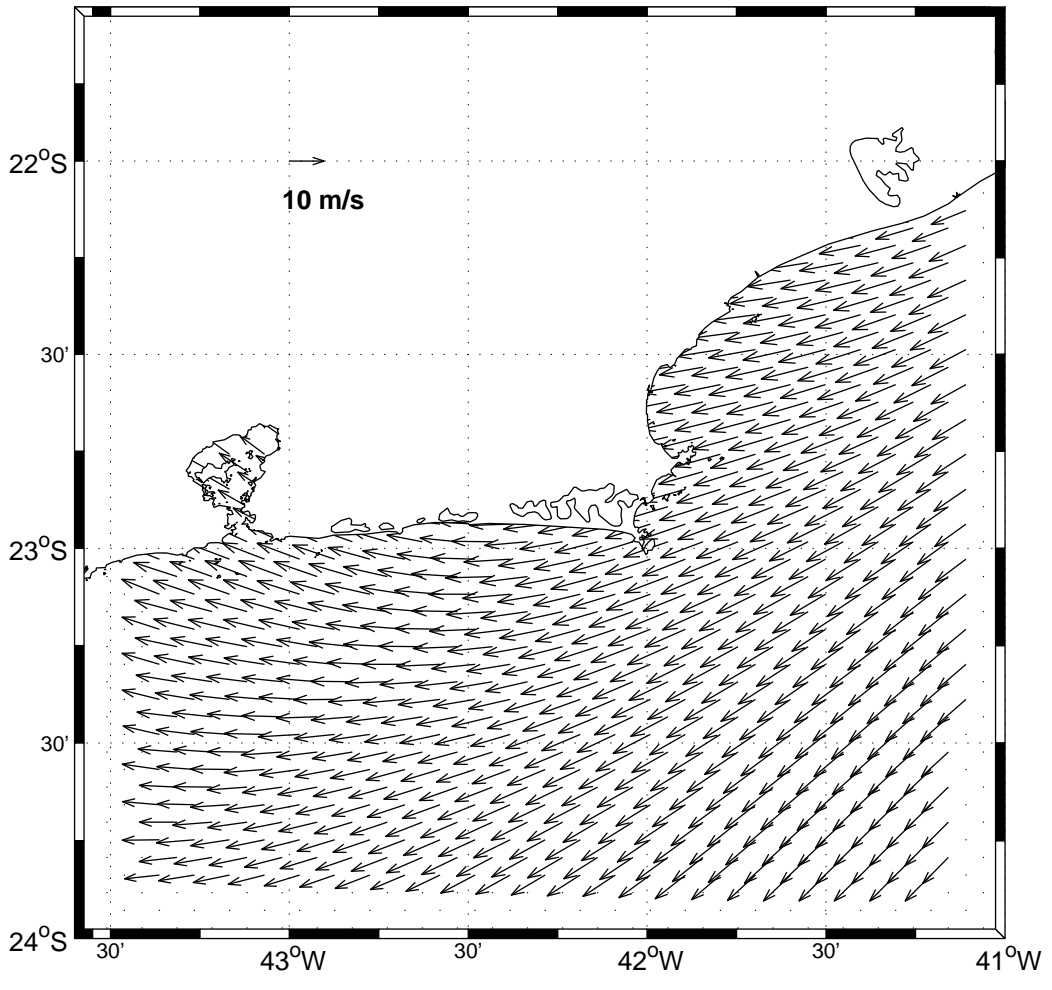

Figura 3.4: Vento $18 Z$ de $16 J A N 86$ 


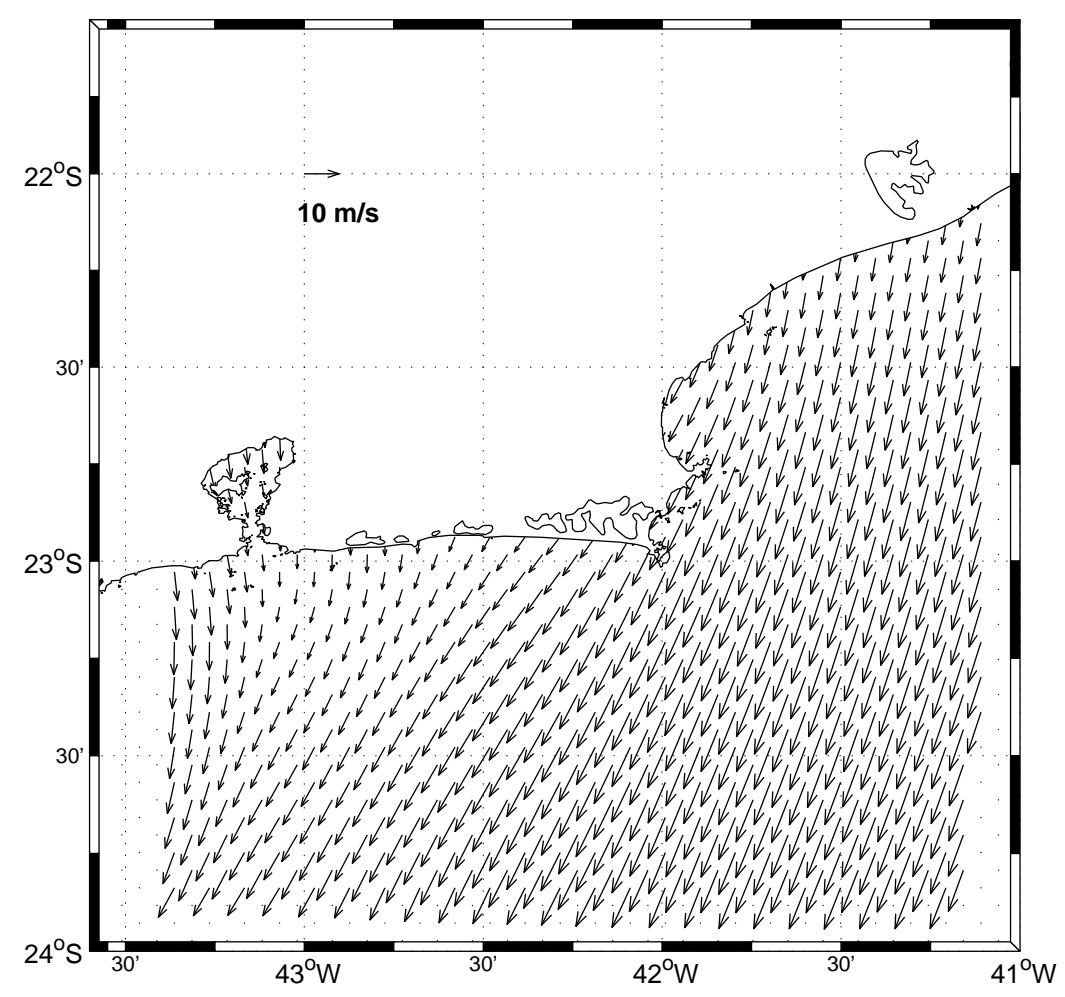

Figura 3.5: Vento $09 Z$ de $17 J A N 86$

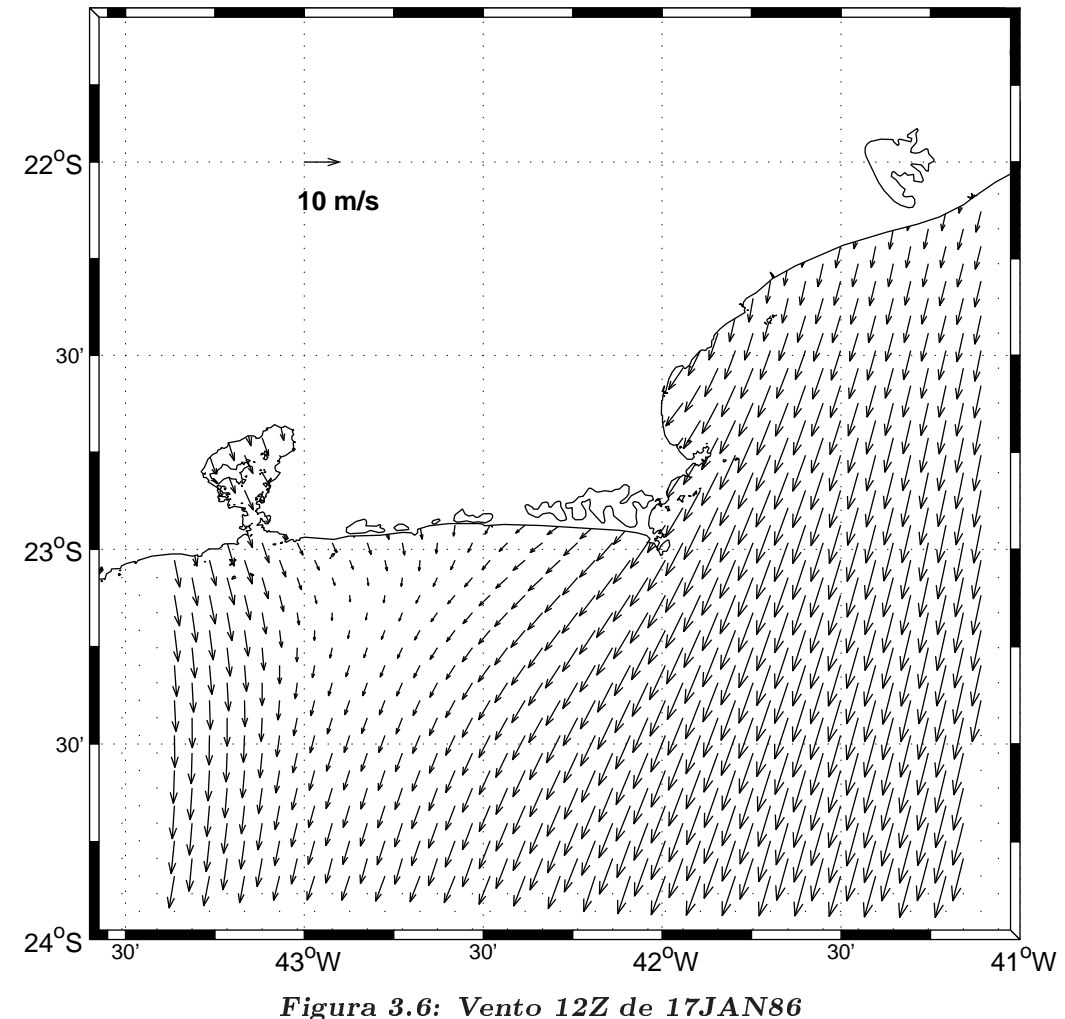




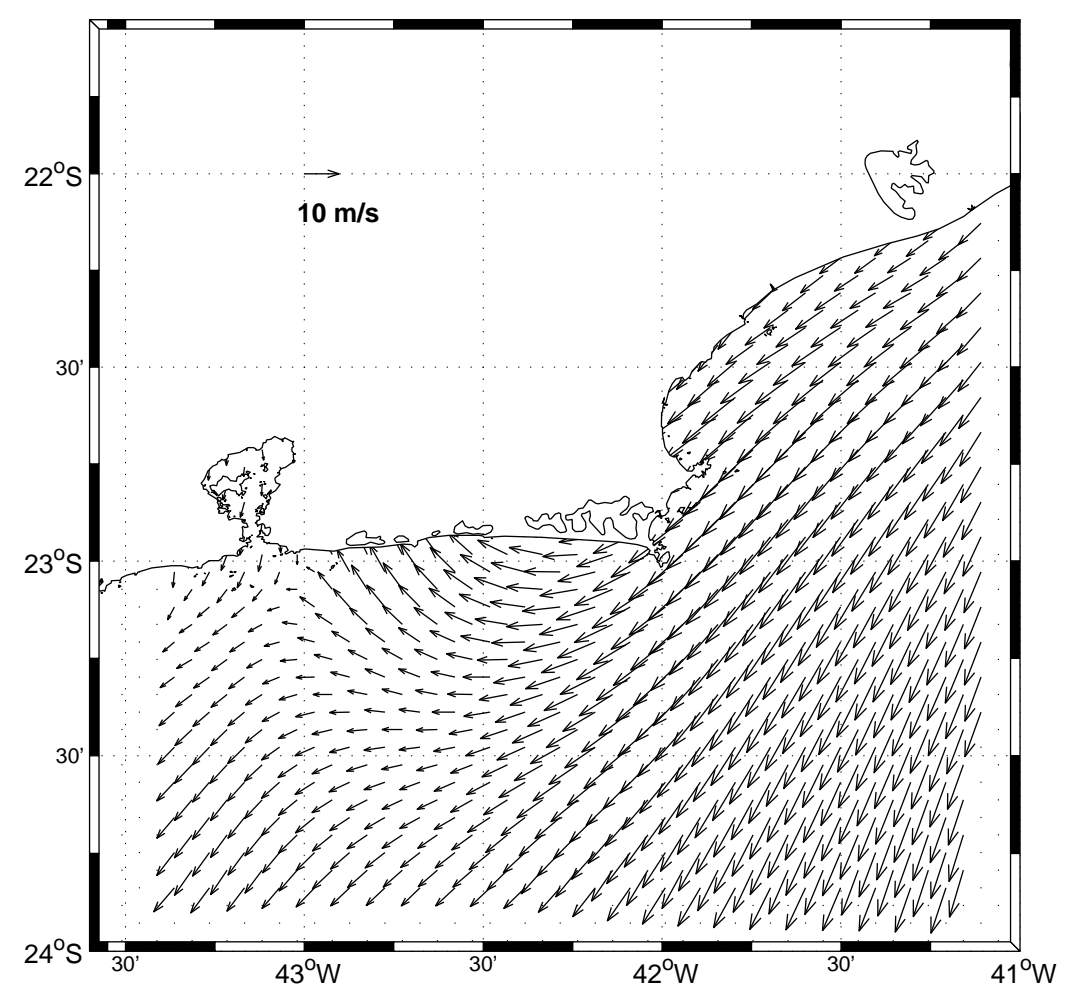

Figura 3.7: Vento $15 Z$ de $17 J A N 86$

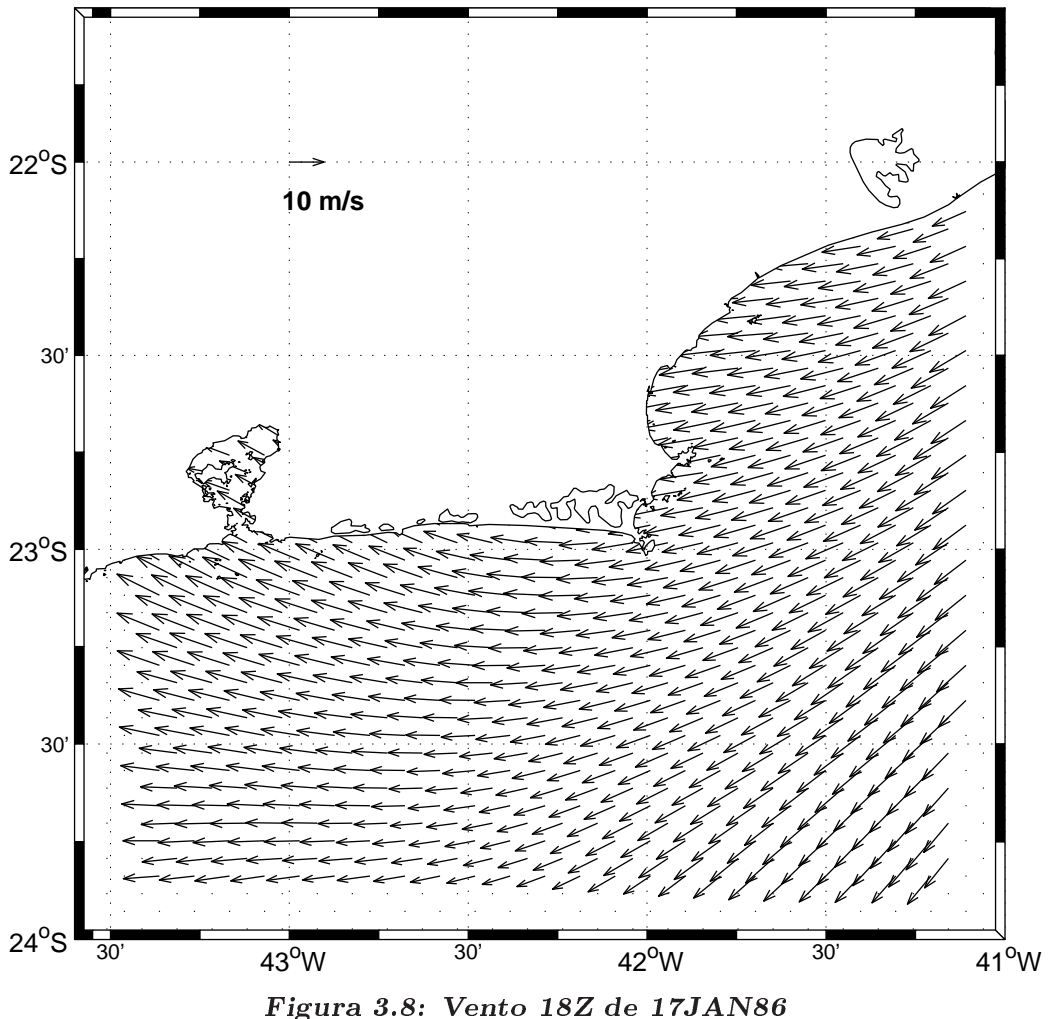




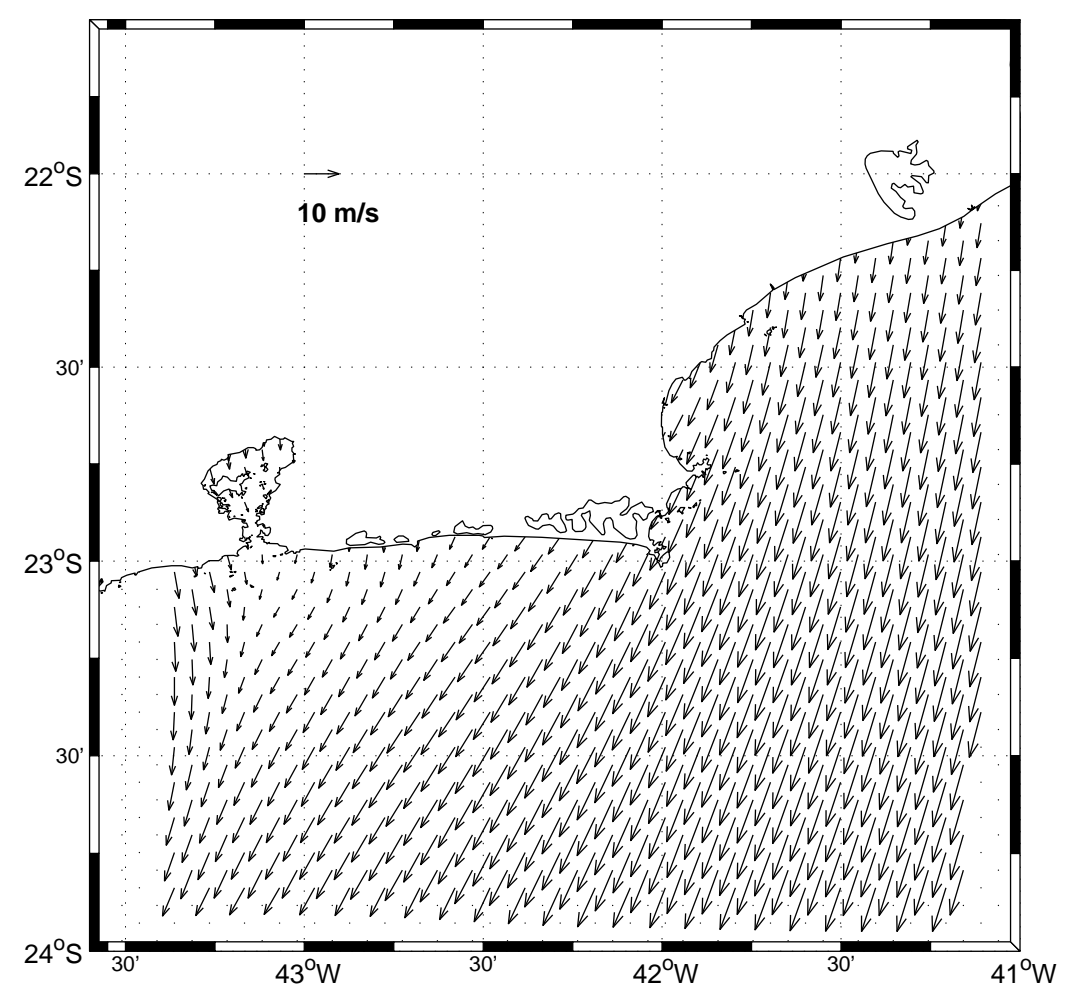

Figura 3.9: Vento $09 Z$ de 18JAN86

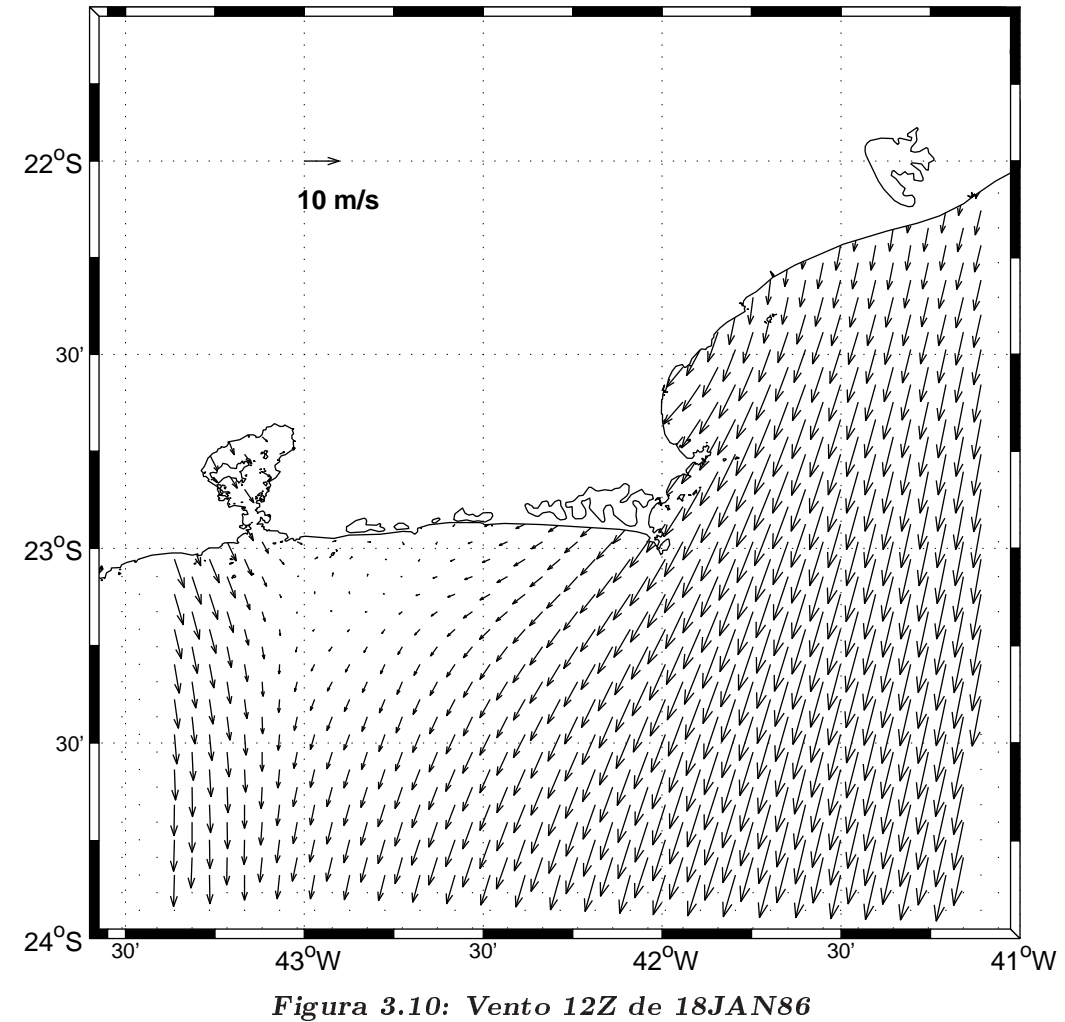




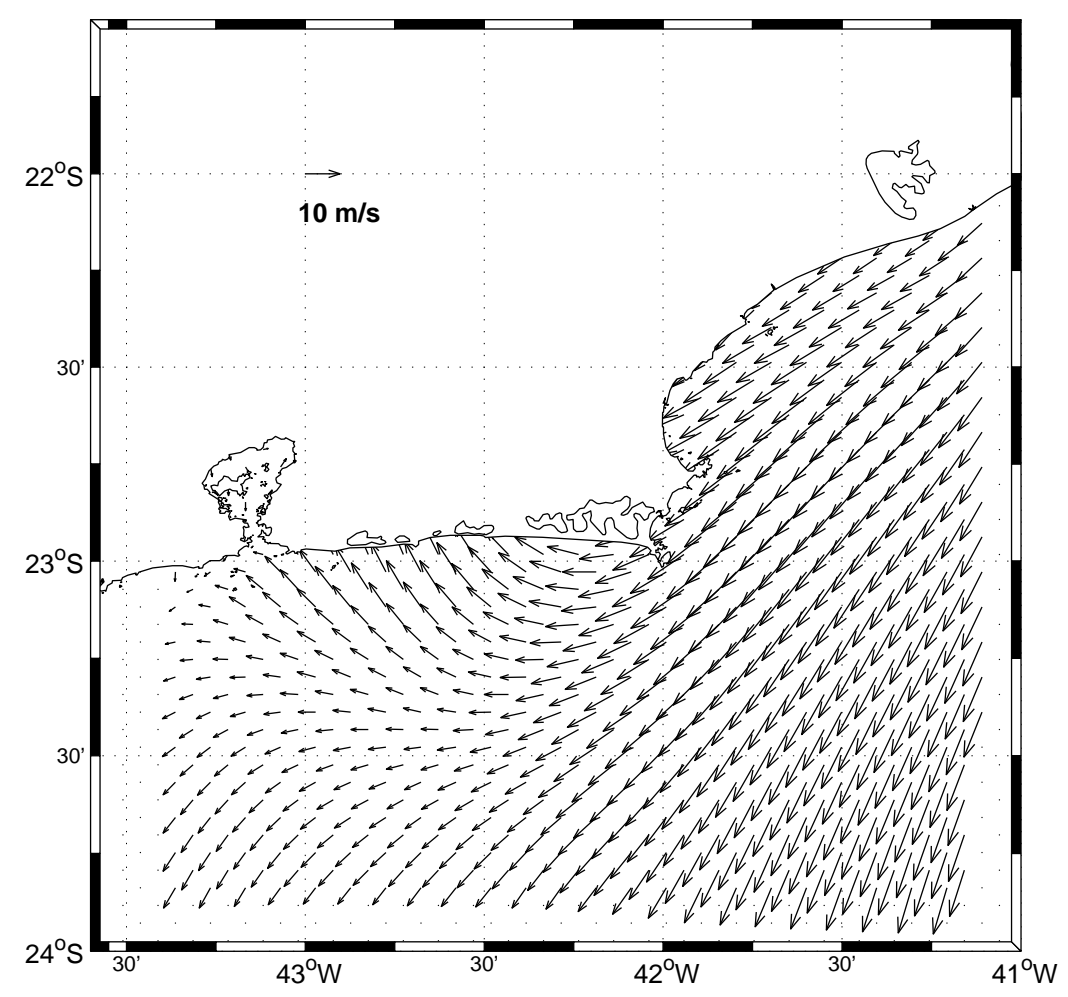

Figura 3.11: Vento $15 Z$ de 18JAN86

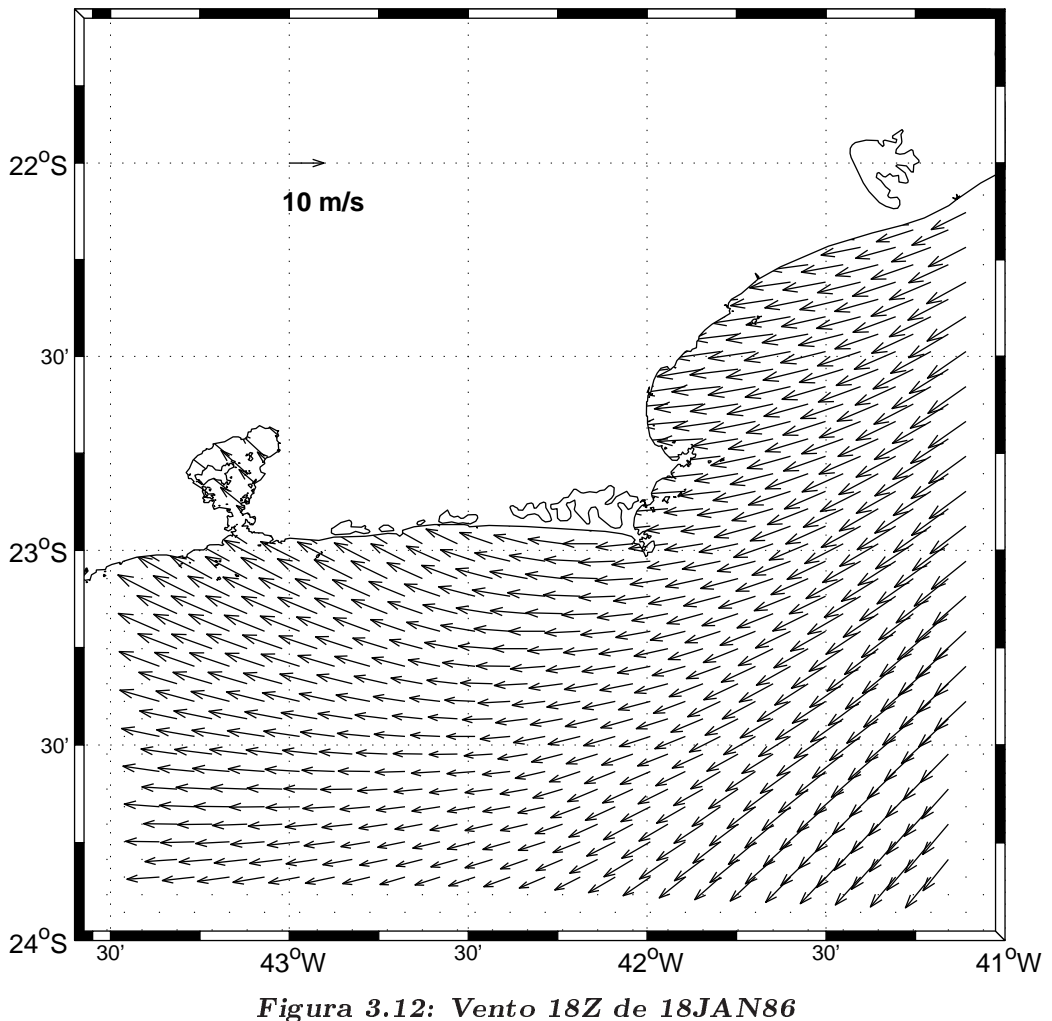


Na figura 3.13 observamos a variação diurna do vento na superfície próximo à Cabo Frio no período de 16-22JAN de 1986. Estes dados foram coletados pela Marinha do Brasil. Podemos também constatar claramente através da série temporal abaixo uma forte componente de circulação local. Entre os dias 16 e 20JAN observase entre o início da tarde até o anoitecer um vento resultante mais zonal. Após o dia 20JAN o comportamento irregular do vento está, possivelmente, associado à chegada de um sistema frontal na região.

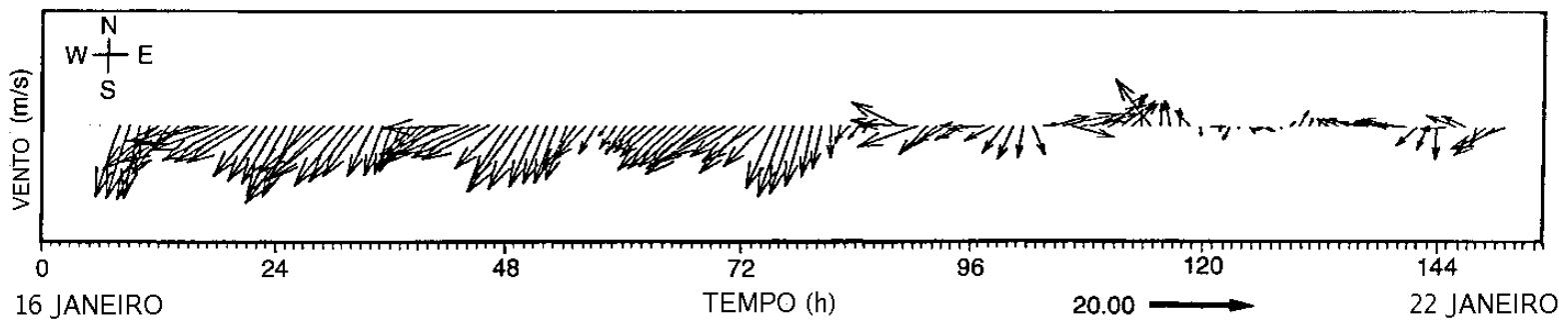

Figura 3.13: Série temporal do vetor de vento na superficie

As figuras 3.14 e 3.15 representam respectivamente a variação zonal e meridional do vento para uma posição localizada na latitude $23.118^{\circ} \mathrm{S}$ e longitude $041.991^{\circ} \mathrm{W}$, bem próxima da estação de coleta de verão. No gráfico da componente zonal observase um aumento na intensidade do vento com o início da brisa do mar, enquanto que no gráfico da componente meridional ocorre o contrário. Isso pode ser explicado pelo fato da BM atuar perpendicularmente à costa fazendo com que, quando somada vetorialmente ao vento predominante na região, apareça um vetor resultante cuja componente zonal é maior ou mais intensa que a respectiva componente do vento predominante. 


\section{VENTO ZONAL}

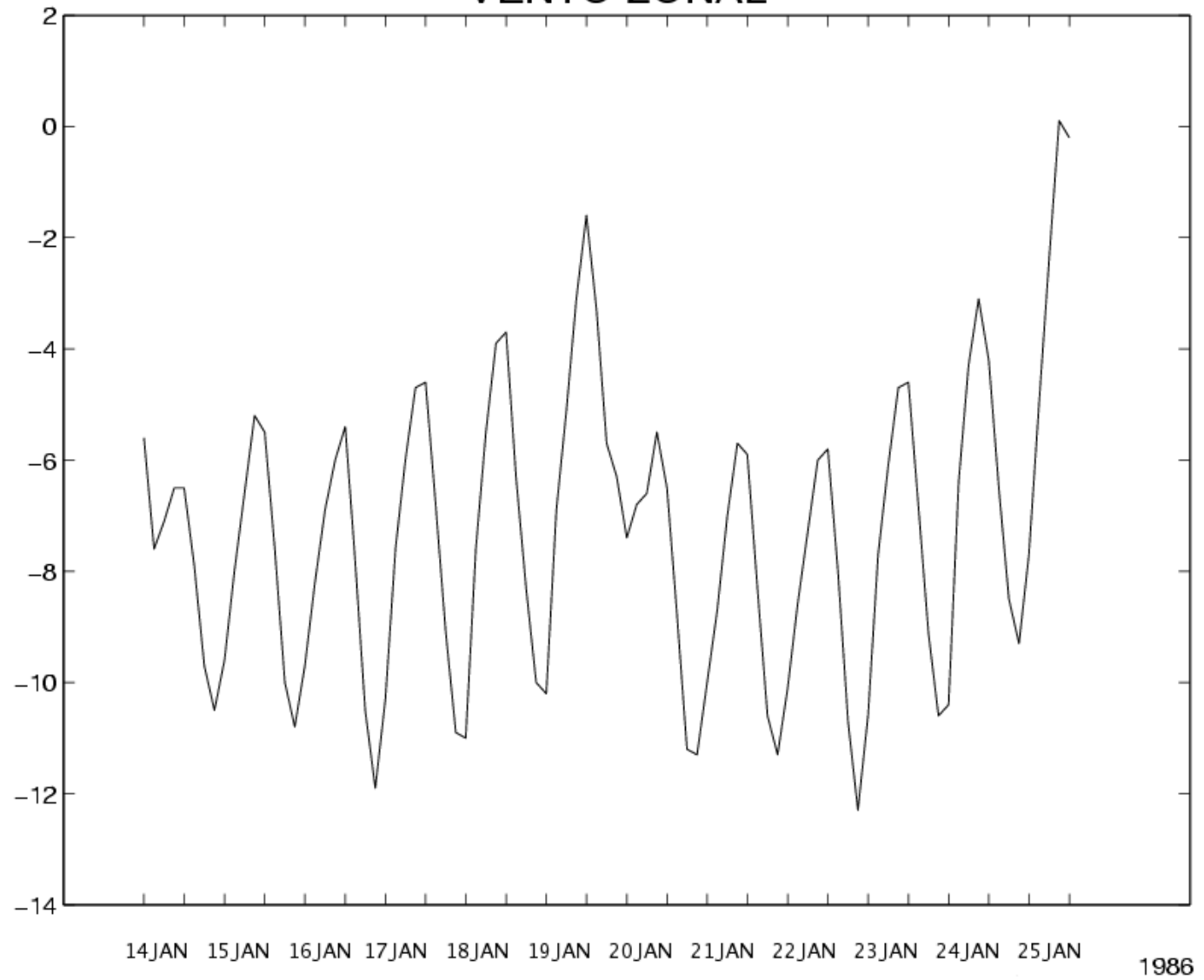

Figura 3.14: Vento zonal

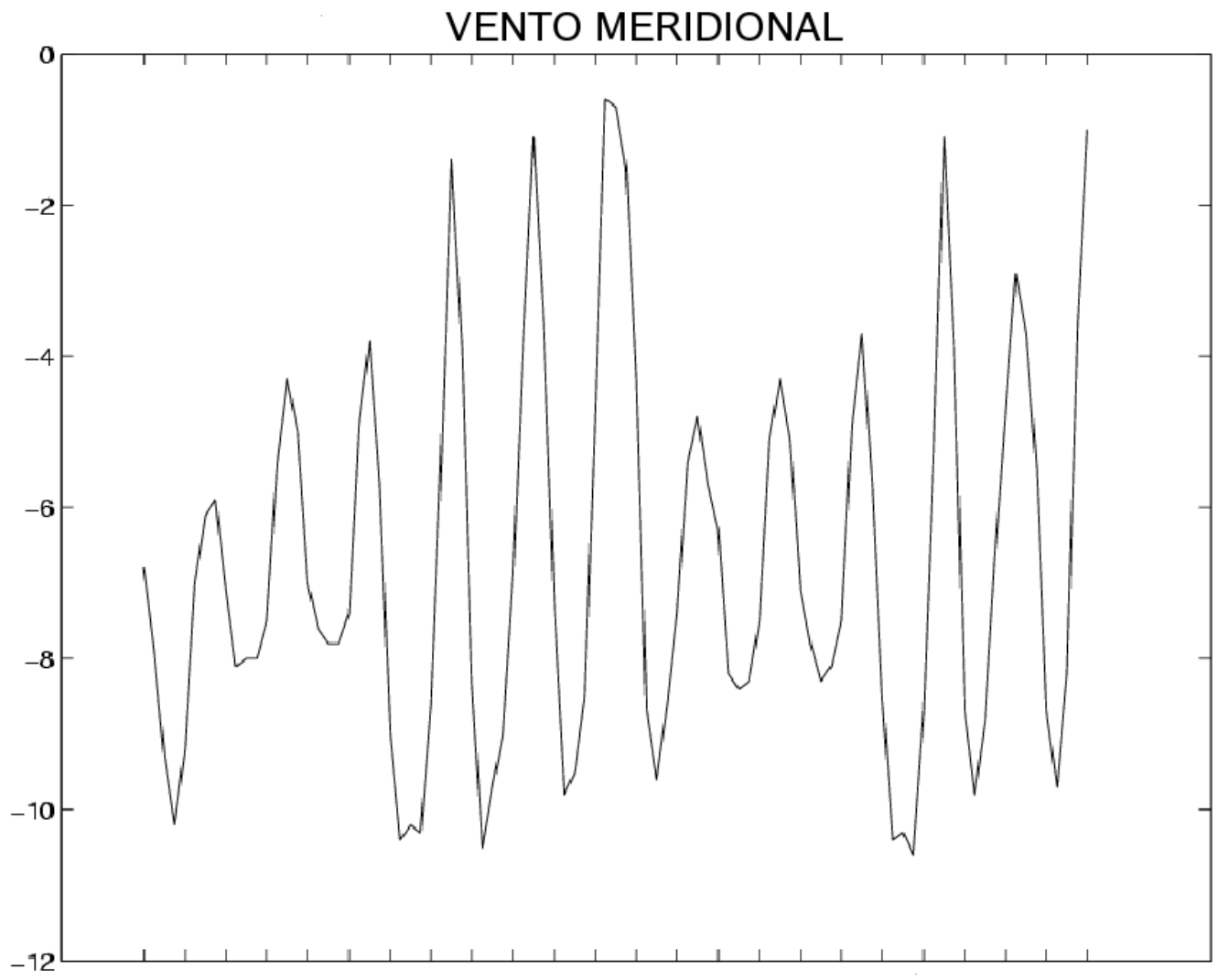

14JAN 15JAN 16JAN 17JAN 18JAN 19JAN 20JAN 21JAN 22JAN 23JAN 24JAN 25JAN

Figura 3.15: Vento meridional 


\subsection{O Modelo Numérico}

Na modelagem em oceanografia utiliza-se, basicamente, três tipos de modelos no que diz respeito a representação das coordenadas verticais. O formalismo mais antigo usa coordenadas cartesianas de profundidade $z$. O segundo utiliza coordenadas sigma, onde cada camada corresponde a uma porcentagem da profundidade local, $D(\sigma=z / D)$. A utilização da coordenada sigma em modelagem funciona bem para resolver problemas em regiões com fortes gradientes batimétricos, como é o caso da plataforma Continental. O terceiro tipo sã coordenadas isopcnais, em que as superfícies de coordenadas são superfícies de igual densidade. Esse terceiro tipo de abordagem é particularmente apropriado para o oceano profundo, onde os processos físicos de grande escala ocorrem predominantemente ao longo de superfícies isopicnais.

Cada um desse três tipos de modelo tem suas vantagens e desvantagens, dependendo do problema e da região sendo modelada. Com base nessa premissa, nos últimos anos um modelo baseado nessas três formas de representação da estrutura vertical vem sendo desenvolvido. Esse modelo, HYCOM (Hybrid Coordinate Ocean Model), combina os três tipos de coordenadas e por isso é bastante promissor no estudo de regiões envolvendo a plataforma continental e o oceano profundo adjacente. É também bastante adequado na resolução da dinâmica da camada de mistura, onde utiliza coordenadas $z$.

O HYCOM é um modelo oceânico de circulação geral de coordenadas isopicnais de equações primitivas, o qual evoluiu do Miami Isopycnic-Coordinate Ocean Model (MICOM). O MICOM utiliza coordenadas isopicnais, que apesar de fornecerem uma boa resolução no interior do oceano, já que a maioria dos processos de larga escala acompanha isolinhas de densidade, fornecem pouca ou nenhuma resolução na camada de mistura e na plataforma continental. A estratégia alternativa empregada no HYCOM é o uso de uma seleção de modelos de mistura vertical para que o melhor modelo de mistura vertical para um determinado ambiente oceânico seja utilizado (Halliwell, 2004). Assim, o HYCOM retém as vantagens das coordenadas isopicnais no oceano aberto estratificado, e transforma-as em coordenadas de nível (pressão) em regiões não estratificadas, como a camada de mistura superficial, e em coordenadas sigma nas zonas costeiras (Shaji et al., 2005). Detalhes técnicos do "gerador de 
grade"("grid generator") que mantém as coordenadas verticais híbridas podem ser encontrados no manual do usuário do HYCOM (Bleck, 2002).

O HYCOM contém cinco equações prognósticas - duas para as componentes de velocidade horizontal, uma equação da tendência da largura da camada ou continuidade de massa, e duas equações de conservação para um par de variáveis termodinâmicas, como salinidade e temperatura ou salinidade e densidade. As equações do modelo podem ser vistas em Bleck (2002). As equações prognósticas são complementadas por diversas equações diagnósticas, incluindo a equação hidrostática, uma equação de estado, ligando a temperatura, salinidade e pressão, e uma equação que prescreve o fluxo vertical de massa através de uma superfície, sendo que essa última equação controla o movimento e o espaçamento na interface das camadas, abrangendo, assim, a essência de modelos em coordenadas híbridas. As equações prognósticas são integradas no tempo através de um tratamento explícito de modos barotrópicos e baroclínicos desenvolvidos previamente no MICOM.

Uma medida do sucesso de um modelo de circulação oceânica é sua capacidade em reproduzir o sistema de correntes equatoriais (Bleck, 2002). De acordo com Chen et al. (1994), o melhoramento mais importante conseguido a partir do esquema de mistura vertical híbrida num modelo tridimensional para o Oceano Pacífico Tropical é a melhor simulação da circulação equatorial de larga escala. Comparado com os outros dois esquemas mais comumentemente utilizados, o esquema híbrido ajudou a produzir perfis de velocidade mais realísticos no Pacífico Equatorial Leste e Central.

Para gerar as saídas utilizadas no presente trabalho, o modelo HYCOM foi primeiramente, implementado em uma região estendendo-se de $62^{\circ} \mathrm{S}$ a $60^{\circ} \mathrm{N}$, com extensão latitudinal abrangendo todo oceano Atlântico. A resolução longitudinal foi de $1 / 3^{\circ}$ e a resolução latitudinal foi de $1 / 3^{\circ}$ vezes o cosseno da latitude em cada ponto de grade. A topografia de fundo foi baseada nos dados do Earth Topography - 5 Minute (ETOPO5), com 5' de resolução em longitude e latitude.

O modelo foi configurado com 22 camadas isopicnais, com resoluções variáveis. Os valores da densidade potencial $\left(\sigma_{\theta}\right)$ do topo de cada camada são mostrados na tabela 3.1.

Partindo do repouso e inicializado com temperaturas e salinidades de verão da 


\begin{tabular}{|c|c|c|c|c|c|c|c|c|c|c|c|}
\hline \hline Camada & 1 & 2 & 3 & 4 & 5 & 6 & 7 & 8 & 9 & 10 & 11 \\
\hline \hline$\sigma_{\theta}$ & 19,50 & 20,25 & 21 & 21,25 & 22,5 & 23,25 & 24 & 24,70 & 25,28 & 25,77 & 26,18 \\
\hline \hline Camada & 12 & 13 & 14 & 15 & 16 & 17 & 18 & 19 & 20 & 21 & 22 \\
\hline \hline$\sigma_{\theta}$ & 26,52 & 26,80 & 27,03 & 27,22 & 27,38 & 27,52 & 27,64 & 27,72 & 27,82 & 27,88 & 27,94 \\
\hline
\end{tabular}

climatologia mensal Levitus (Levitus and Boyer (1994) e Levitus et al. (1994)), o modelo foi forçado com ventos, fluxos de calor, evaporação e demais fluxos termodinâmicos da climatologia Comprehensive Ocean-Atmosphere Data Set (COADS). O modelo atingiu um estado de equilíbrio após 23 anos. Em seguida procedeu-se com um processo de aninhamento unidirecional, no qual a sub-região do Atlântico, entre $10^{\circ} \mathrm{S}$ e $40^{\circ} \mathrm{S}$, limitada a leste pelo meridiano $30^{\circ} \mathrm{W}$, foi utilizada para uma versão do modelo com resolução de 1/12 de graus. Essa versão de maior resolução horizontal utilizou a mesma distribuição de níveis isopicnais e foi inicializada com condições obtidas da simulação de menor resolução. Forçado com os mesmos fluxos da climatologia COADS, o modelo foi executado por mais dois anos, até a obtenção de um novo estado de equilíbrio. Ao final desse dois anos, os experimentos aqui descritos foram executados, conforme será detalhado no Capítulo 4. 


\section{Capítulo 4}

\section{Discussão dos resultados}

\subsection{Análise dos Dados Hidrográficos de verão e inverno}

Com a utilização dos dados hidrográficos temos na figura 4.1 as séries temporais, nas profundidades nominais de 0m, 10m e 48m, da temperatura, salinidade e da densidade. De 16-21JAN de 1986 as séries, na parte superior do oceano, nos revela uma oscilação quase periódica de alta freqüência com amplitude de $3^{\circ} \mathrm{C}$ para temperatura e 0,4 para salinidade. Os eventos quentes acontecem com alta salinidade e baixa densidade e essas ocorrências mais quentes acontecem ao final do entardecer sugerindo um efeito diário do calor proveniente do sol, entretanto o fluxo de calor necessário para produzir tal aquecimento seria teoricamente maior aliado ao fato de que o calor do sol, por si só, não poderia explicar o aumento simultâneo da salinidade. Ainda segundo Defant, no volume 1 do livro "Physical Oceanography", diz que a variação diurna da temperatura no mar aberto, usualmente, é menor que $0.4^{\circ} \mathrm{C}$ e pode subir até no máximo à $1^{\circ} \mathrm{C}$ com condições de tempo calmo e regular. Então podemos inferir que os eventos frios ocorrem, inicialmente, pela ressurgência das águas de profundidades moderadas. Observando a similaridade das freqências da ressurgência e da circulação local (BM) podemos também inferir que as oscilações na parte superior do oceano são causadas, principalmente, pela presença da BM que altera o vento resultante na região. Na série observamos, em superfície, que a temperatura começa a cair no entardecer e vai continuando a diminuir atingindo um valor mínimo nas primeiras horas do dia subsequente o que está em conformidade 
com Franchito et al., 1998, ao afirmar que mesmo quando a temperatura sobre a terra se torna menor do que sobre o mar, o fluxo de circulação local permanece no sentido do mar para terra porém diminuindo sua intensidade a medida que o tempo passa até reverter a circulação e surgir uma fraca brisa no sentido terra-mar durante as horas iniciais da manhã do dia seguinte.
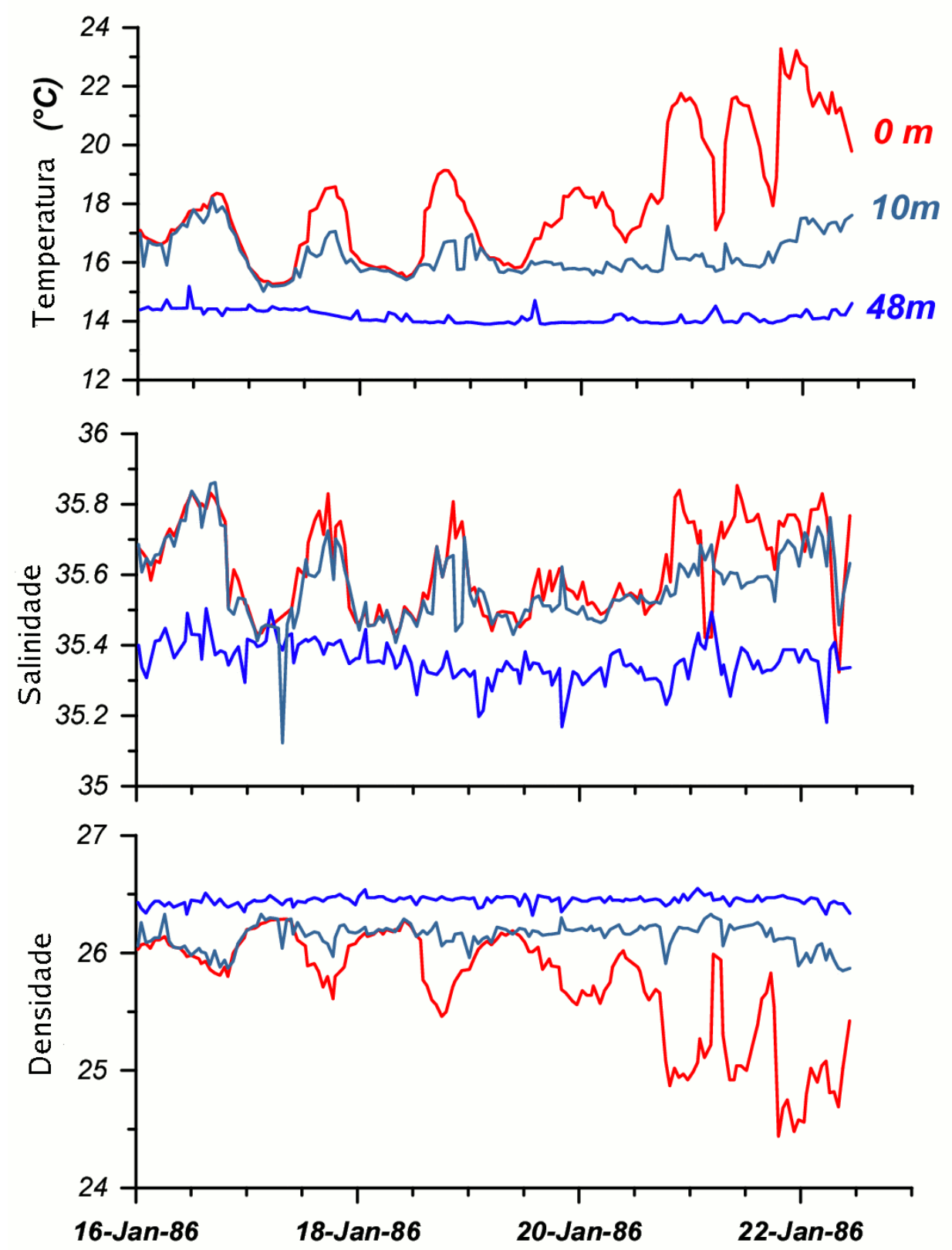

Figura 4.1: Séries temporais de $T$ e $S$ no verão 
Na figura 4.2 abaixo observamos dois gráficos tempo-profundidade. Na parte superior temos a temperatura e na inferior a salinidade. A figura nos revela que a estrutura termohalina quente e salina na parte superior do oceano $\left(\mathrm{T}>17^{\circ} \mathrm{C}\right.$ e $\mathrm{S}>35.5)$ se extende verticalmente até aproximadamente $30 \mathrm{~m}$ de profundidade entre os dias 16 e 21 de janeiro e é totalmente removida do local por períodos de 12 horas. Os eventos frios e com salinidade baixa são observados nos dias 17, 18 e 19 de janeiro e, pouco intenso, em 20 de janeiro. Após o dia 21 se desenvolve na superfície uma camada quente e salina, porém ainda há evidências de pulsos curtos de baixas temperatura e salinidade até $10 \mathrm{~m}$ de profundidade.
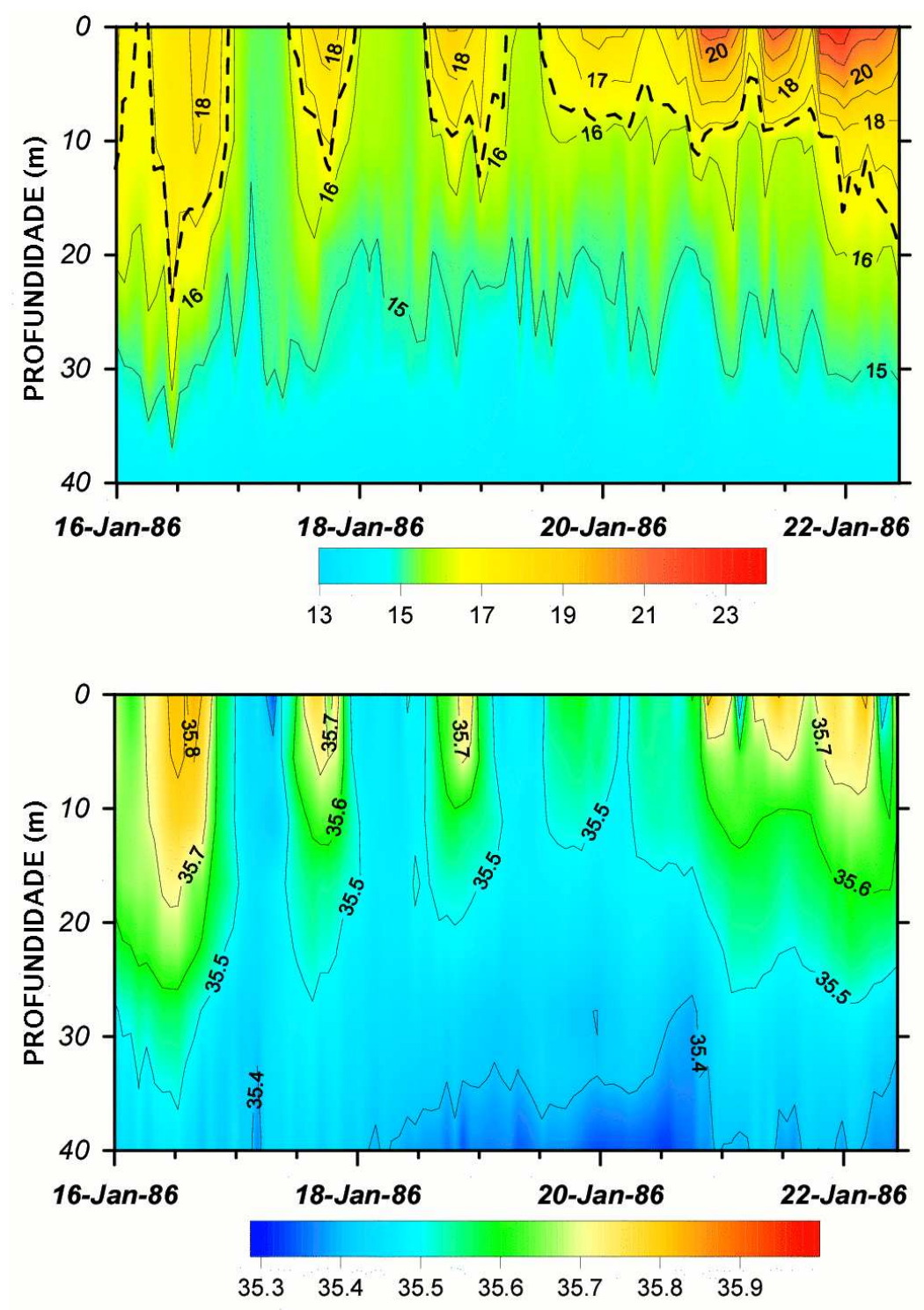

Figura 4.2: gráficos profundidade-tempo de $T$ e $S$ 
Temos na figura 4.3 o diagrama T-S revelando que a ACAS é a fonte da ressurgência naquela localidade. O diagrama T-S mostra a distribuição durante os eventos quentes (vermelho e sem ressurgência) e durante os eventos frios (azul e com ressurgência). Também é mostrado no diagrama a distribuição (preto) de uma estação localizada no talude continental com dados coletados no núcleo da Corrente do Brasil. A distribuição em vermelho, quando não ocorre ressurgência, mostra valores característicos de águas costeiras e quando da ocorrência de transporte de Ekman favorável à ressurgência, essa massa de água costeira é advectada para longe da costa. Na distribuição azul, quando ocorre ressurgência, as características termohalinas se aproximam muito da ACAS encontrada no núcleo da CB.

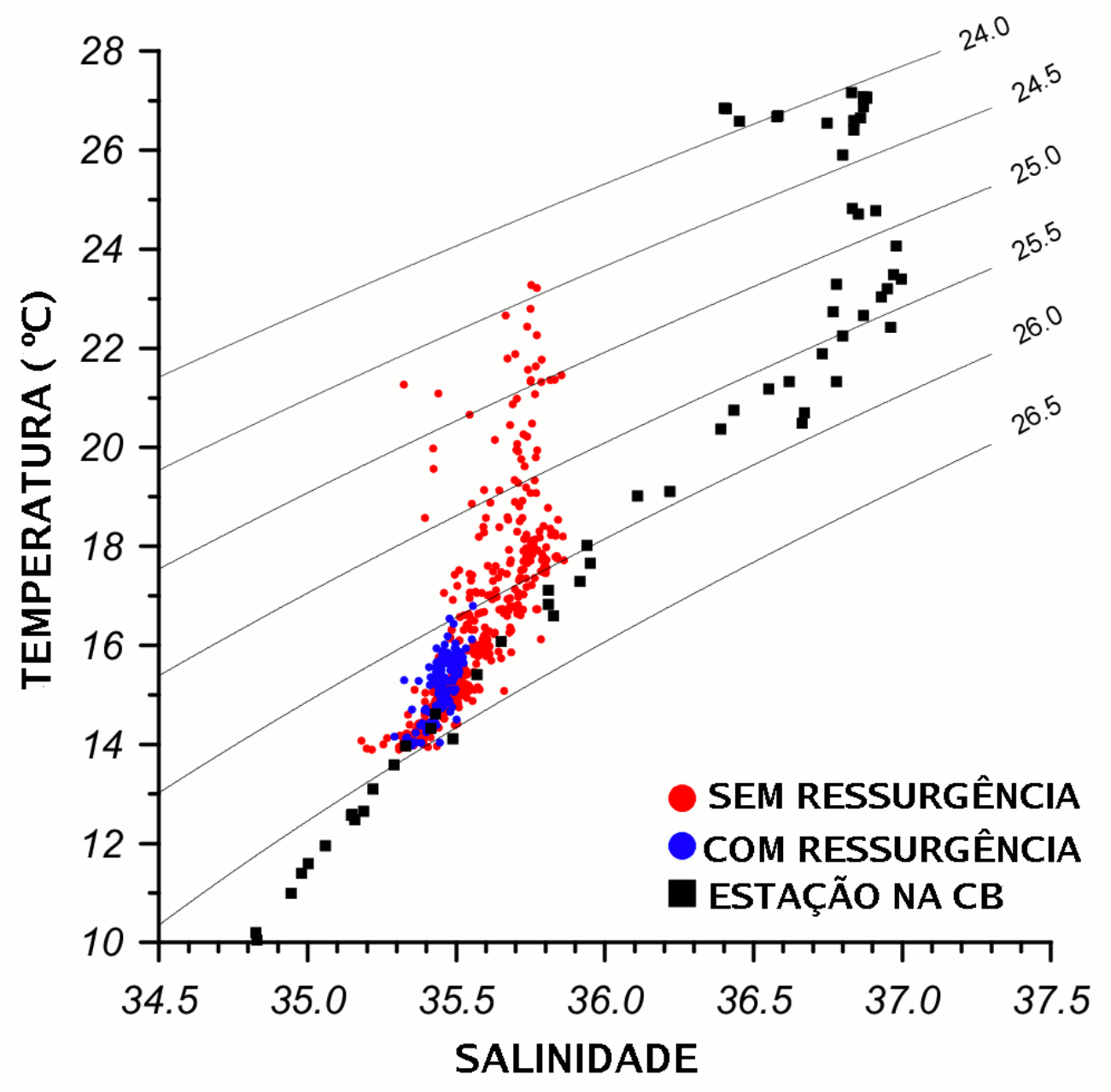

Figura 4.3: Diagrama T-S verão 
Na figura 4.4 temos as séries temporais para o período de 9 a 22SET de 1972 nas profundidades nominais de 0, 10, 30 e 75 metros. Observamos diferenças significativas entre as séries temporais de verão e inverno. No inverno não se observa uma oscilação diária na parte superior do oceano como no verão. Outra observação é que a variabilidade da temperatura, salinidade e densidade se extende ao longo da coluna d’água no inverno.
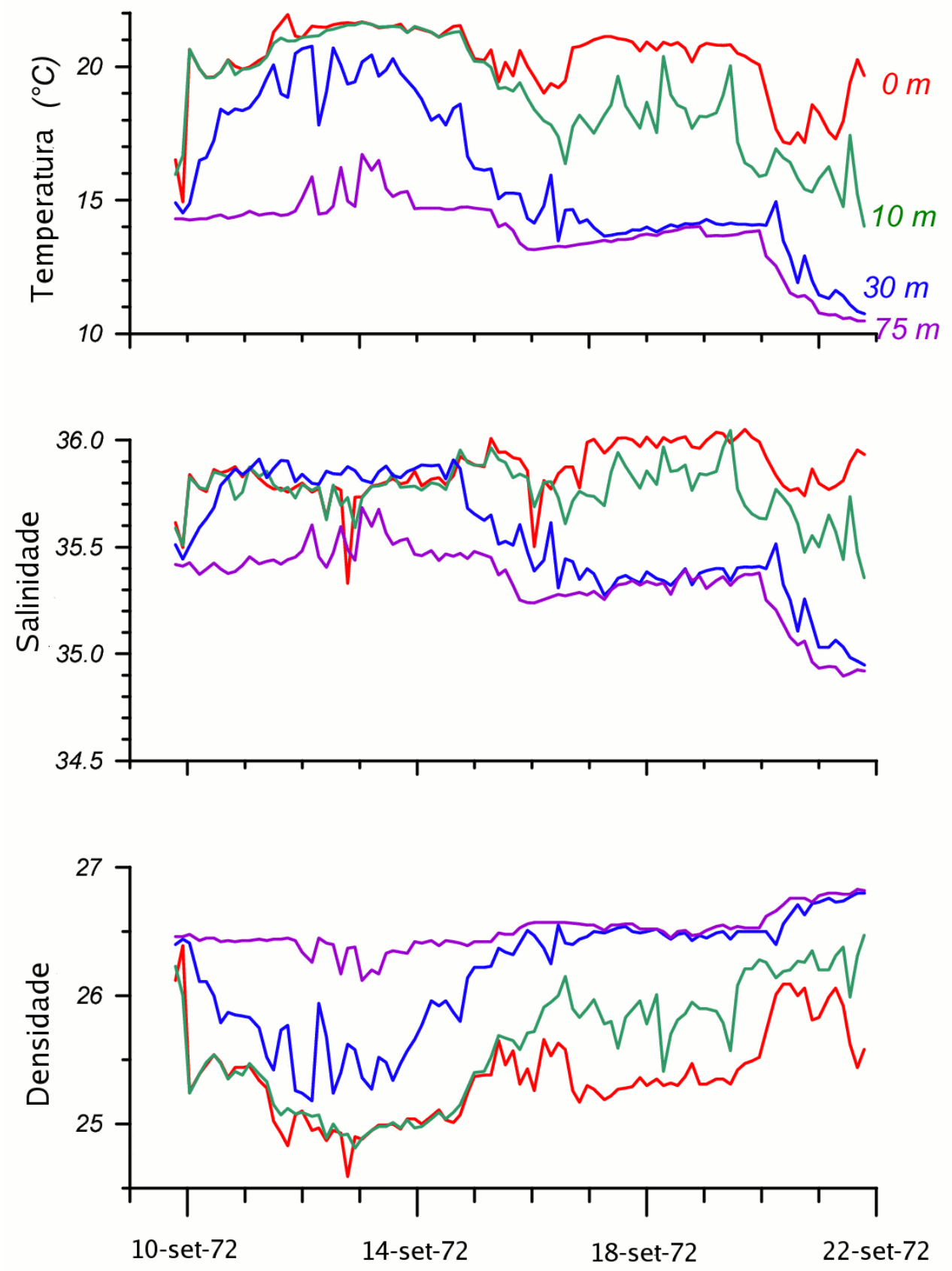

Figura 4.4: Séries temporais de $T$ e $S$ no inverno 
Na figura 4.5 observamos dois gráficos tempo-profundidade. Na parte superior temos a temperatura e na inferior a salinidade. A figura mostra que a termoclina e haloclina afundam de $20 \mathrm{~m}$ em 09SET para $50 \mathrm{~m}$ próximo de 13SET subindo novamente para $20 \mathrm{~m}$. Este comportamento pode ser explicado pelas mudanças nas intensidades e direções dos ventos.
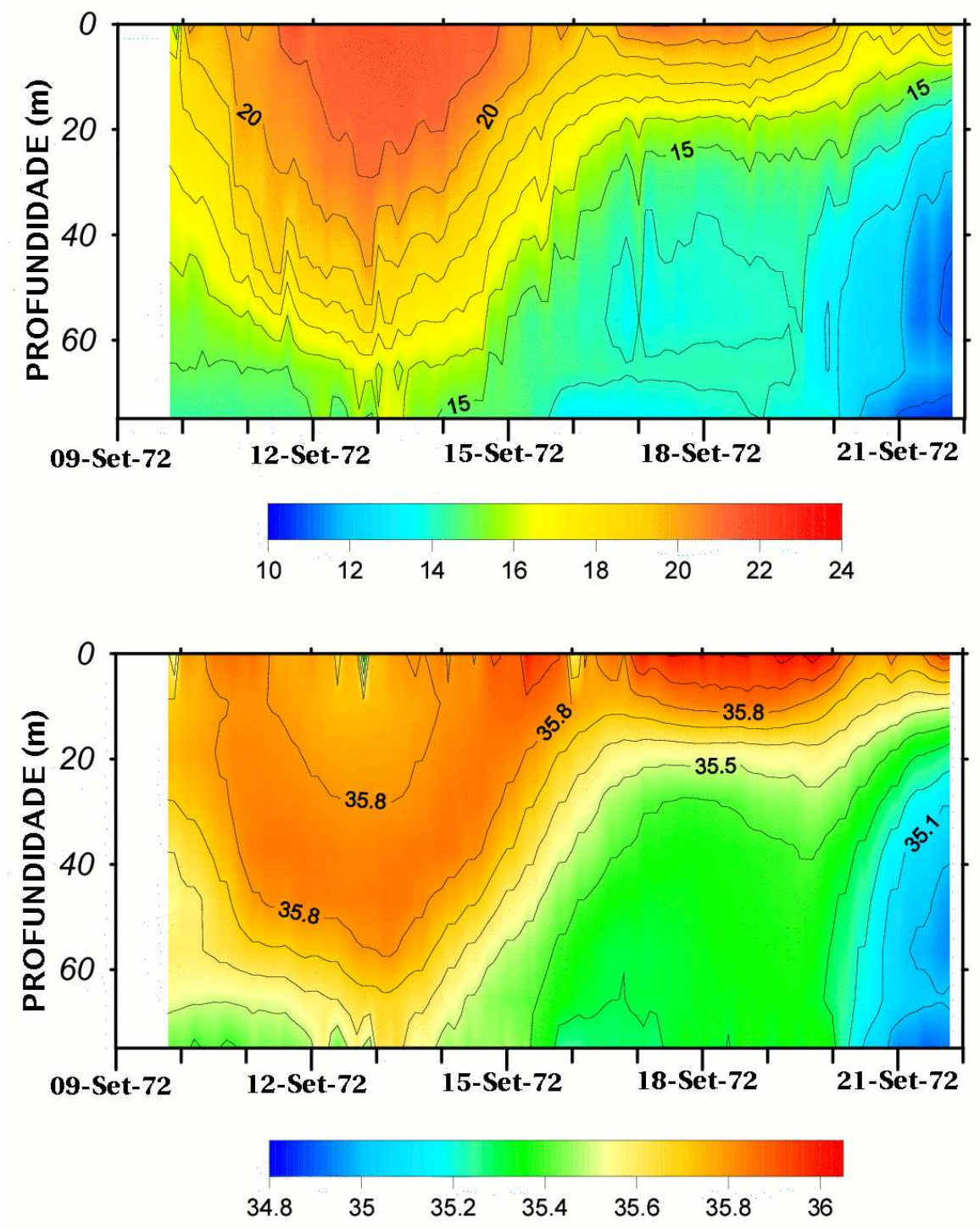

Figura 4.5: Gráficos profundidade-tempo de $T$ e $S$ 
Temos na figura 4.6 o diagrama T-S para os dias 12-13SET (vermelho e sem ressurgência) e 20-21SET (azul e com ressurência). Como no diagrama T-S de verão também é mostrado a distribuição (preto) de uma estação localizada no talude continental com dados coletados no núcleo da Corrente do Brasil. Como no diagrama T-S de Janeiro de 1986, a figura mostra que a fonte da ressurgência é a ACAS mas, contrastando com a situação de verão, no inverno as águas na camada superior são mais quentes e menos salinas que a ACAS, sugerindo que as águas costeiras impedem o afloramento total da ACAS. Isto explica, em parte, a ausência de uma temperatura da superfície local mínima na climatologia de TSM no inverno.

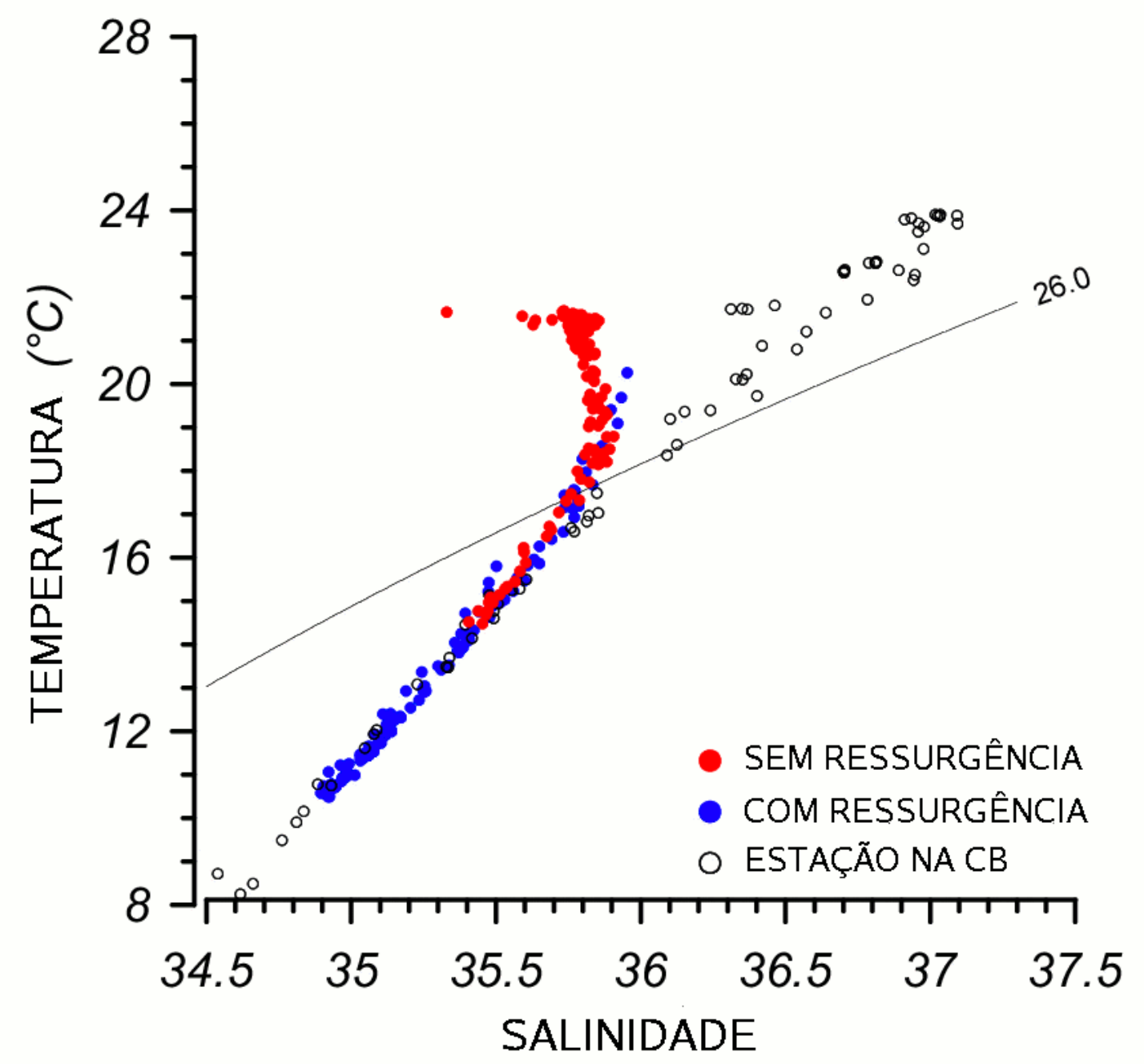

Figura 4.6: Diagrama T-S inverno 
Na figura 4.7 temos uma seção E-W feita em 22 de setembro de 1972, após completar as séries temporais de inverno. A seção corre no sentido leste a partir de Cabo Frio e indo até a quebra de plataforma. A estação mais à oeste (estação 93) foi a última das séries temporais a ser ocupada ao sul de Cabo Frio e serviu como primeira estação da seção. A estação 98 está localizada na quebra de plataforma. A leste de Cabo Frio a ACAS é quente e salina. A ACAS fria e menos salina (T $<15^{\circ} \mathrm{C}$ e $\left.\mathrm{S}<35.5\right)$ somente é encontrada na plataforma interna, na vizinhança de Cabo Frio e não chegou na região pelo leste de maneira que, presumivelmente, o fornecimento de ACAS vem do sul, onde há um intenso gradiente batimétrico, como se pode ver na figura 4.8 .

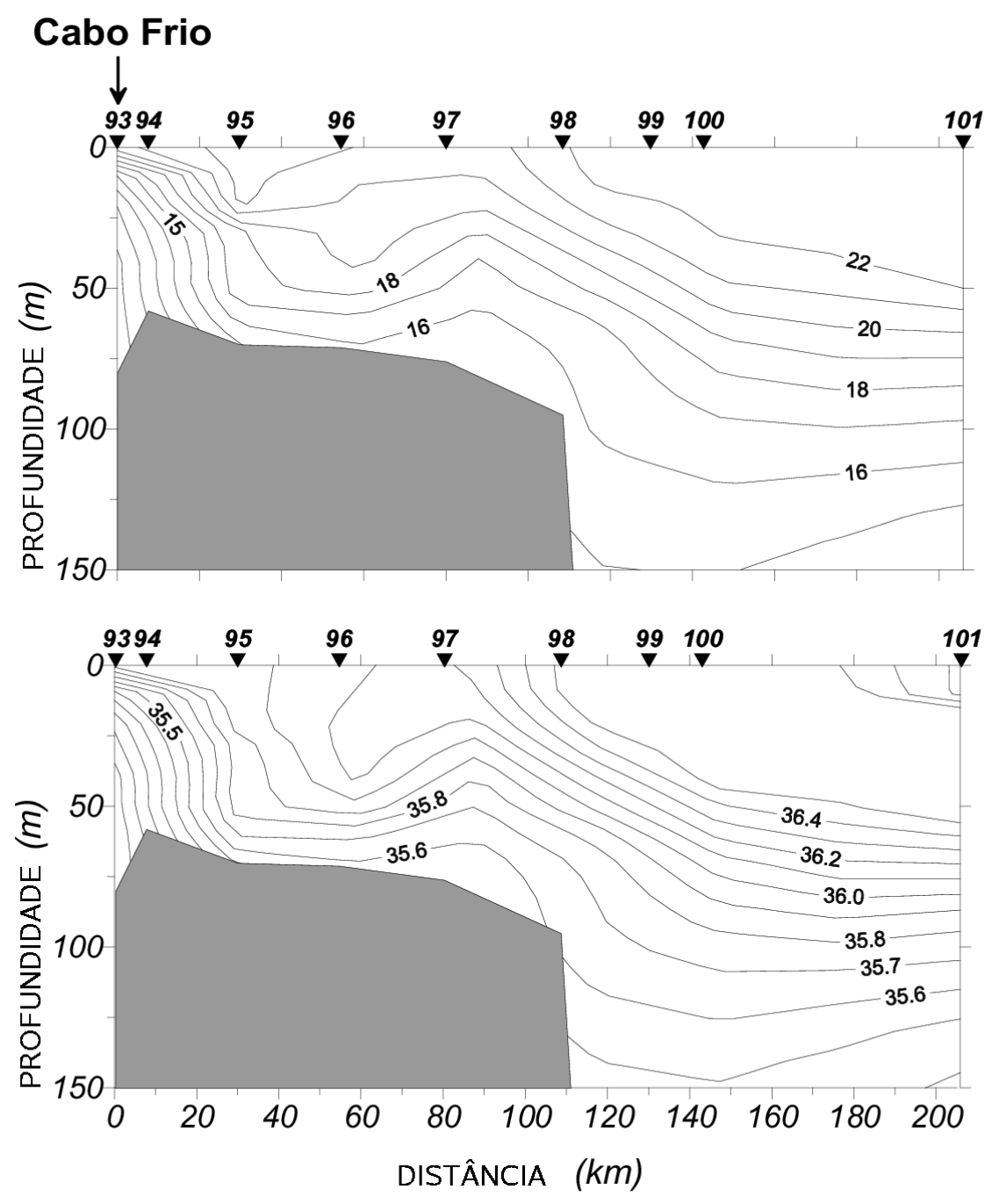

Figura 4.7: Seção zonal de $T$ e $S$ 
Na figura 4.8, que mostra as isóbatas de Vitória até Cabo Frio, podemos observar bem o comportamento das isolinhas de mesma profundidade com a mudança da orientação da linha de costa na região de modo que pode-se constatar, claramente, o adensamento das isóbatas bem próximo à Ilha de Cabo Frio.

$\mathrm{Na}$ figura 4.9 temos uma vista de cima de duas seções de temperatura feitas em março de 1967, ambas começando em Cabo Frio. A seção I no sentido leste e a seção II no sentido sudeste. Estas duas seções mostram como a batimetria local controla a penetração da parte fria e pouco salina da ACAS na plataforma interna. Podemos observar através da figura 4.10, na seção II, a penetração de ACAS fria $\left(\mathrm{T}<15^{\circ} \mathrm{C}\right)$ no sentido noroeste percorrendo uma distância aproximada de $100 \mathrm{~km}$. Podemos dizer que esta penetração da ACAS na plataforma interna, a partir da seção II, é possível e facilitada devido a profundidade maior da plataforma naquela região causada pelo intenso gradiente batimétrico, haja vista que a isóbata de 100 m está bem próxima da costa, aproximadamente, na distância de $7 \mathrm{~km}$ da costa. 


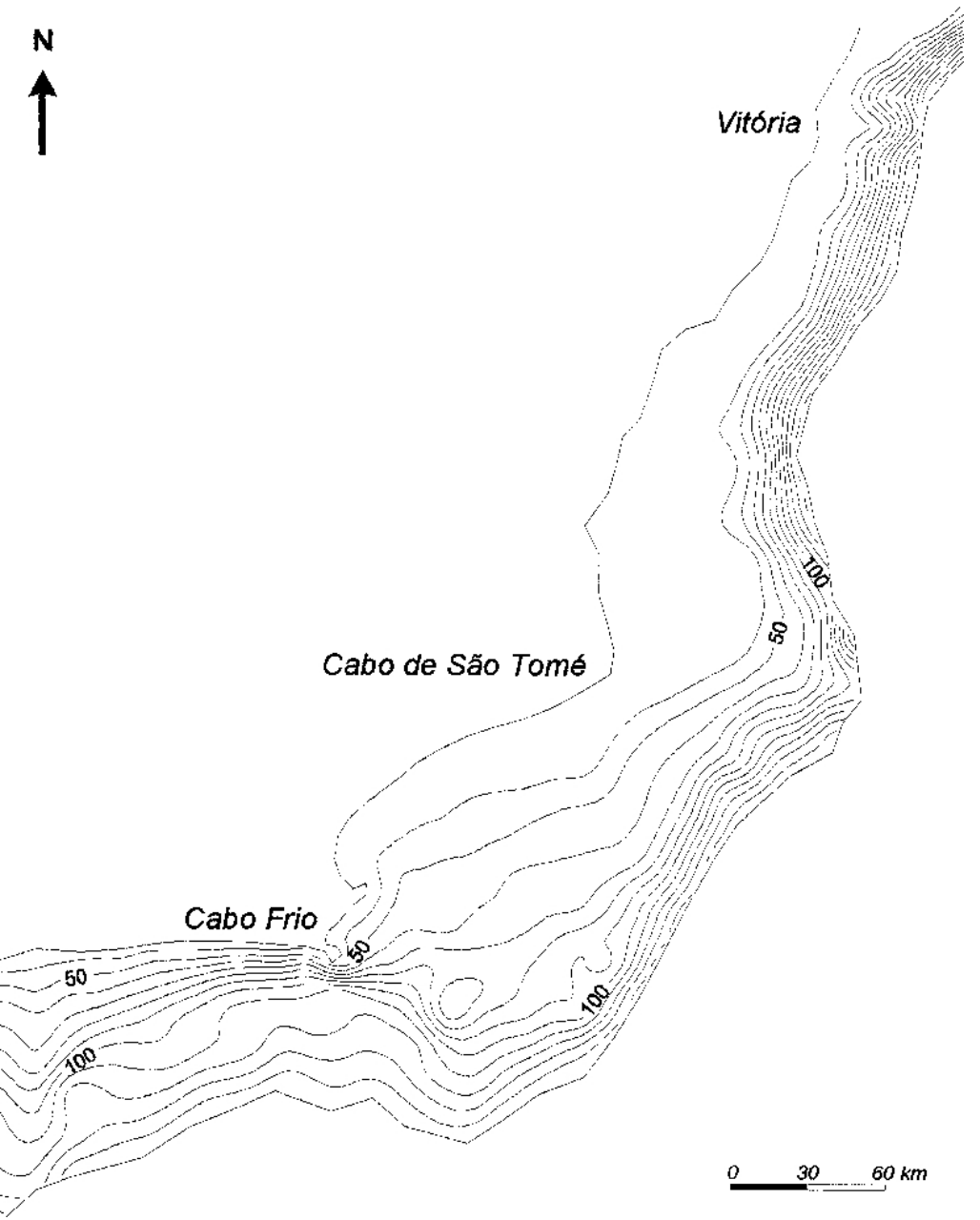

Figura 4.8: Topografia de fundo extraída da carta náutica No.70 da Marinha do Brasil 


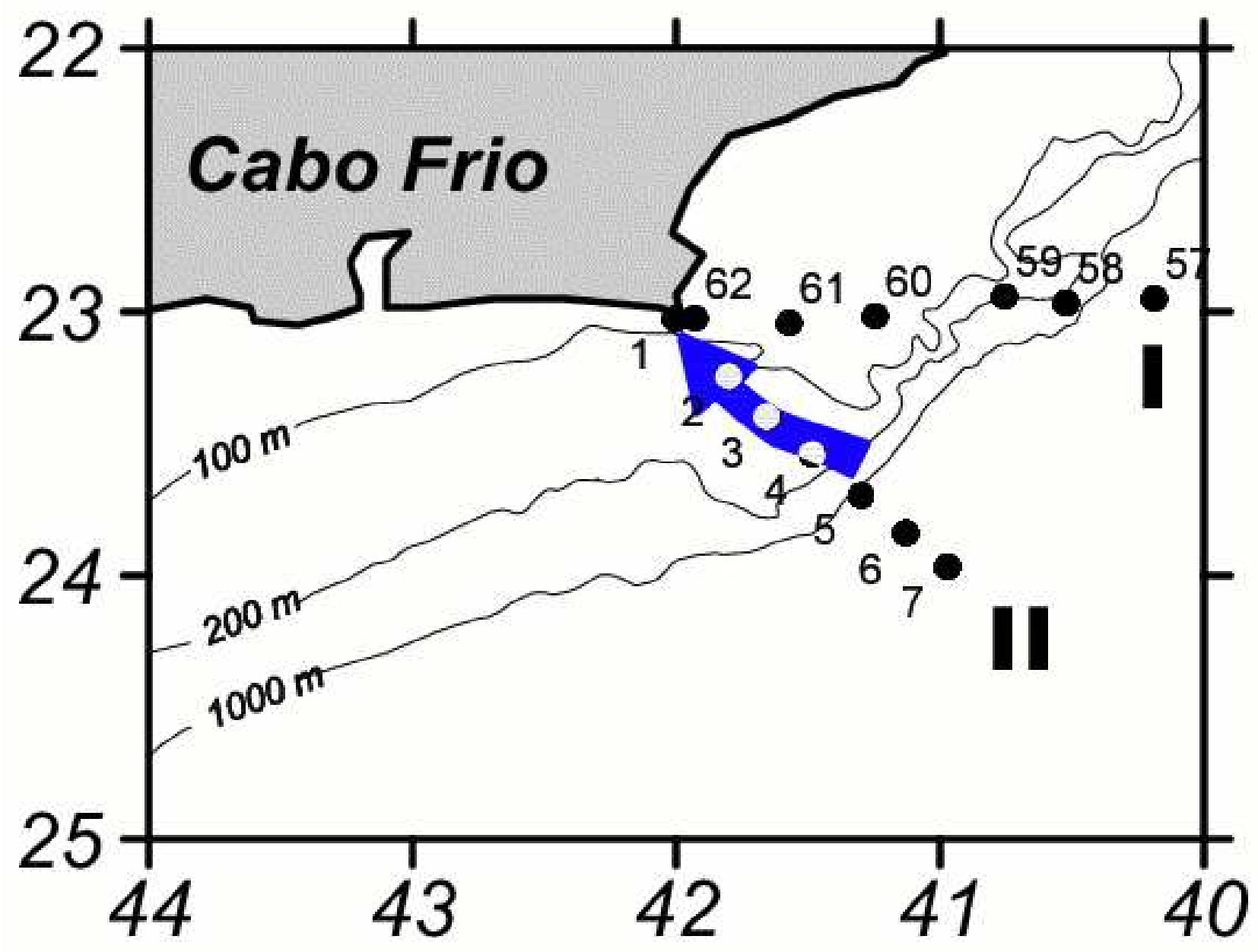

Figura 4.9: Vista de topo das seções I e II de T 


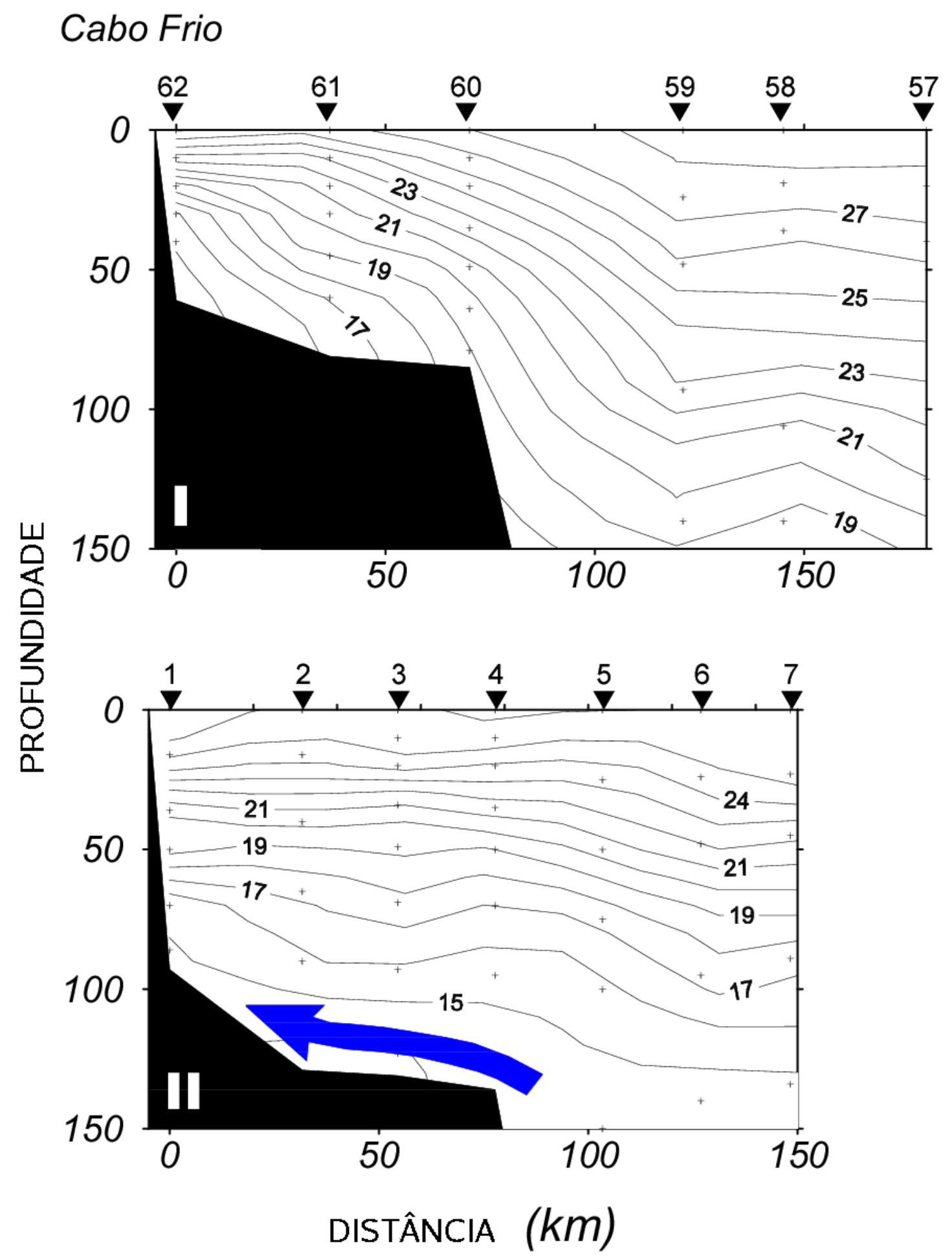

Figura 4.10: Seções I e II de T 
A figura 4.11 mostra a profundidade da isoterma de $16^{\circ} \mathrm{C}$, que determina, de maneira razoável, o limite superior da ACAS fria e pouco salina, presente na ressurgência de Cabo Frio em setembro de 1972. A profundidade da isoterma de $16^{\circ} \mathrm{C}$ é um bom indicador da intensidade da ressurgência. Entre 14 e 16 de setembro a isoterma de $16^{\circ} \mathrm{C}$ se eleva em $50 \mathrm{~m}$ passando de $70 \mathrm{~m}$ para $20 \mathrm{~m}$ de profundidade. A figura também mostra a velocidade e direção do vento medido à bordo do ex-Noc Alte. Saldanha. Durante a mudança de profundidade da isoterma de $16^{\circ} \mathrm{C}$ observamos que o vento mudou, tanto na intensidade (linha tracejada) quanto na direção (linha cheia). Stech e Lorenzetti (1992) investiga a resposta da 'South Brazil Bight' (SBB) quando da passagem de frentes frias no inverno austral e observa que na parte quente da frente o vento inicialmente passa de NE para NW. Imediatamente após a passagem do sistema frontal, o vento passa a ser do quadrante sul asumindo a direção SW no setor frio da frente e posteriormente, girando no sentido anti-horário, passa novamente para a direção NE que é favorável à ressurgência.

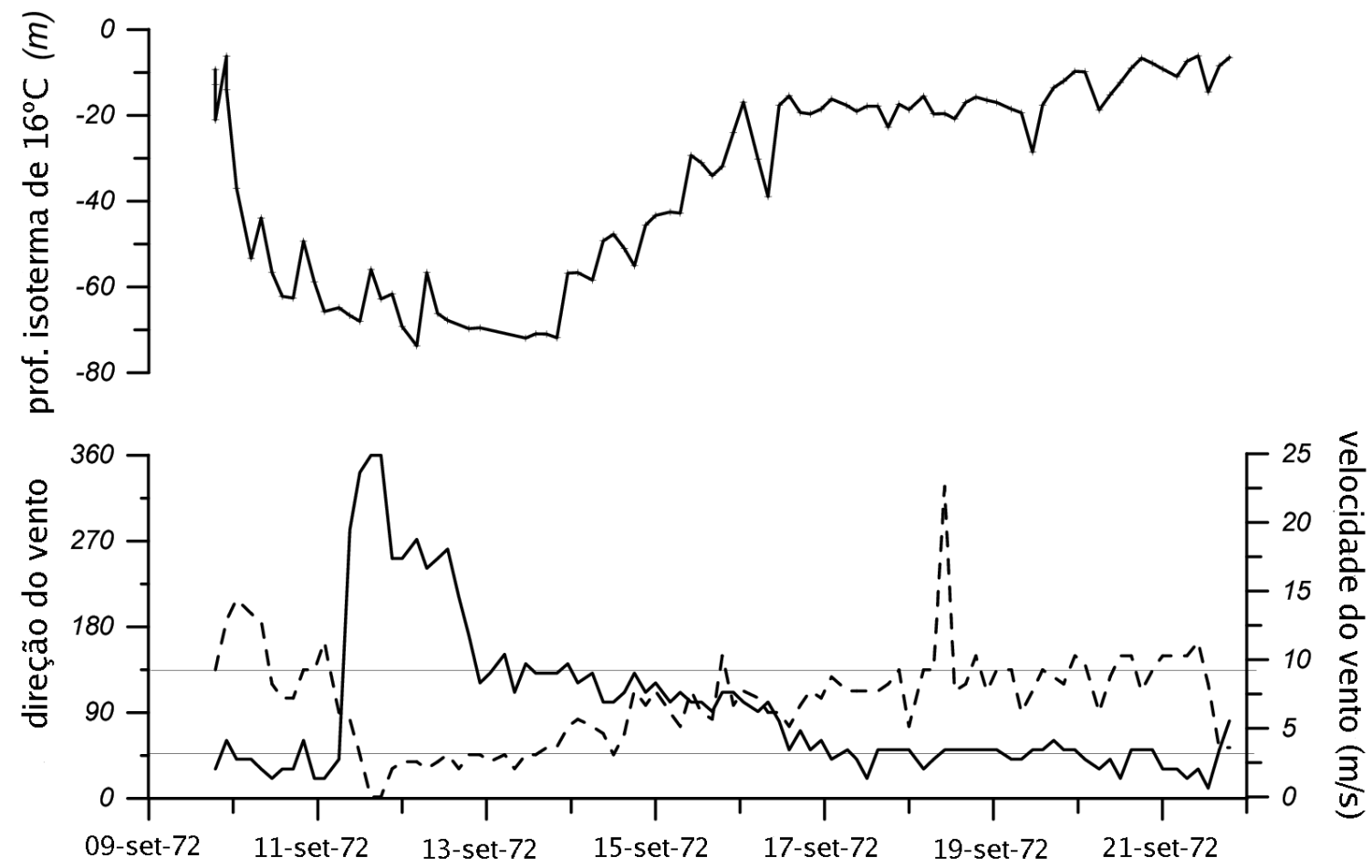

Figura 4.11: Isoterma de $16^{\circ} \mathrm{C}$

O comportamento do vento, mudando tanto a direção quanto a intensidade, está associado à chegada de um sistema frontal na região cuja evolução pode ser acompanhada através das figuras 4.12 a 4.20, que consistem nas cartas sinóticas do 
período da observação, também disponibilizadas pela Marinha do Brasil através do CHM. Observamos na figura 4.14, que consiste na carta sinótica de $1200 \mathrm{Z}$ do dia 11SET72, a aproximação da frente fria na região de Cabo Frio o que está coerente com o gráfico da figura 4.11 pois no mesmo verifica-se o início da alteração no vento observado entre os dias 11 e 12SET. Na figura 4.11 verificamos que no dia 10SET72 a isoterma de $16^{\circ} \mathrm{C}$ encontra-se na profundidade de $10 \mathrm{~m}$, profundidade esta indicativa da ocorrência da ressurgência. Com a aproximação do sistema frontal naquela região se observa uma resposta imediata da isoterma em questão no sentido de afundar pois, apesar de ainda não ter ocorrido uma mudança significativa na direção do vento, a intensidade diminuiu afetando assim a ressurgência. No dia 11SET72 ocorre uma alteração acentuada no vento, tanto em direção quanto em intensidade, e então a isoterma de $16^{\circ} \mathrm{C}$ afunda de $10 \mathrm{~m}$ para $60 \mathrm{~m}$, permanecendo assim até o dia 14 SET72 quando então se eleva novamente passando de $70 \mathrm{~m}$ para $20 \mathrm{~m}$. 


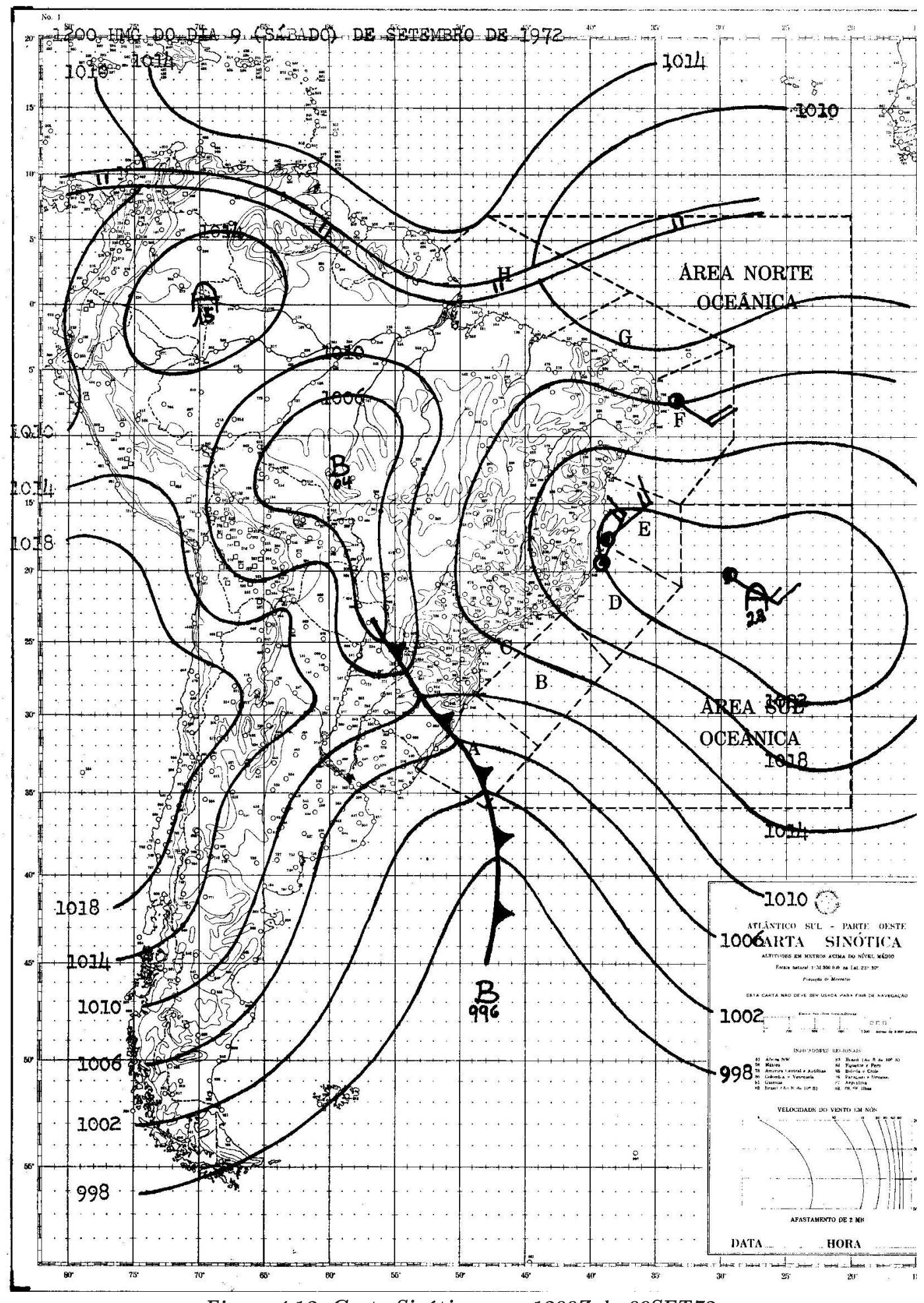

Figura 4.12: Carta Sinótica para $1200 Z$ de 09SET72 


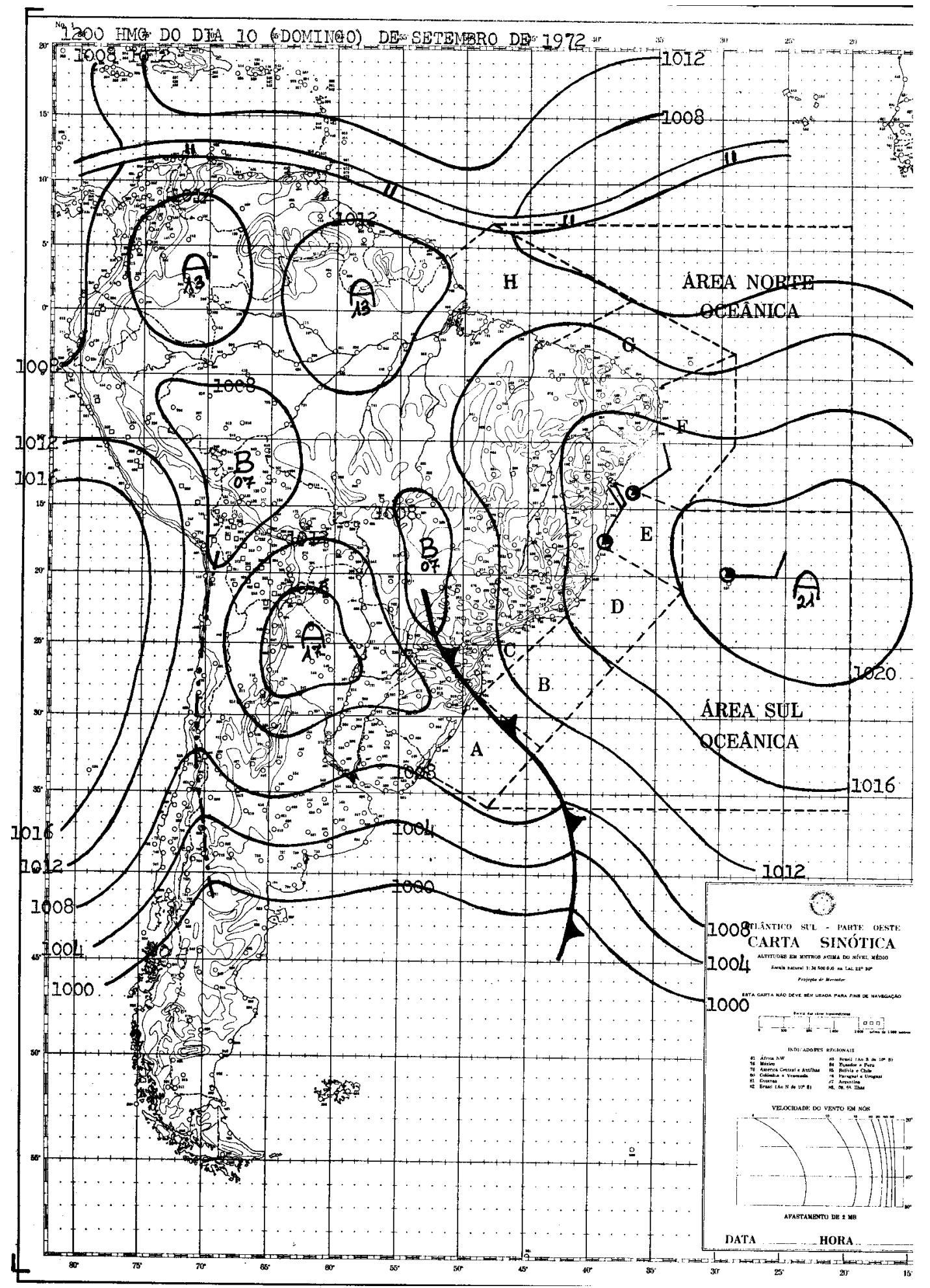

Figura 4.13: Carta Sinótica para 1200Z de 10SET72 


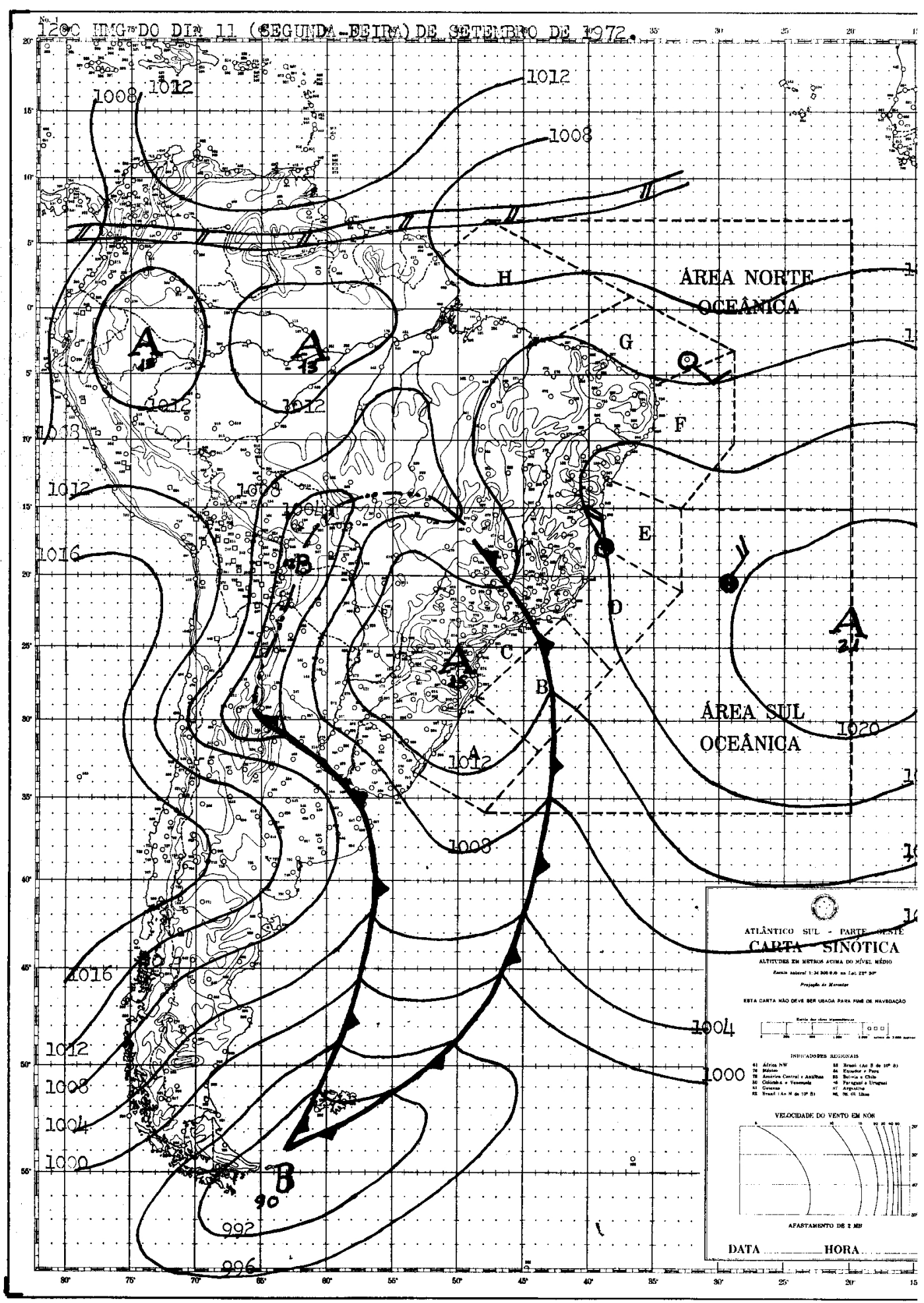

Figura 4.14: Carta Sinótica para 1200Z de 11SET72 


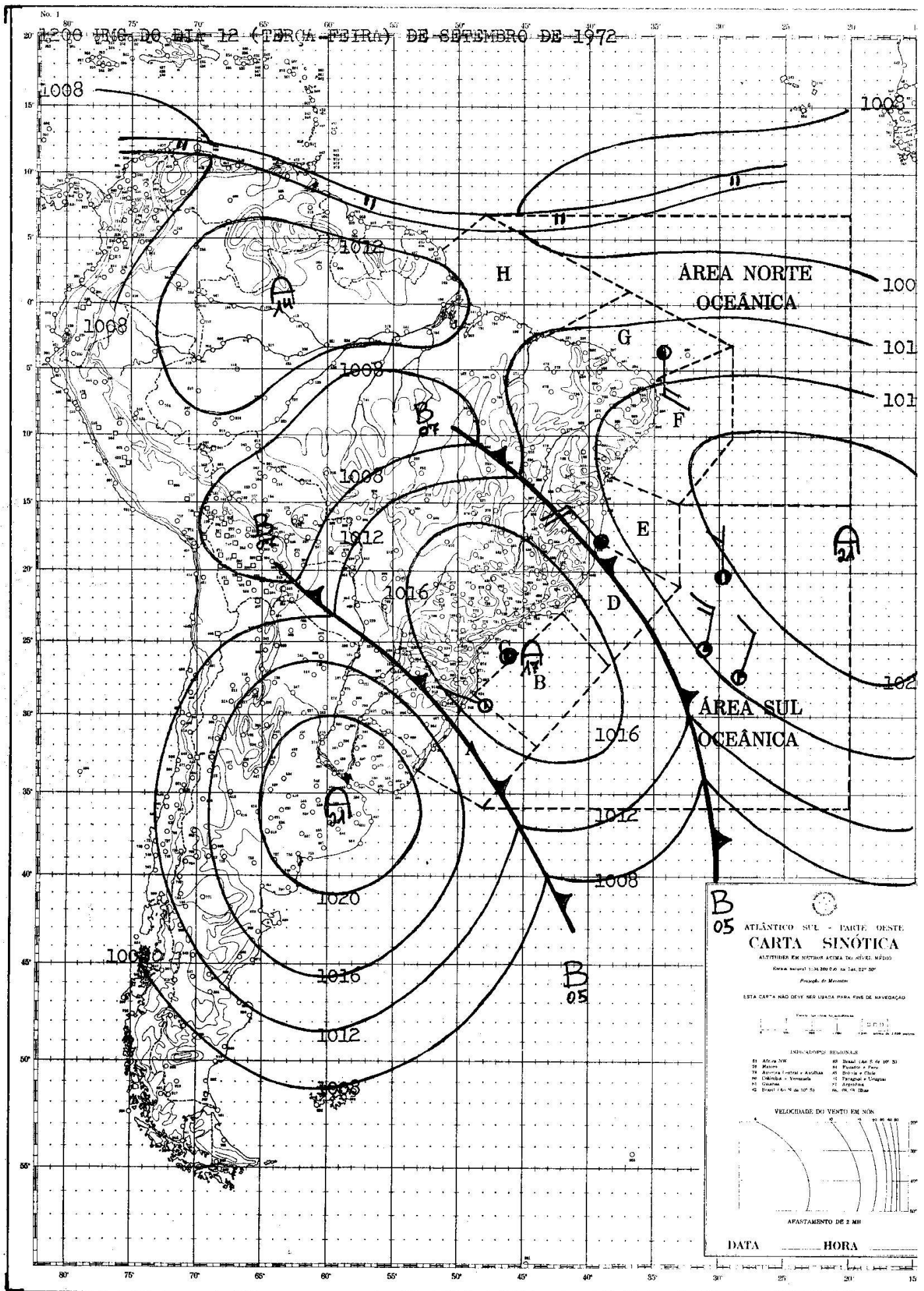

Figura 4.15: Carta Sinótica para 1200Z de 12SET72 


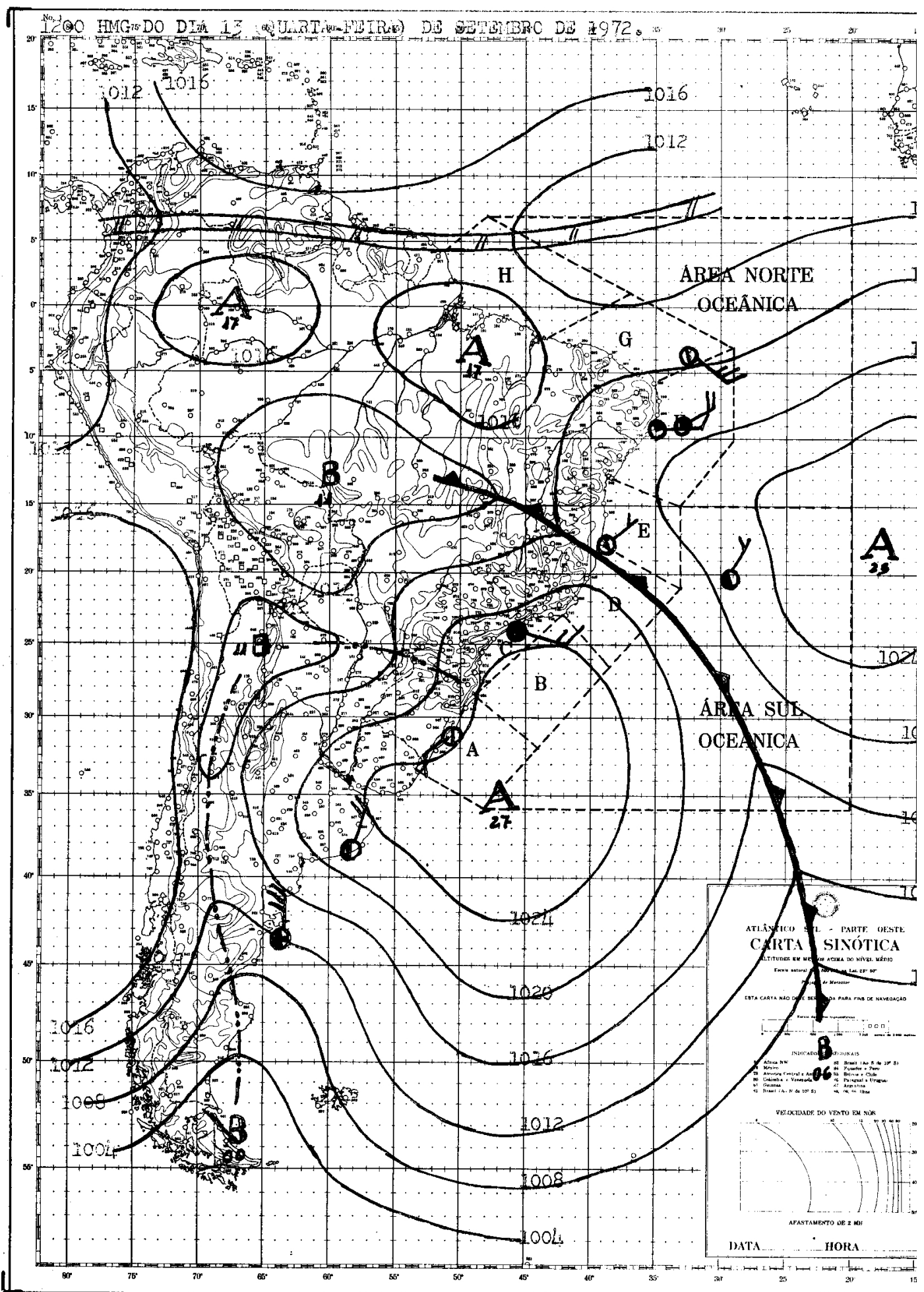

Figura 4.16: Carta Sinótica para 1200Z de 13SET72 


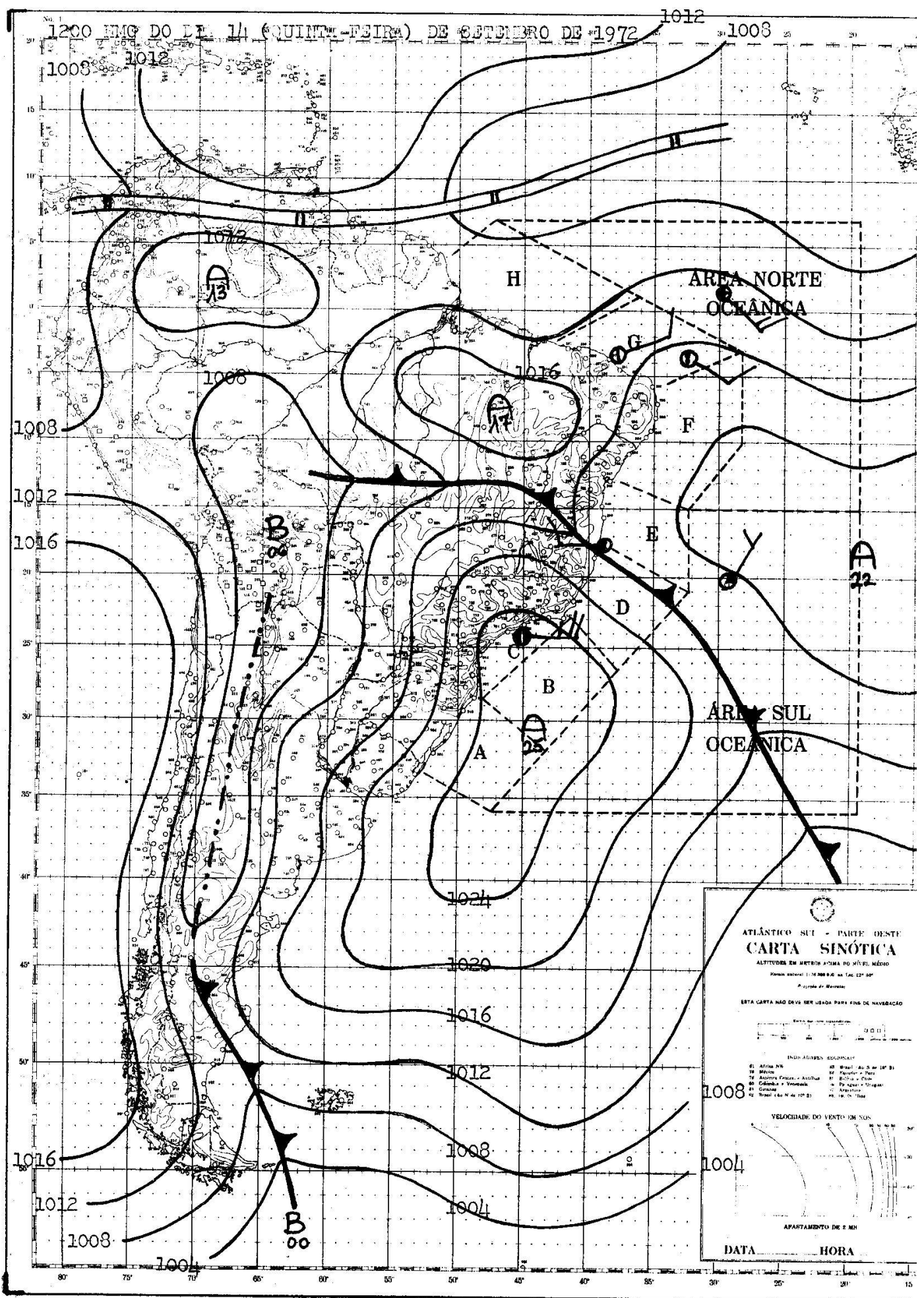

Figura 4.17: Carta Sinótica para 1200Z de 14SET72 


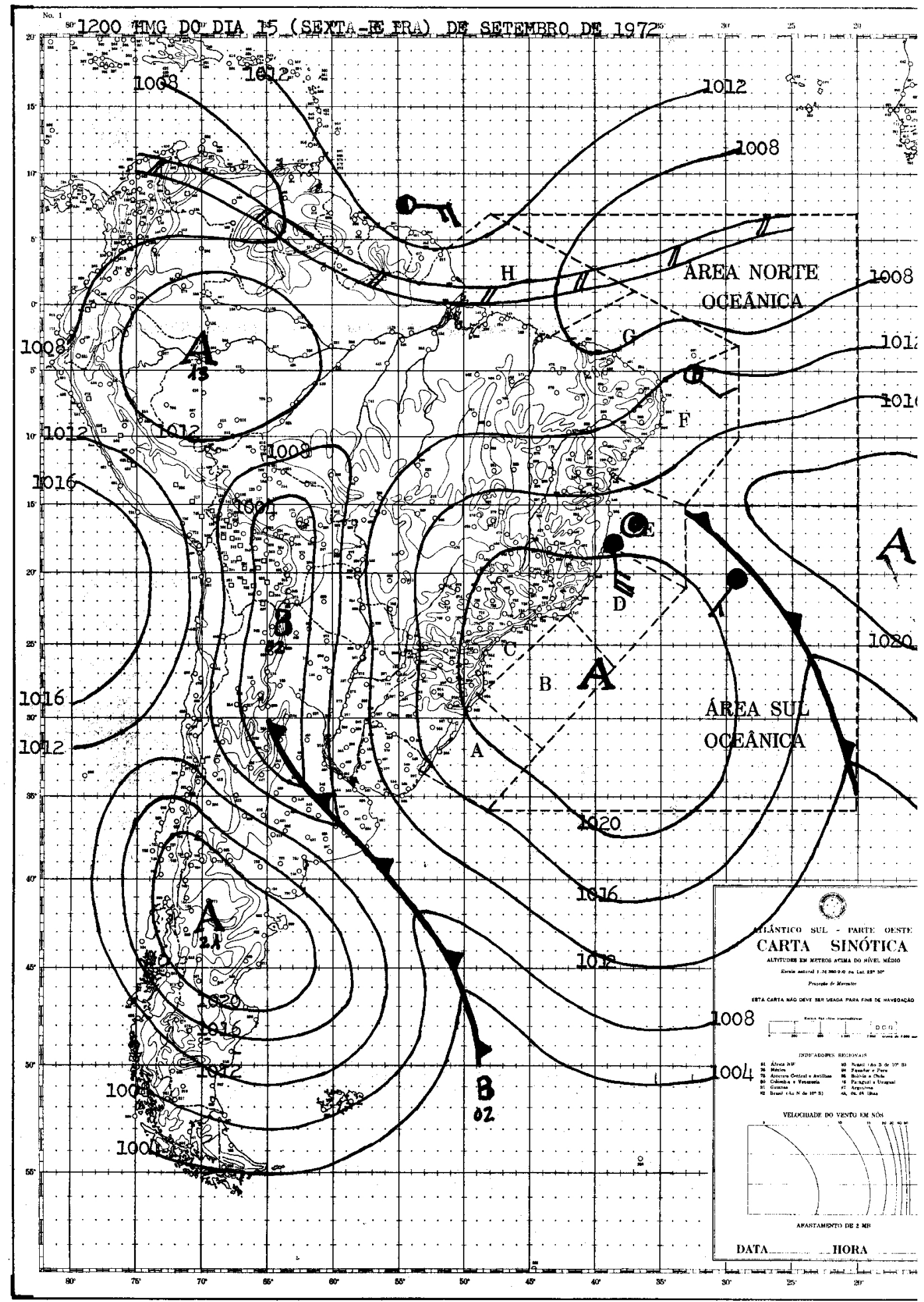

Figura 4.18: Carta Sinótica para 1200Z de 15SET72 


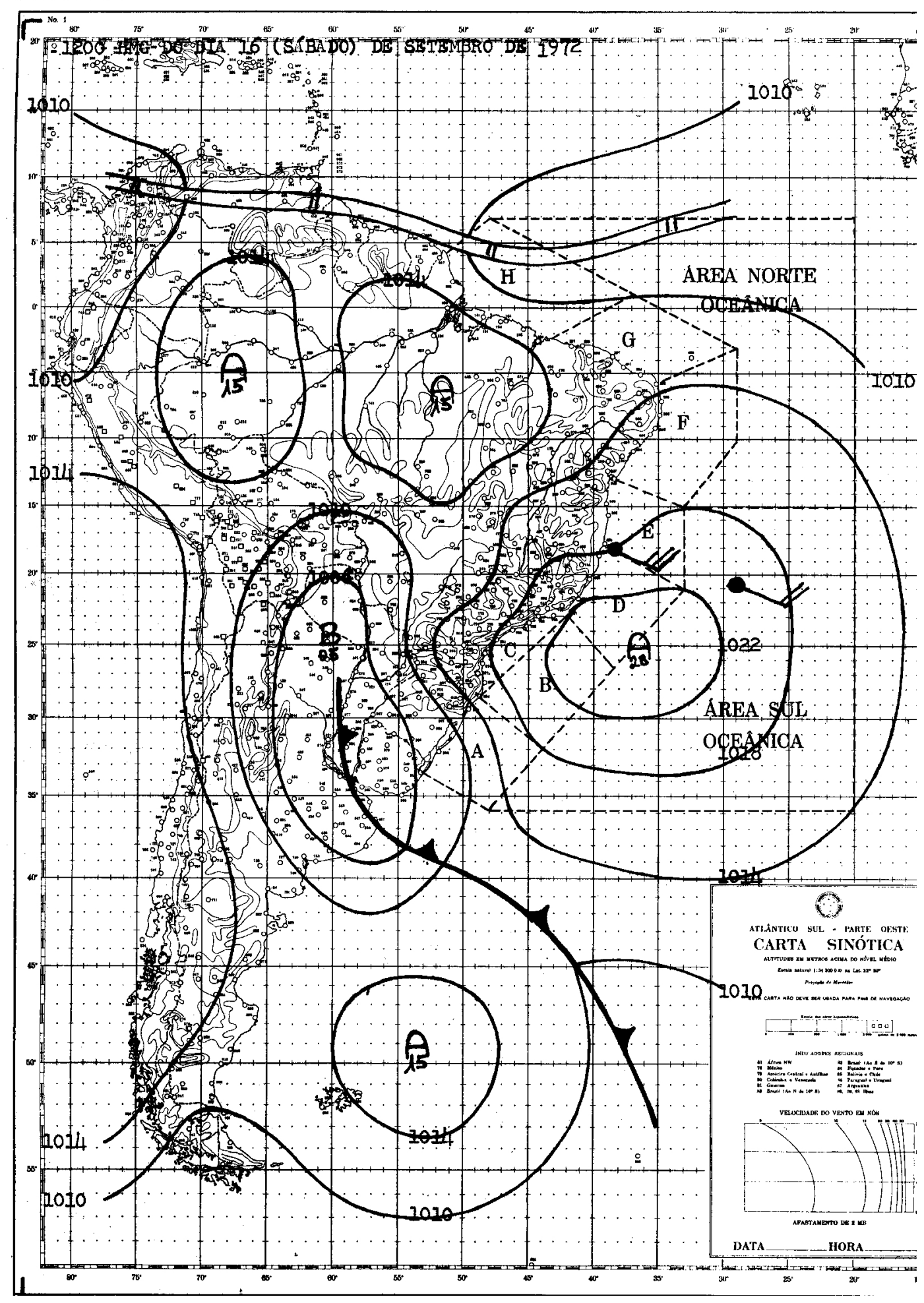

Figura 4.19: Carta Sinótica para 1200Z de 16SET72 


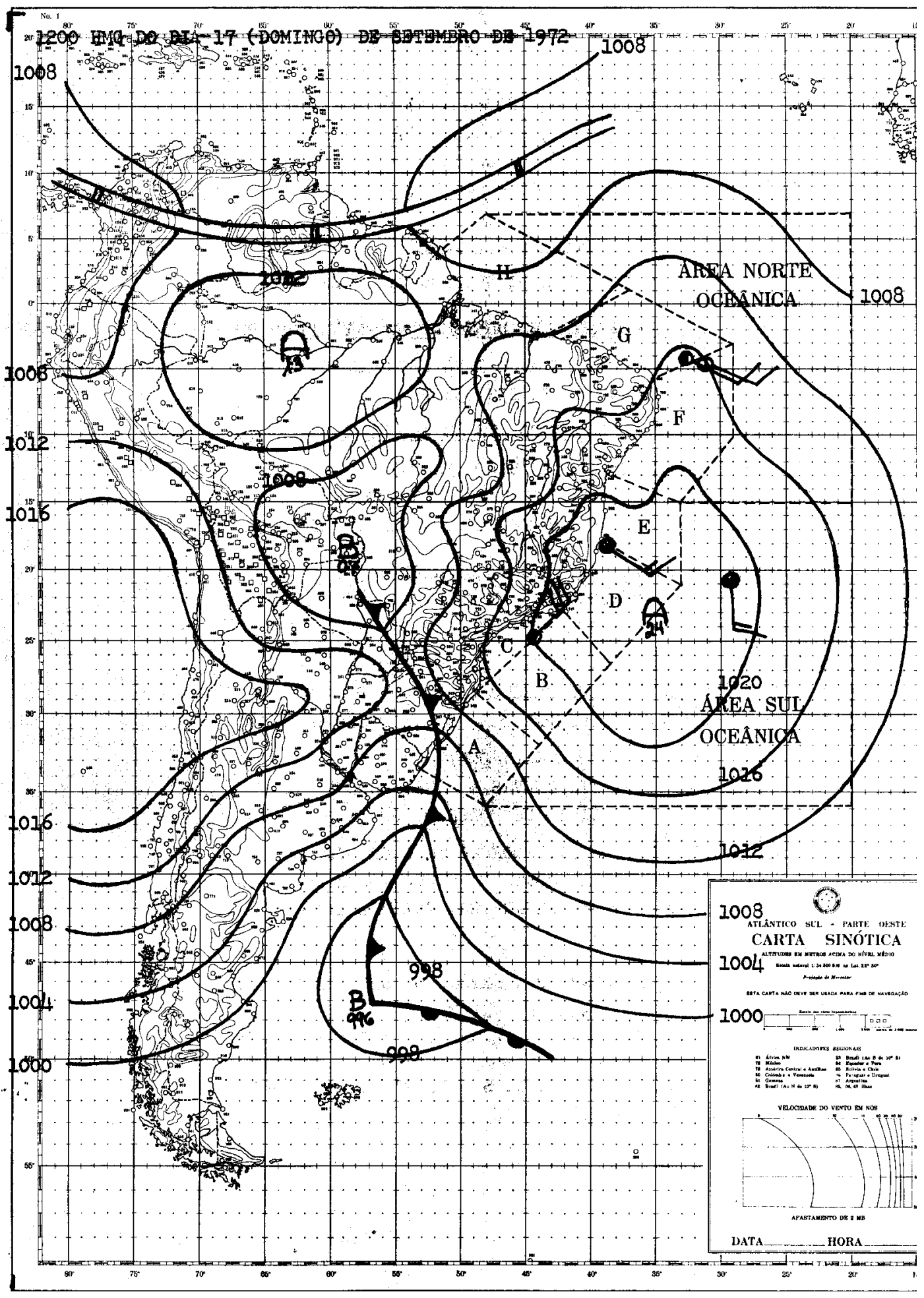

Figura 4.20: Carta Sinótica para 1200Z de 17SET72 


\subsection{O Modelo Numérico}

Para investigar o efeito de transientes de alta freqüência do regime de ventos sobre a circulação costeira foi realizada uma simulação com o modelo numérico de coordenadas híbridas desenvolvido pela Universidade de Miami (Hybrid Coordinate Ocean Model - HYCOM). Este modelo adota alternativamente coordenadas isopicnais (superfícies de igual densidade), coordenadas $\sigma$ (frações da profundidade local) e as tradicionais coordenadas $z$, dependendo das circunstâncias. Nas regiões profundas, abaixo da camada de mistura, utiliza-se coordenadas isopicnais. Próximo à superfície, a estrutura vertical da camada de mistura é resolvida com o emprego de coordenadas $z$. Em regiões costeiras com profundidades inferiores a um valor pré-determinado (200 metros, no presente caso), são adotadas as coordenadas sigma, as quais refletem de forma adequada o perfil batimétrico da região. A versão do modelo utilizada neste trabalho consiste de uma grade de alta resolução horizontal (1/12 de grau), aninhada em uma implementação do modelo sendo executada para toda a bacia do Atlântico no Laboratório de Modelagem dos Oceanos (LABMON).

\subsubsection{Experimento Forçado com Output do RAMS}

Um primeiro experimento foi realizado forçando-se o modelo com uma combinação de dados de vento climatológicos do COADS (Comprehensive Oceanic and Atmospheric Data Set), com dados gerados pelo modelo atmosférico RAMS (Regional Atmosferic Model System), executado no Depto. de Ciências Atmosféricas do IAG/USP. O modelo foi forçado por quatro dias, a partir de um determinado instante, correspondendo ao dia 1 de janeiro de um ano climatológico. Os dados de vento fornecidos pelo IAG são representados pela Figura 4.21, a qual mostra a variação da intensidade e direção do vento e as anomalias das componentes do tensor de cisalhamento, representadas pela figura 4.22 computados pela fórmula $\vec{\tau}=C_{D} \rho_{a r} \vec{v}|\vec{v}|$. Nessa figura fica evidente a variabilidade do vento em escalas variando de horas a dias. Essas variações estão associadas ao regime de brisas na região de estudo. Deve-se notar, entretanto, que em momento algum o vento abandona o terceiro quadrante. Isto é, a orientação do vento está sempre soprando de Nordeste, com diferentes intensidades. 


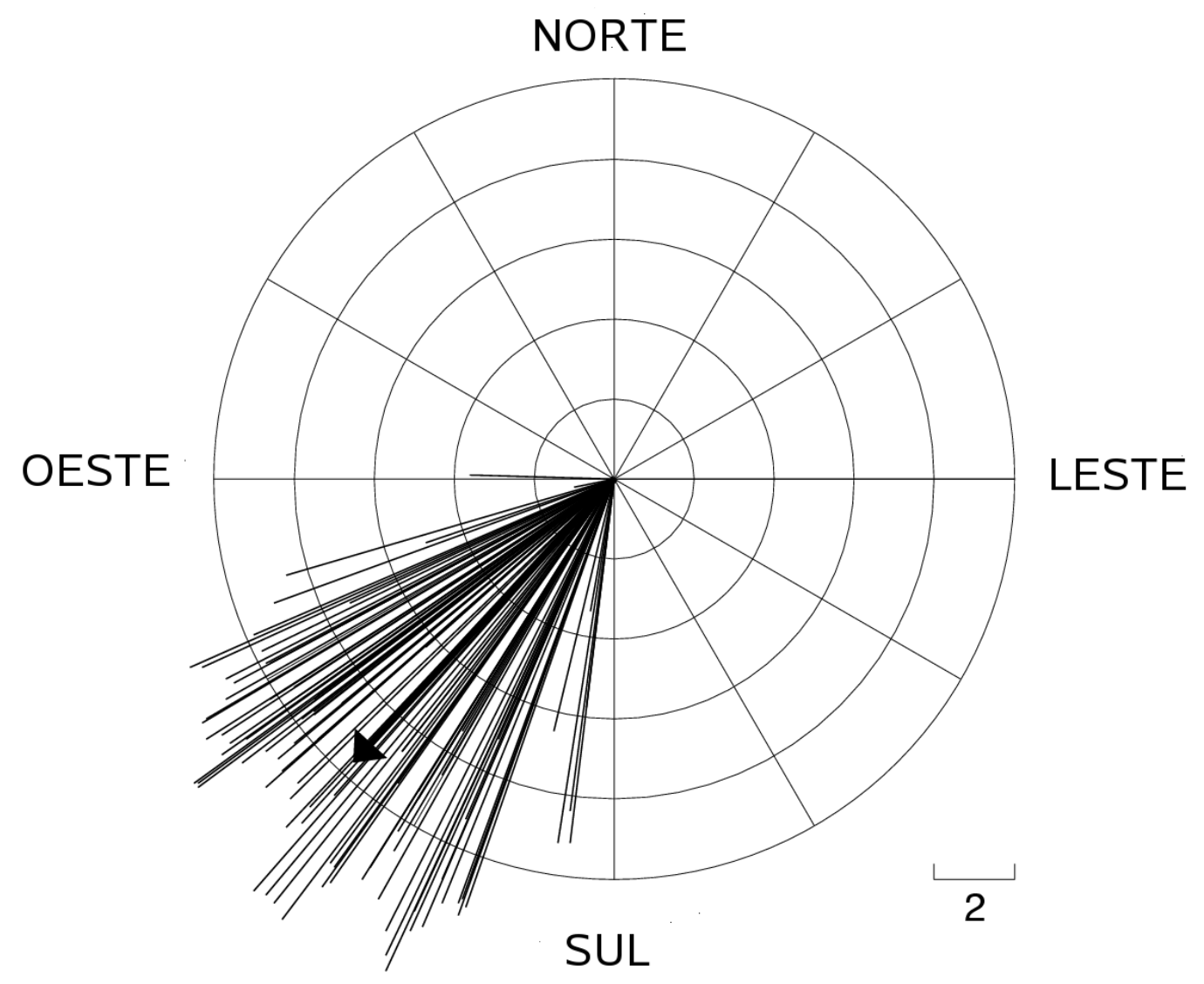

Figura 4.21: Vetores do vento do modelo atmosférico 


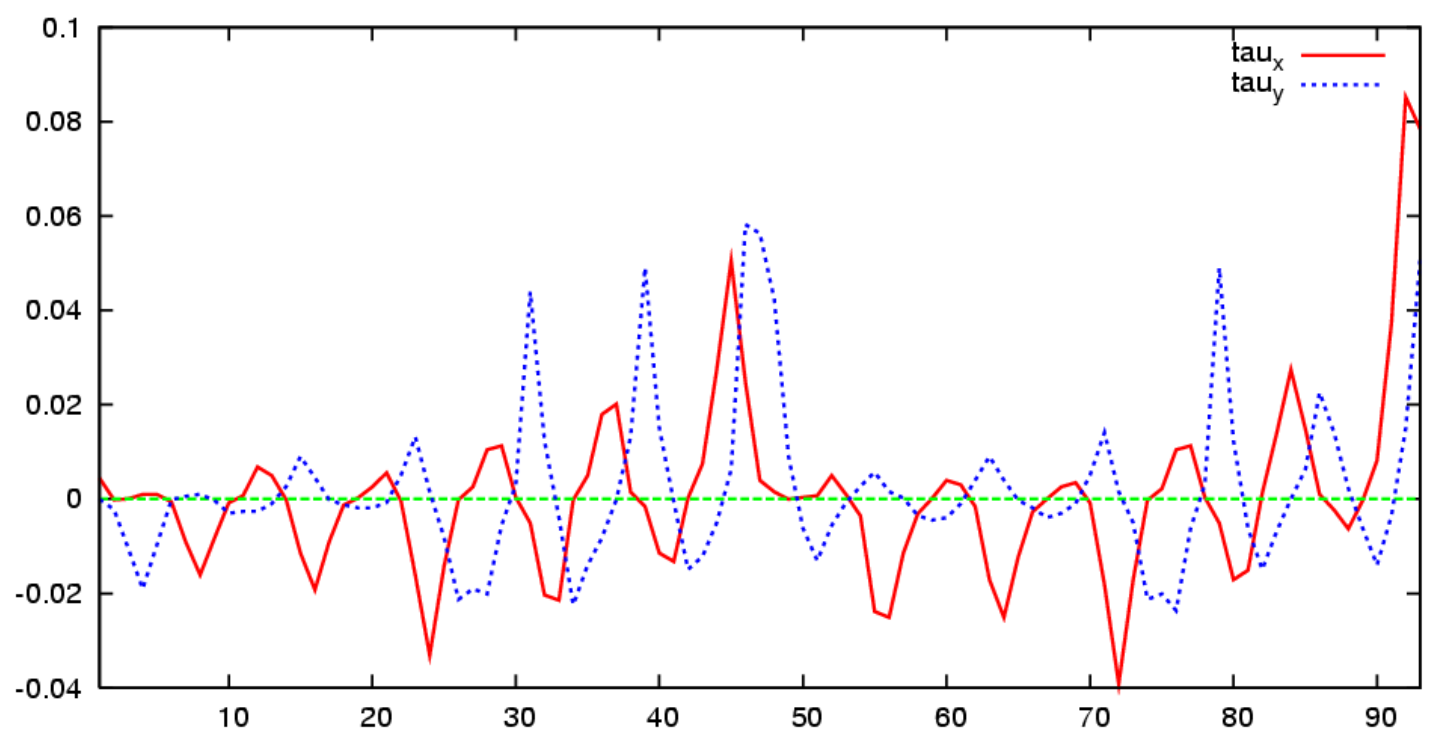

Figura 4.22: Anomalias das componentes do tensor de cisalhamento do vento

A sequência das figuras 4.23 a 4.28 representa a evolução do campo de temperatura na simulação forçada com o vento contendo transientes de alta freqüência. A primeira delas, Figura 4.23, mostra a circulação na profundidade de 10 metros, sobreposta ao campo de temperatura da camada de mistura, em quatro diferentes instantes: $t=0, t=1$ dia, $t=2$ dias e $t=3$ dias. Fica bastante evidente o aumento da área com baixas temperaturas (tonalidades de verde-azul) nas proximidades da costa, indicando uma intensificação do fenômeno da ressurgência costeira. Esse é um resultado esperado, considerando-se o comportamento do vento indicado na Figura 4.21. Ou seja, apesar da intensa variabilidade apresentada pelo vento no período, não se observou nenhuma mudança significativa na direção do vento. Como o vento de NE é favorável ao fenômeno da ressurgência, e também considerando-se que os ventos calculados pelo modelo do IAG fornecem intensidades superiores aos valores climatológicos do COADS, isso implica em um aumento na ressurgência. Na figura 4.25 observamos também o comportamento da isoterma de $16^{\circ} \mathrm{C}$ para os quatro diferentes instantes de tempo. Percebe-se bem a elevação da isoterma quando inserido os dados de vento proveniente do modelo atmosférico. 


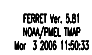

DATA SET: hycom.0027_016_00

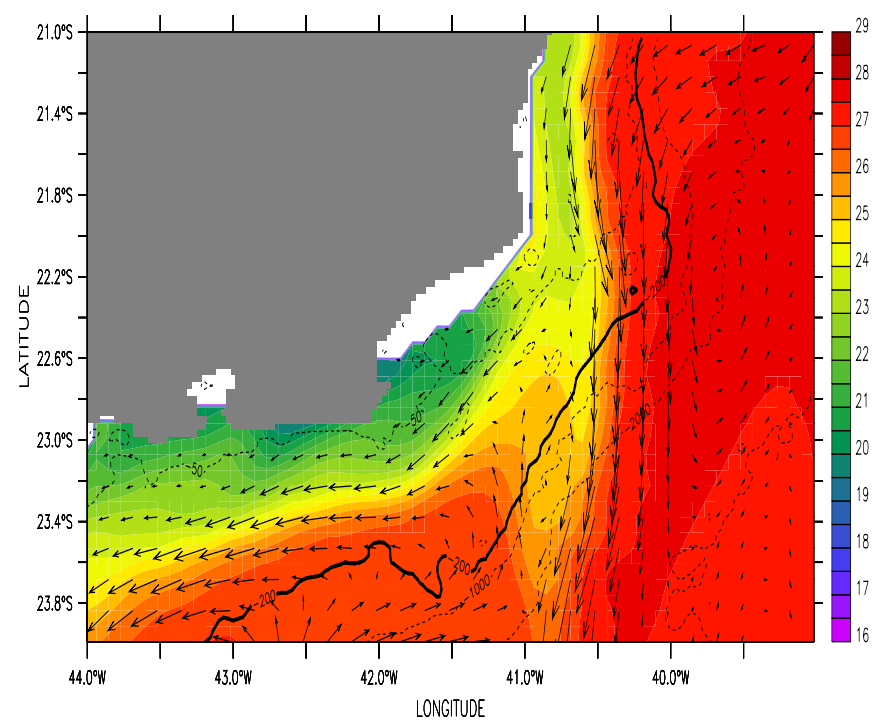

Mixed layer temperature (degree C)

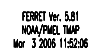

DATA SET: hycom.0027_018_00

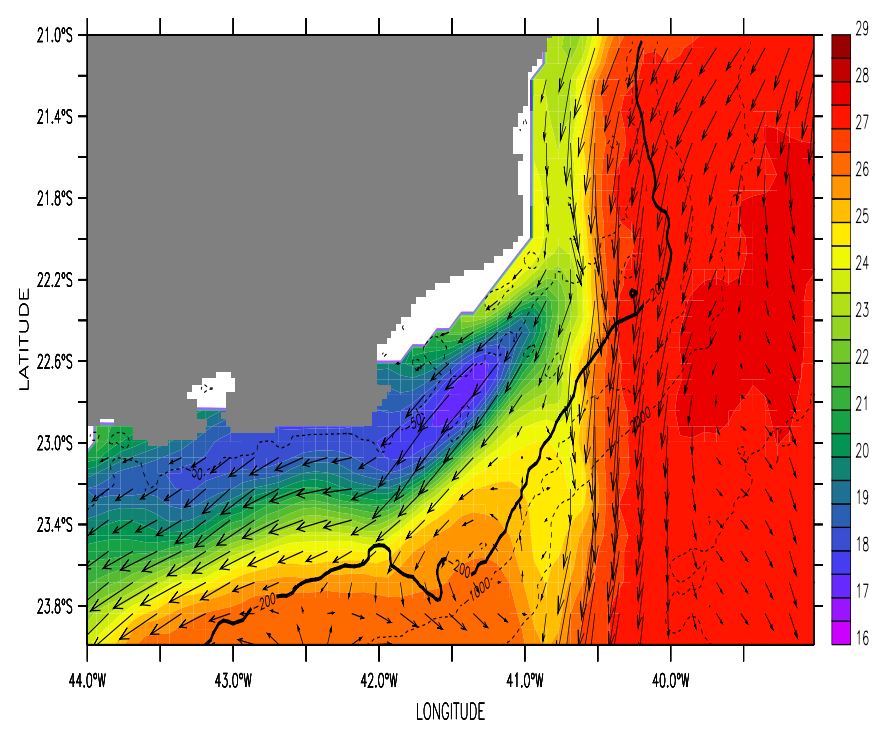

Mixed layer temperature (degree C)

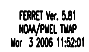

DATA SET: hycom.0027_017_00

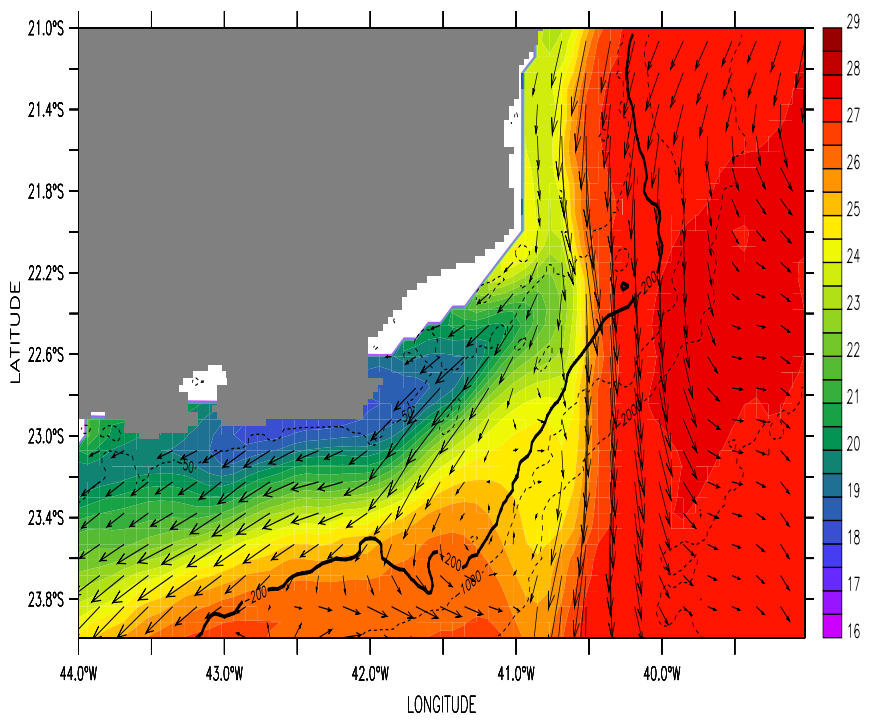

Mixed layer temperature (degree C)

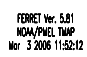

DATA SET: hycom.0027_019_00

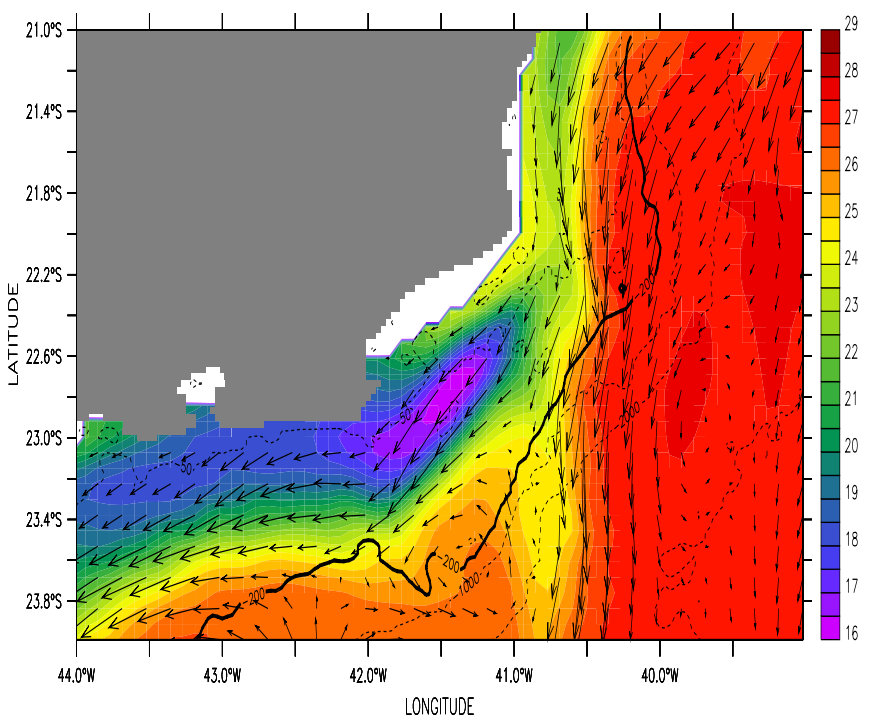

Mixed layer temperature (degree C)

Figura 4.23: Temperatura em quatro diferentes instantes: $t=0, t=1$ dia, $t=2$ dias e $t=3$ dias. 


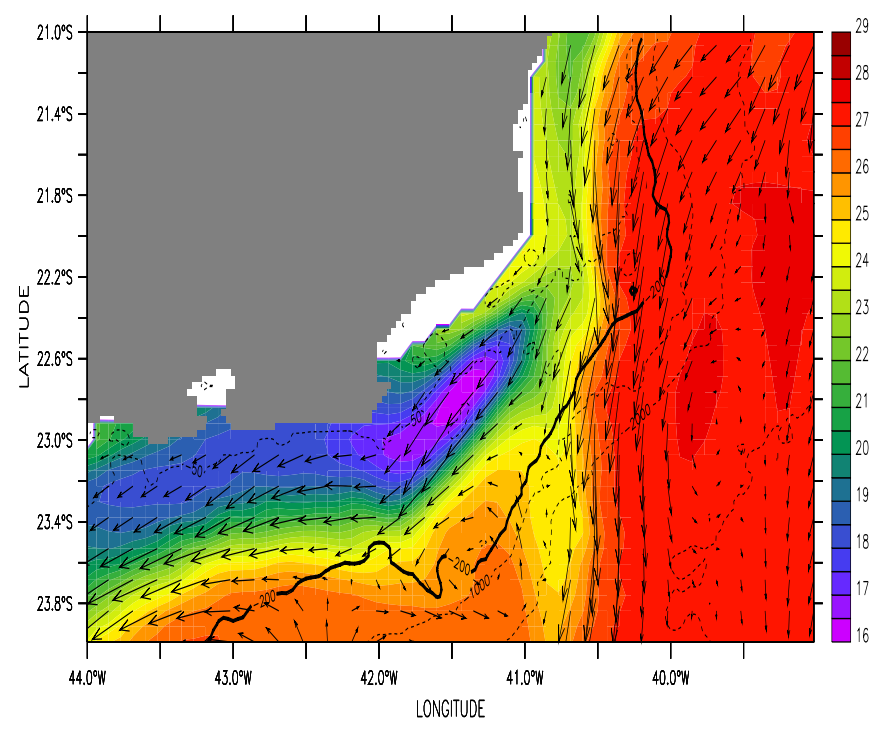

Mixed layer temperature (degree C)

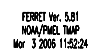

DATA SET: hycom.0027_019_12

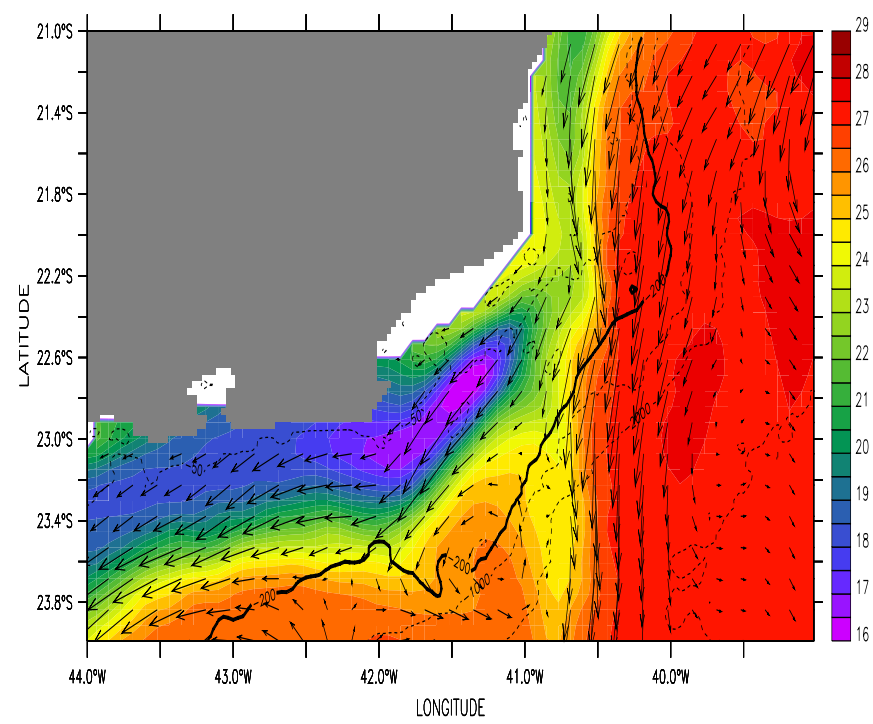

Mixed layer temperature (degree C)

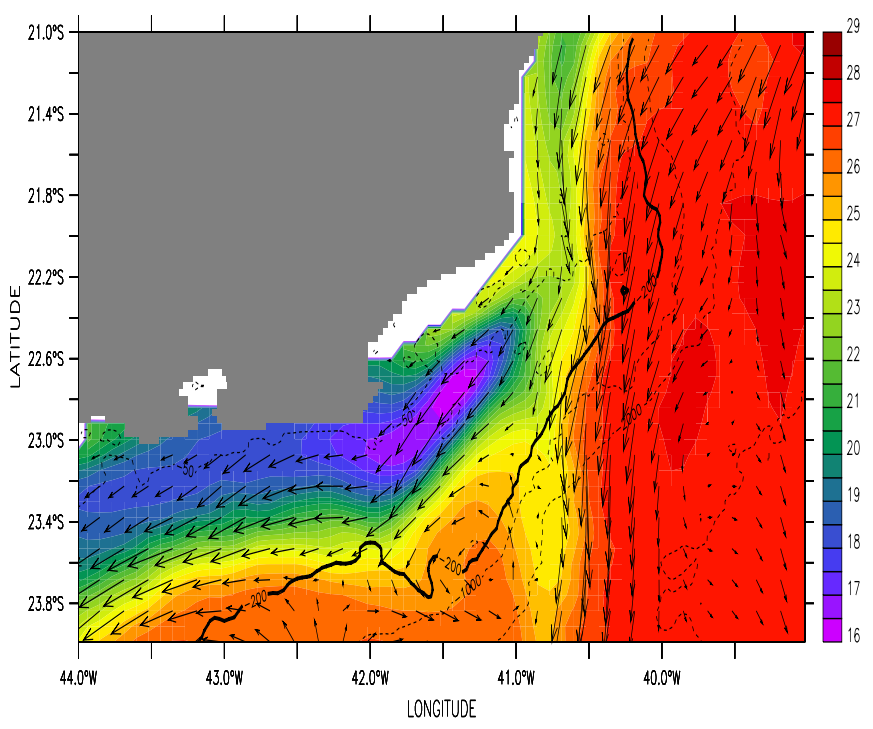

Mixed layer temperature (degree C)

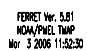

DATA SET: hycom.0027 01918

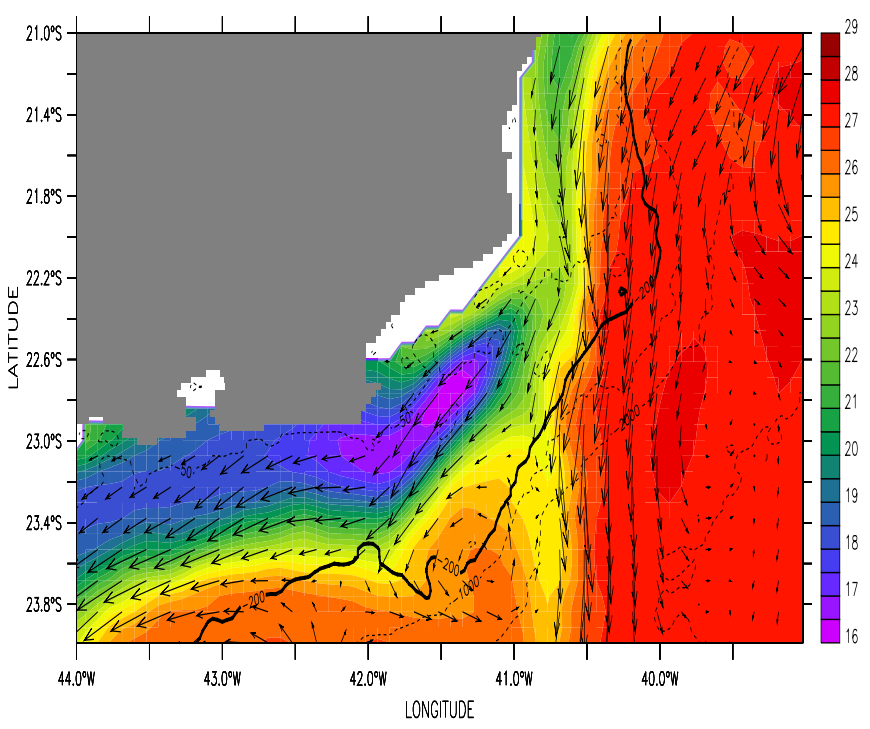

Mixed layer temperature (degree C)

Figura 4.24: Temperatura em quatro diferentes instantes: $t=0$ horas, $t=6$ horas , $t=12$ horas $\mathrm{e} t=18$ horas. 


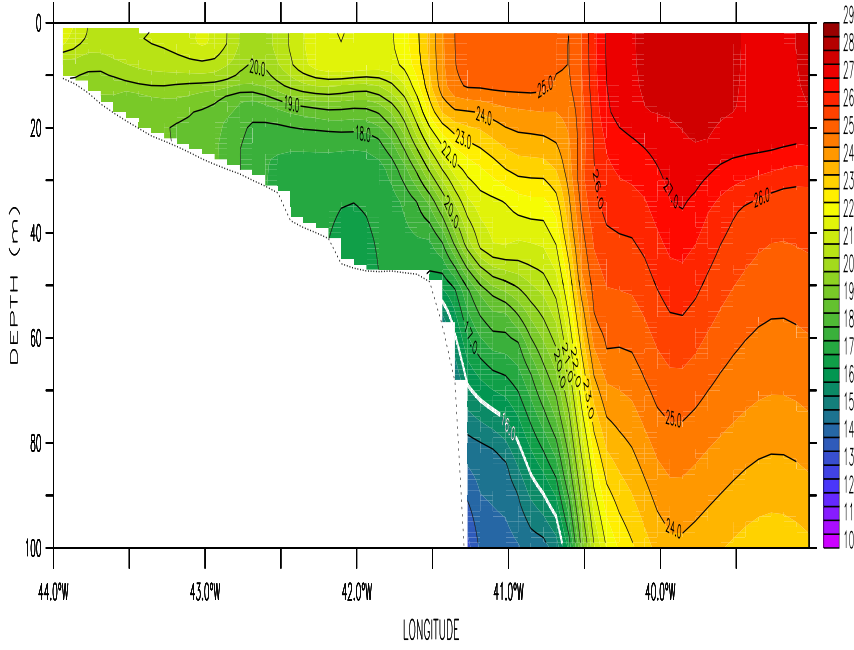

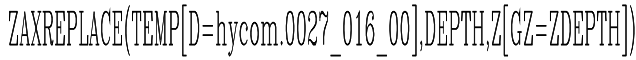

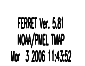

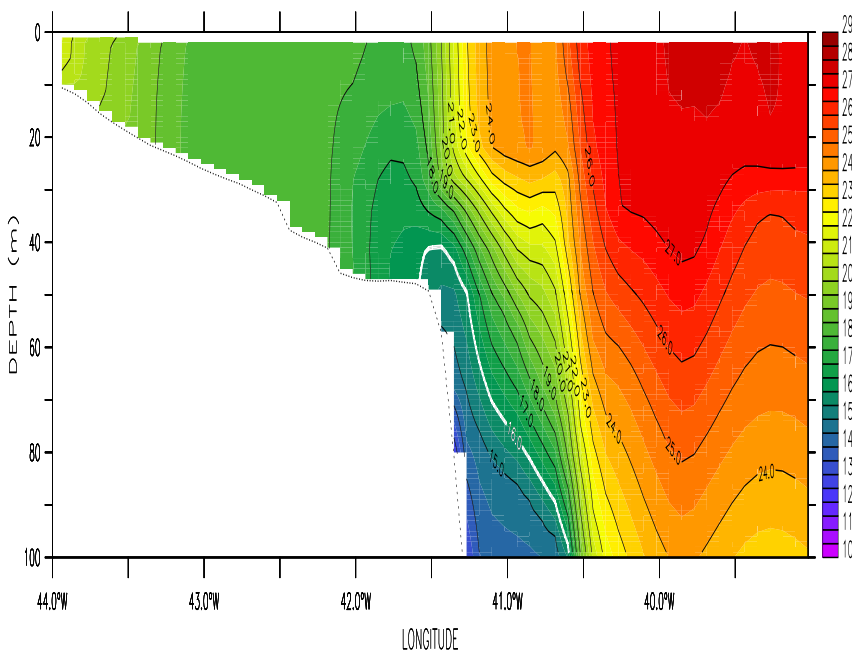

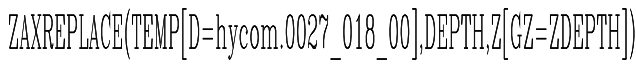

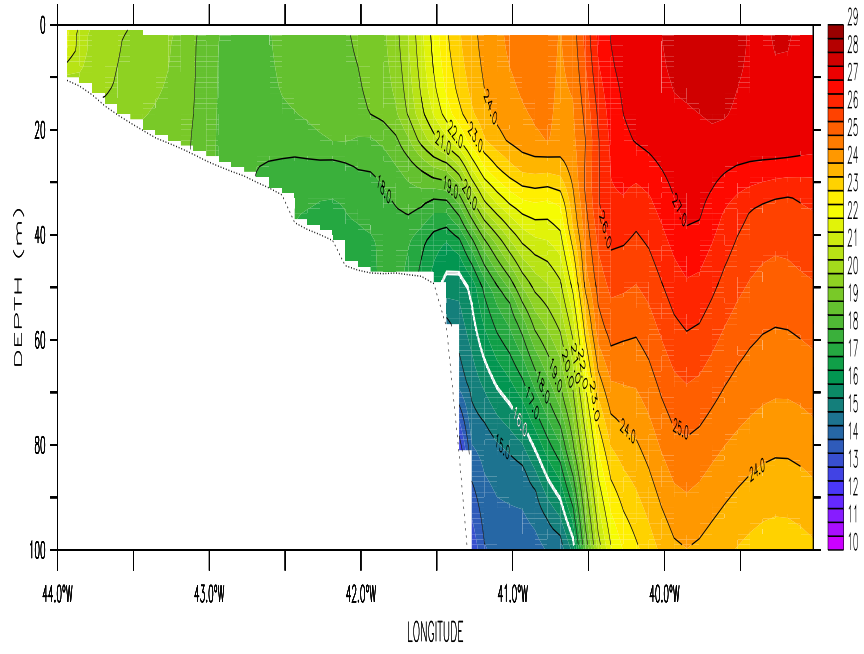

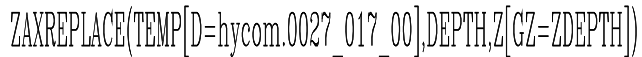

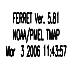

LATIVOE : 235

DATA SET: hycom.0027 01900

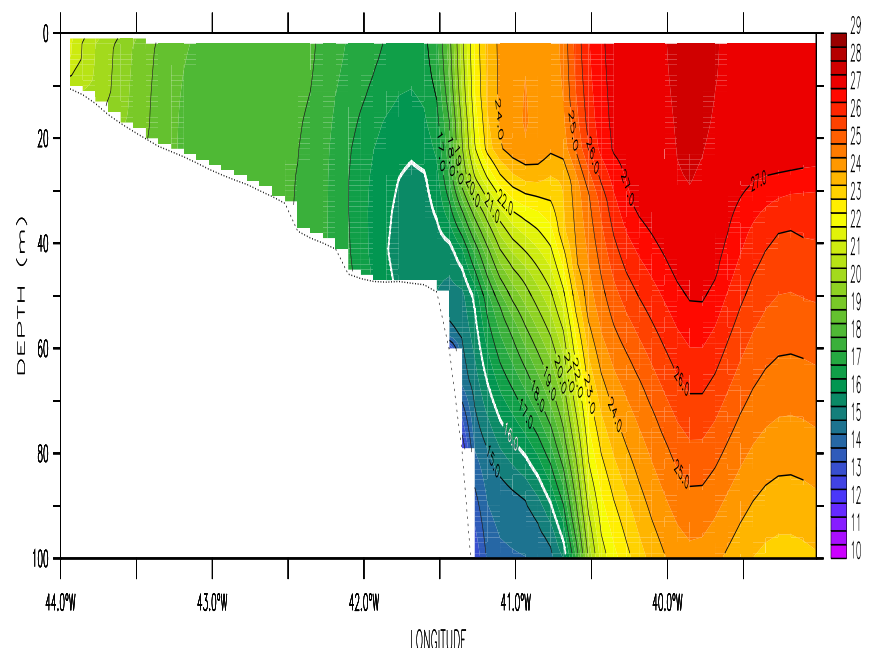

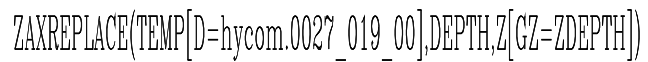

Figura 4.25: Seção zonal na latitude $23^{\circ} \mathrm{S}$ em quatro diferentes instantes: $t=0$, $t=1$ dia, $t=2$ dias e $t=3$ dias. 


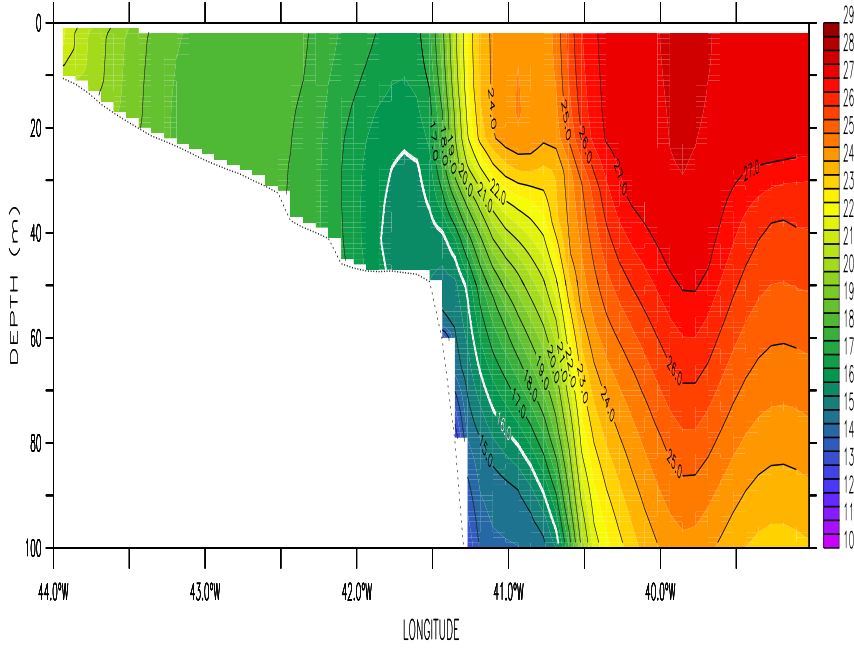

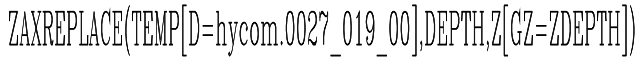

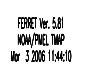

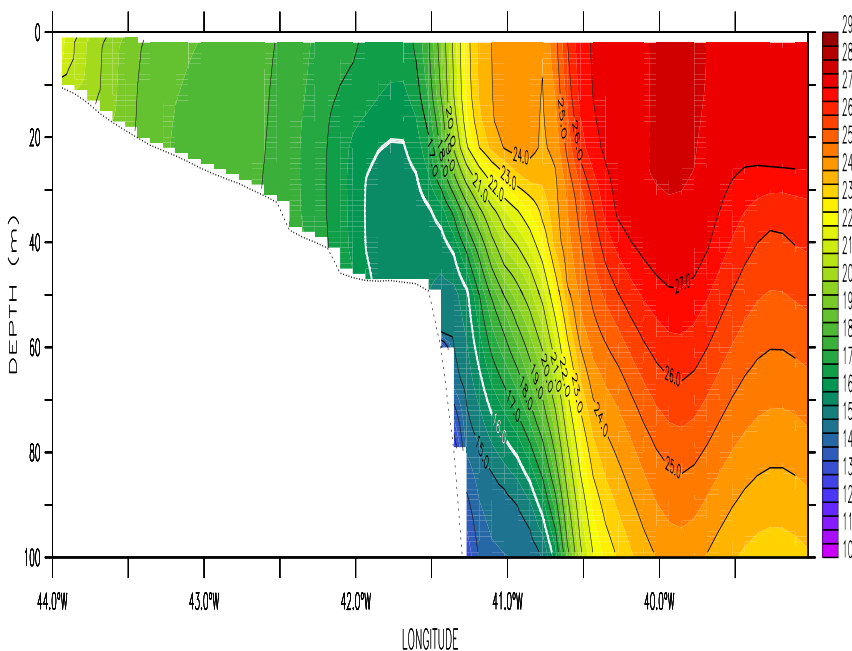

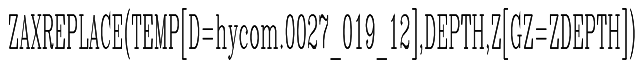

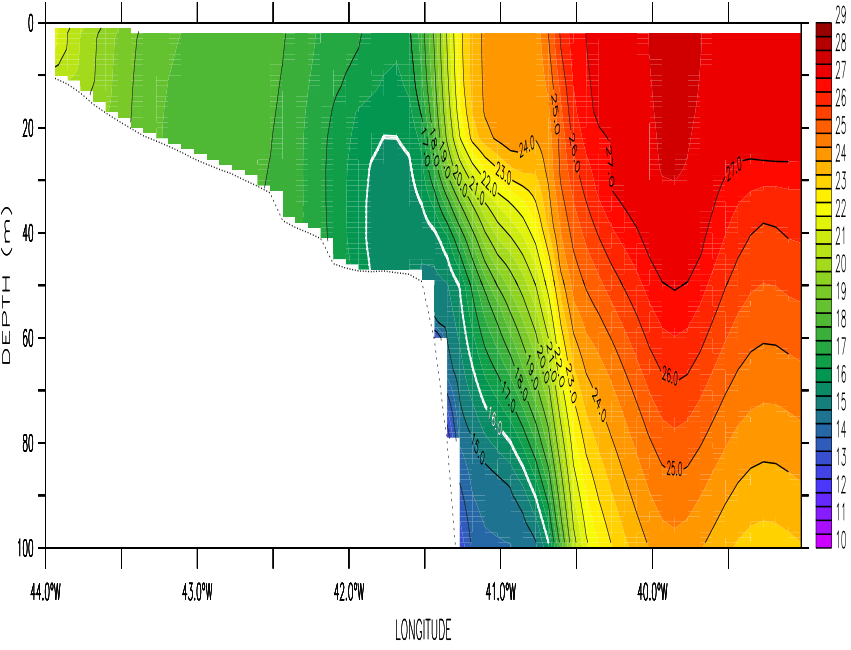

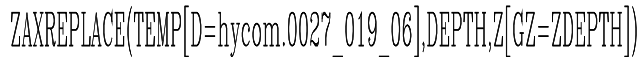

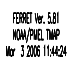

LATIVOE : 235

DATA SET: hycom.0027 01918

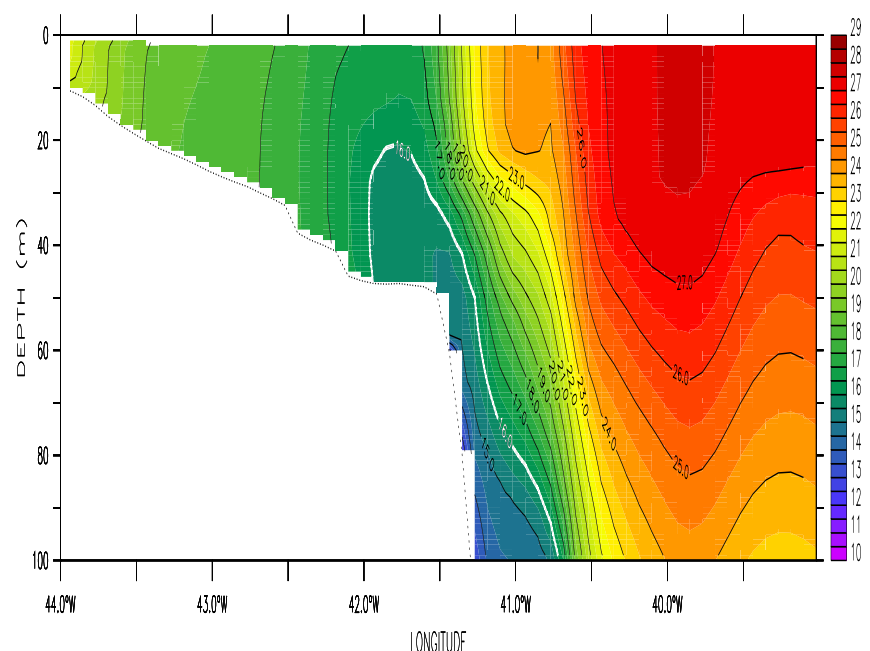

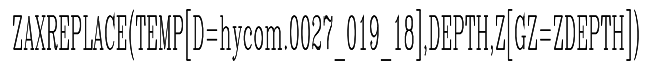

Figura 4.26: Seção zonal na latitude $23^{\circ} \mathrm{S}$ em quatro diferentes instantes: $t=0$ horas, $t=6$ horas, $t=12$ horas $\mathrm{e} t=18$ horas. 


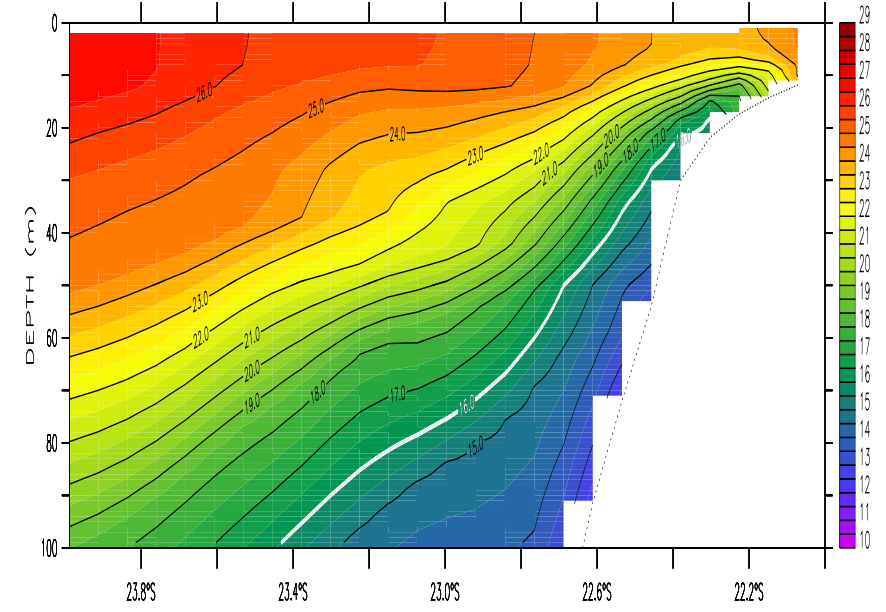

COMnOUR: TELP DP

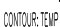

LATTUEE

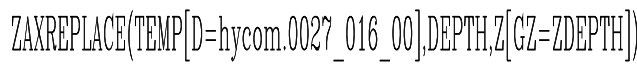

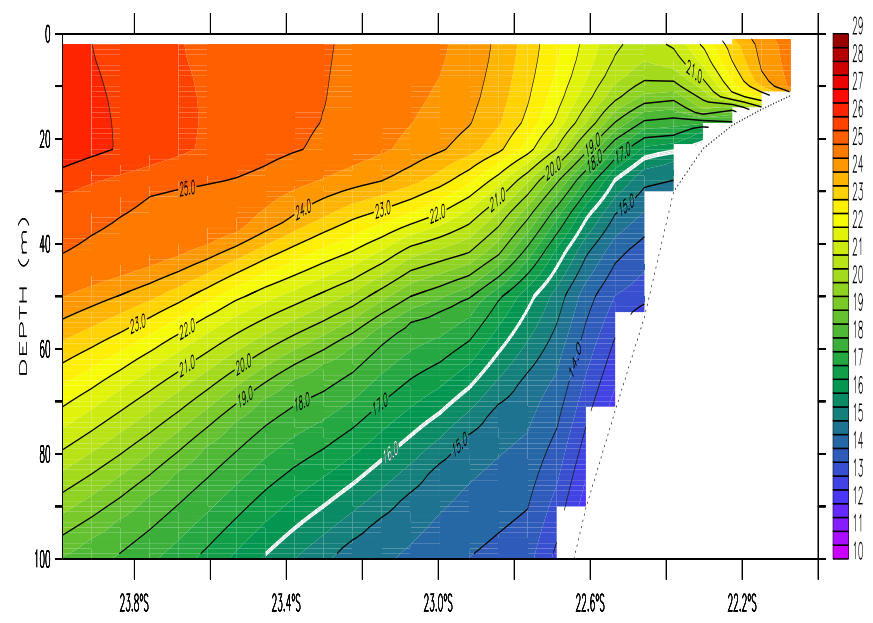

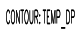

comrin. Etilf.

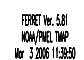

LONGTIUE : 41M(-41)

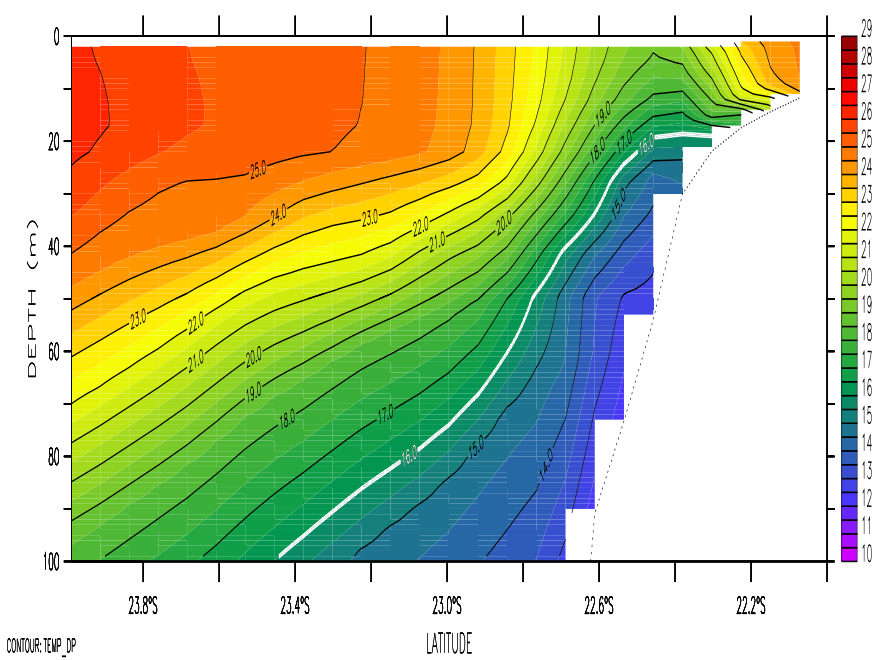

Campre:III

DATA SET: hycom.0027 01800

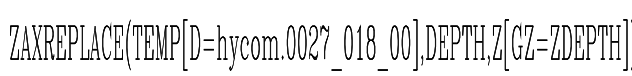

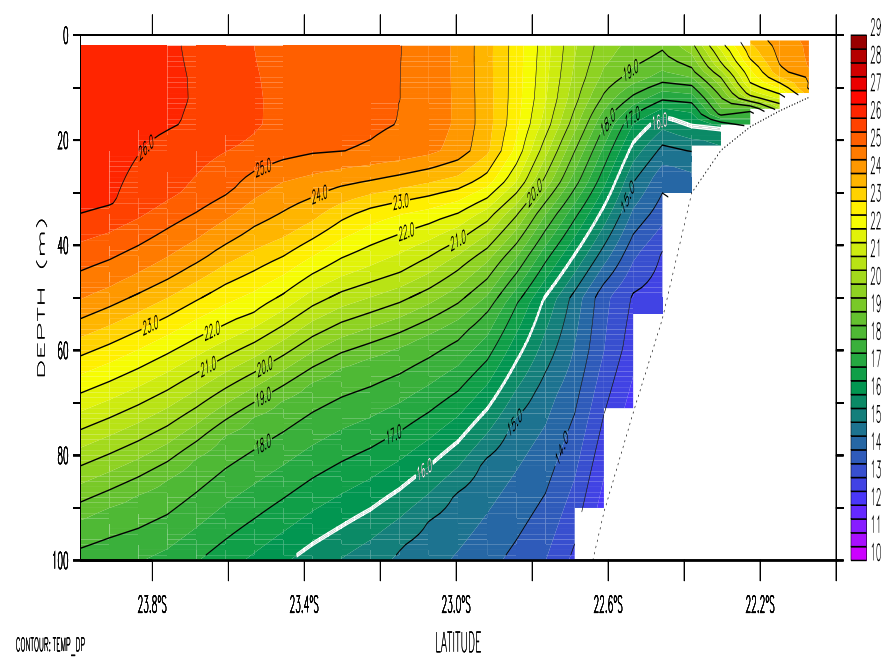

coll

Figura 4.27: Seção meridional na longitude $41^{\circ} \mathrm{W}$ em quatro diferentes instantes: $t=0, t=1$ dia, $t=2$ dias e $t=3$ dias. 


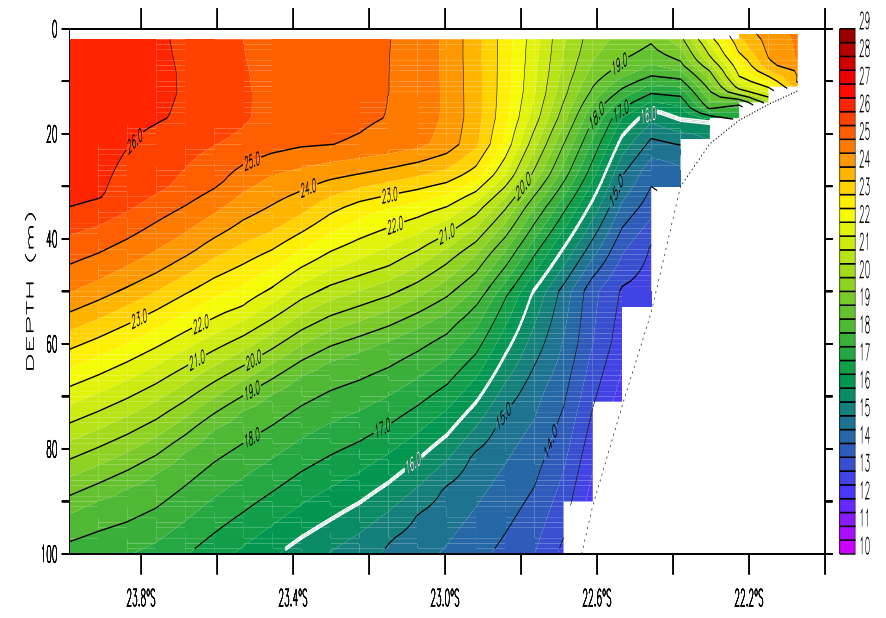

COMTOUR: IELPR DP coll

ZAXREPLACE(TEMP[D=hycom.0027 019 00],DPPTH,Z[CZ=7DRPTH])

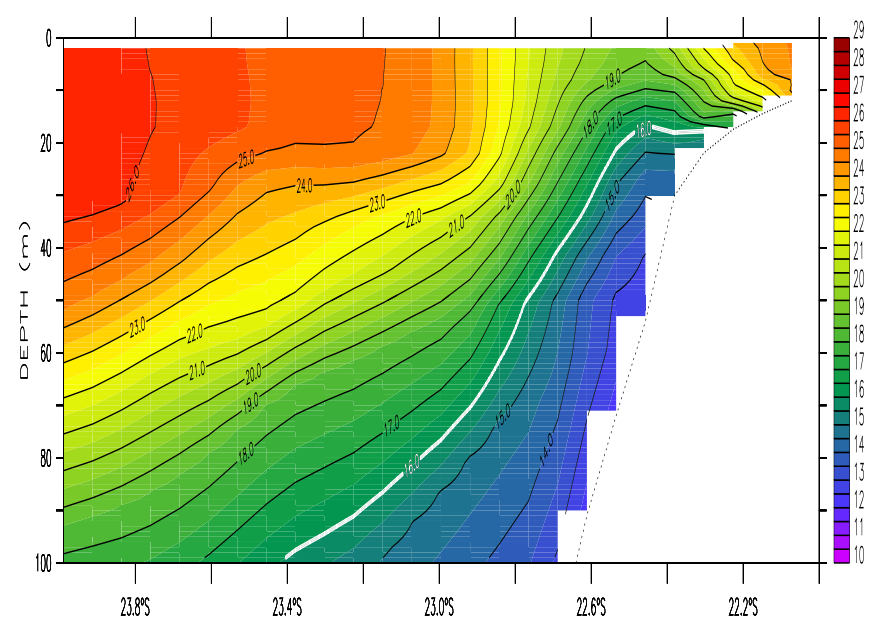

comror: rip of

callo

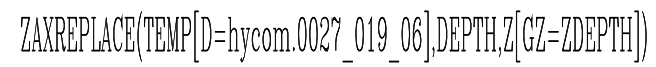

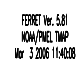

LONGTIUE : 41M(-41)

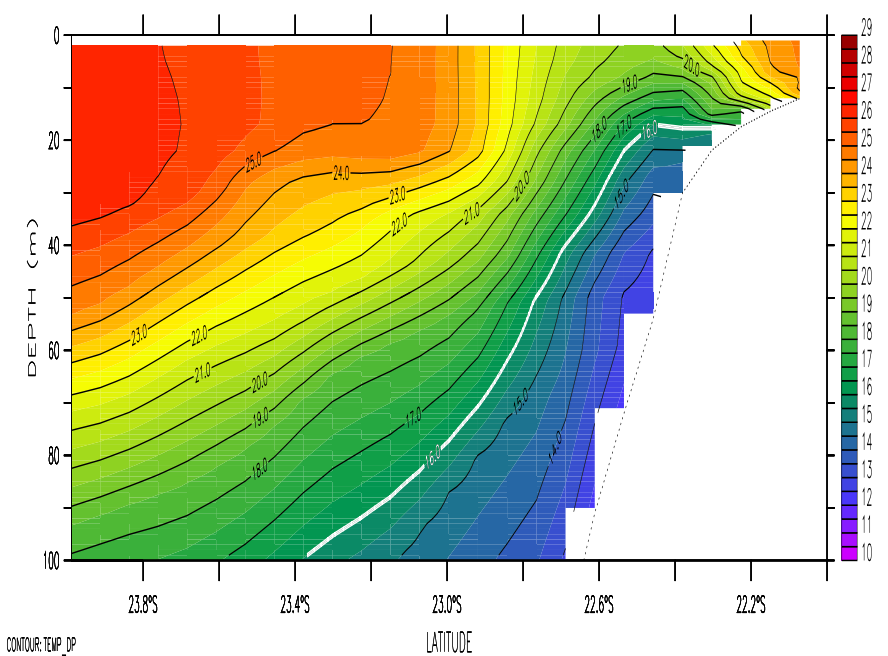

conrove:II

DATA SET: hycom.0027 01912

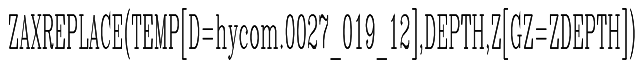

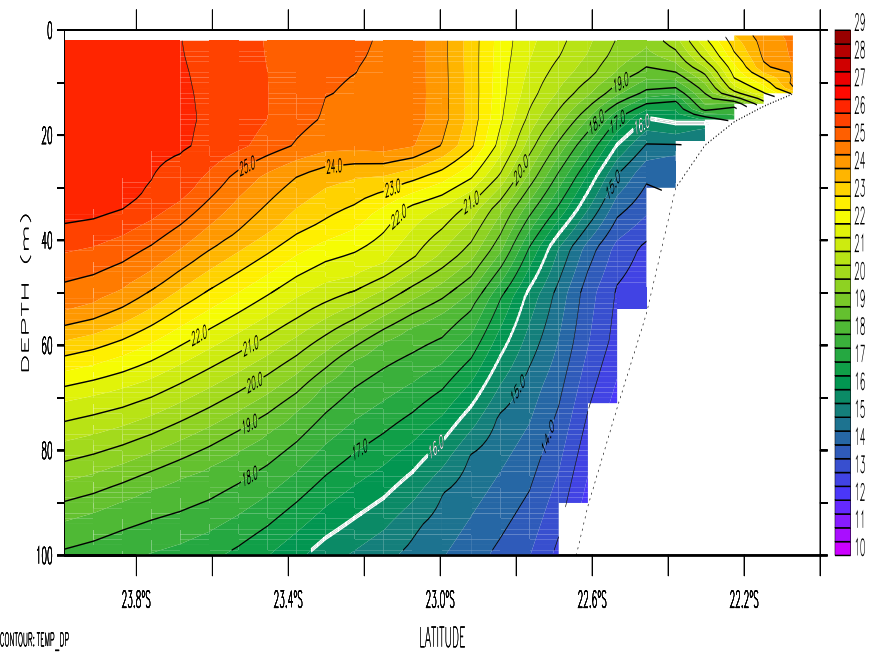

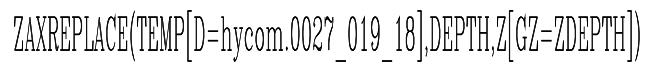

Figura 4.28: Seção meridional na longitude $41^{\circ} \mathrm{W}$ em quatro diferentes instantes: $t=0$ horas, $t=6$ horas, $t=12$ horas $\boldsymbol{e} t=18$ horas. 


\subsubsection{Experimento forçado com vento sintético}

O objetivo central deste trabalho é o estudo do efeito de perturbações de alta freqüência do campo de vento na circulação costeira. Origialmente a idéia era, em adição à análise dos dados, realizar simulações datadas, forçadas com saídas de modelo atmosférico, conforme descrito anteriormente. Entretanto, face aos resultados pouco ilustrativos obtidos nessas simulações, decidimos por explorar um pouco mais o efeito de variações do campo de vento do sistema de ressurgência, forçando o modelo com uma distribuição de vento completamente arbitrária. Assim, da mesma forma como foi feito anteriormente, o modelo foi forçado por um período de oito dias com um arquivo de ventos teórico contendo transientes de alta freqüência.

A série sintética de ventos foi produzida de forma livre, a partir de composição de funções senoidais com base nos ventos predominantes da região. Entretanto, é importante ressaltar que esses experimentos não tem nenhuma pretensão de produzir resultados realísticos, mas de simplesmente observar como o sistema de ressurgência responde a um vento variável. A figura 4.29 mostra a anomalia da tensão de cisalhamento do vento para um período de 20 dias com início correspondendo às 03 horas Z de 24 Janeiro de um ano climatológico.

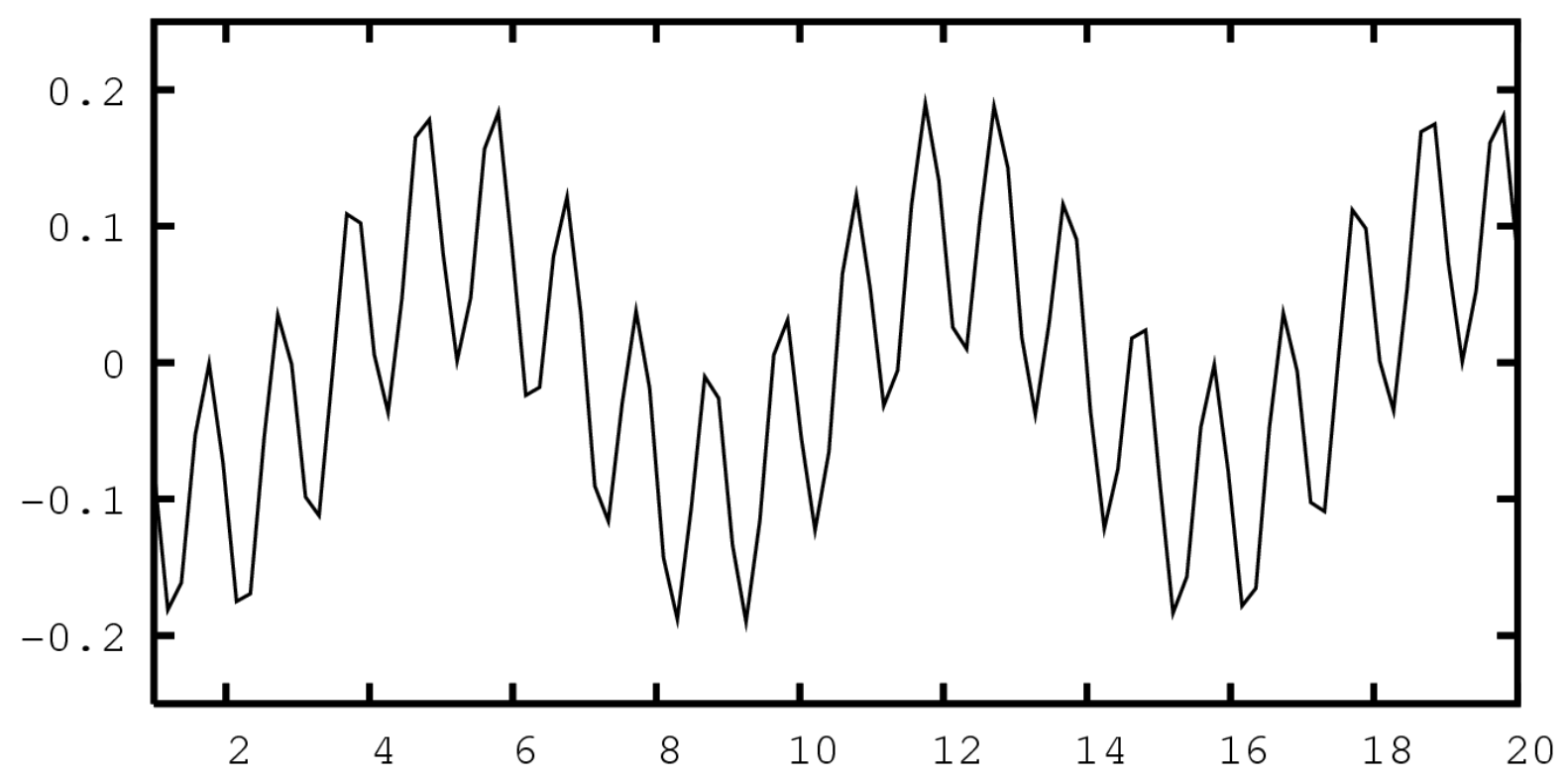

Figura 4.29: Anomalia da tensão de cisalhamento do vento para um período de 20 dias de um arquivo de vento teórico contendo transientes de alta freqüência

Podemos observar no gráfico anomalias positivas e negativas na forçante de ventos acarretando alterações significativas na ressurgência como podemos cons- 
tatar através das seções na latitude $23^{\circ} \mathrm{S}$ nas figuras 4.30 e 4.31. Na figura 4.30, que corresponde as $03 \mathrm{Z}$ de $24 \mathrm{JAN}$ temos uma anomalia negativa da tensão de cisalhamento,o que indica ventos de norte e nordeste favoráveis à ocorrência de ressurgência. Isso fica evidenciado na figura pela coloração azul clara sobre plataforma continental, indicando águas com temperaturas mais baixas em torno de $12^{\circ} \mathrm{C}$. Por outro lado, na figura 4.31 temos a mesma seção na latitude $23^{\circ} \mathrm{S}$, porém correspondendo ao dia 28 de Janeiro, apresentando anomalia positiva da tensão de cisalhamento do vento o que indica ventos do quadrante sul, desfavoráveis à ocorrência de ressurgência. Nas figuras a seguir, que são resultados do modelo HYCOM, um modelo que utiliza coordenadas híbridas, temos as linhas solídas representando coordenadas isopcnais no interior do oceano, coordenadas de nível "z", na camada de mistura e coordenadas sigma na plataforma interna que são regiões mais rasas. A linha mais grossa representa o fundo da camada de Ekman. 


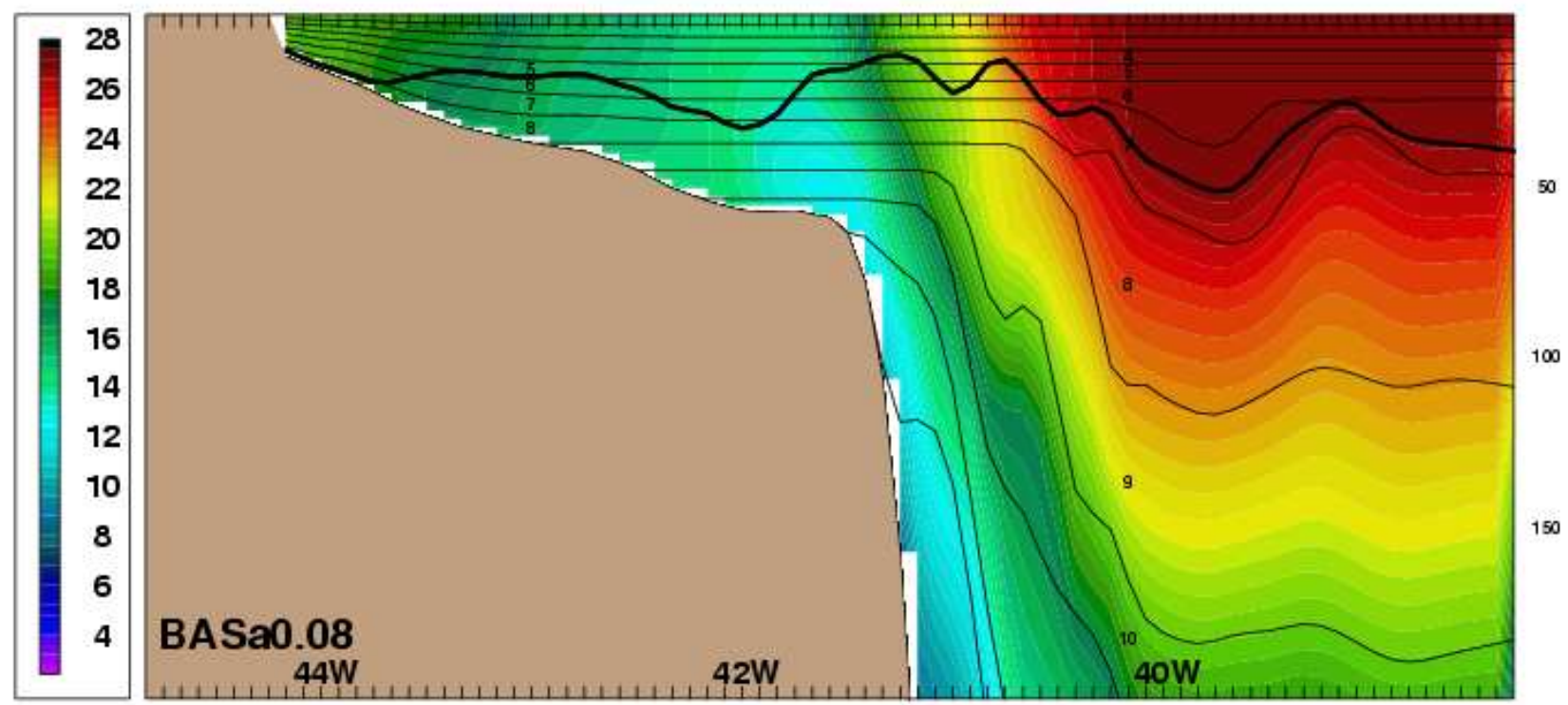

Figura 4.30: Seção zonal de temperatura na latitude $23^{\circ} \mathrm{S} 03 \mathrm{Z}$ dia $24 \mathrm{JAN}$. As linhas sólidas nesssas figuras representam superfícies coordenadas: isopicnais no interior; camadas " $z$ ", na camada de mistura; e coordenadas sigma nas regiões mais rasas da plataforma continental. A linha mais grossa representa aproximadamente o fundo da camada de Ekman.

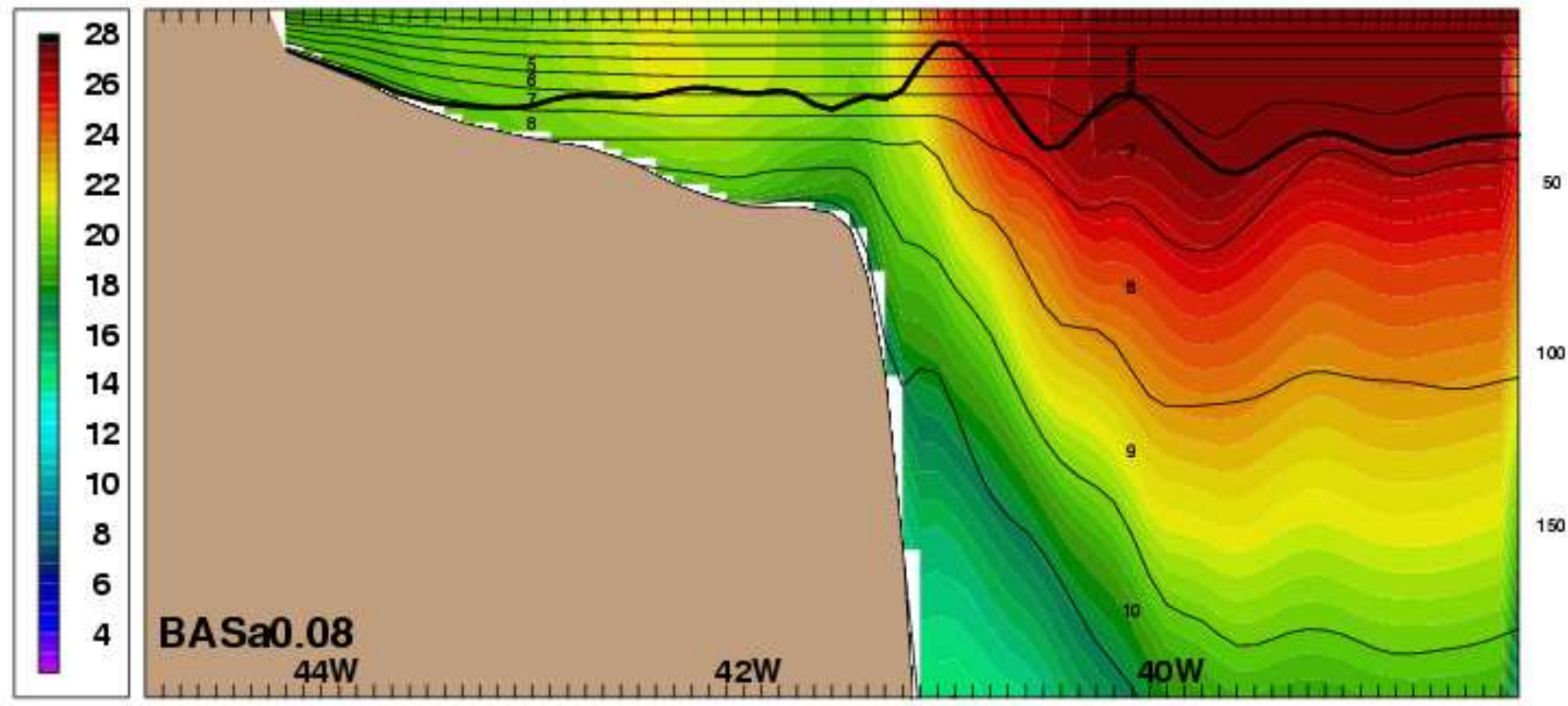

Figura 4.31: Seção zonal de temperatura na latitude $23^{\circ} \mathrm{S} 03 \mathrm{Z}$ dia $28 J A N$. 
Nas figuras 4.32 e 4.33 temos as mesmas seções para a salinidade. Observa-se na figura 4.32 uma região na plataforma com tonalidade verde clara indicando valores de salinidade menores.

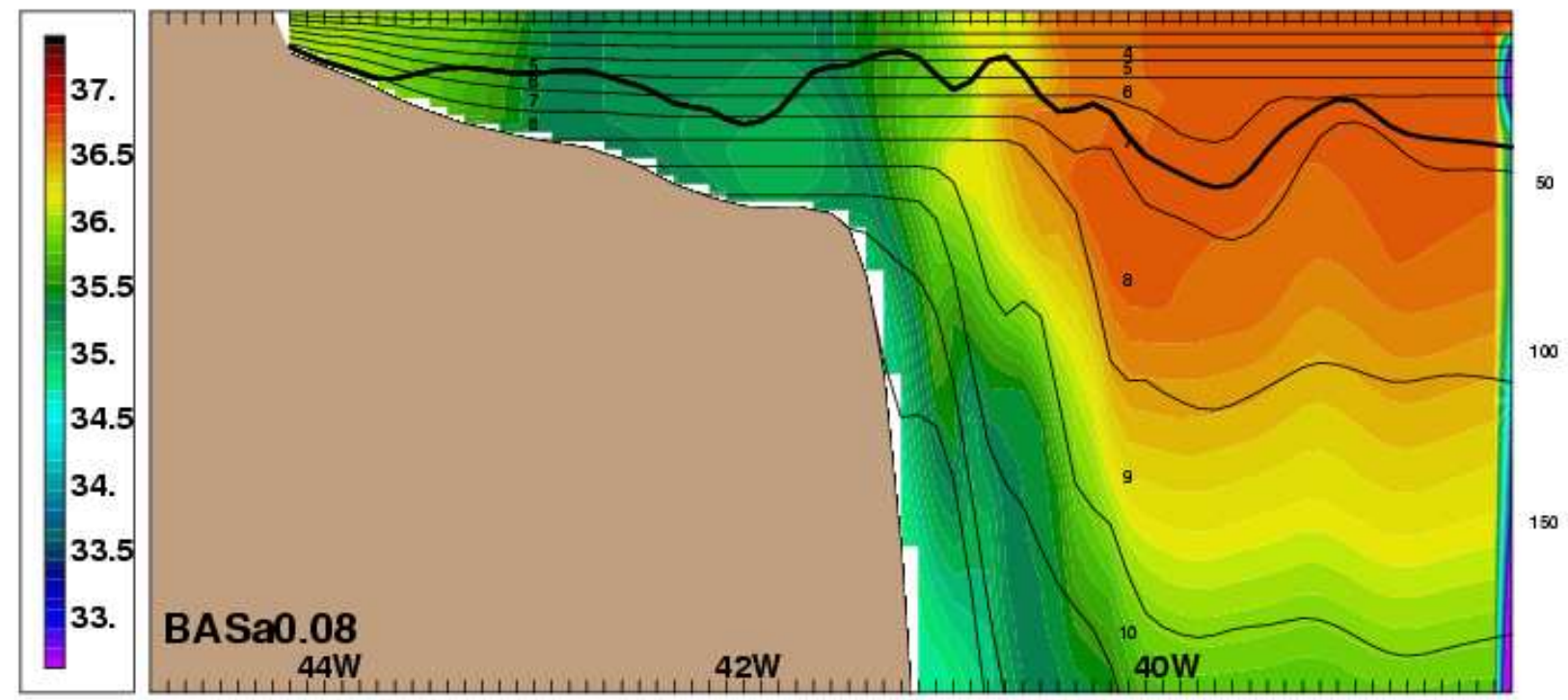

Figura 4.32: Seção zonal de salinidade na latitude $23^{\circ} \mathrm{S} 03 \mathrm{Z}$ dia $24 J A N$

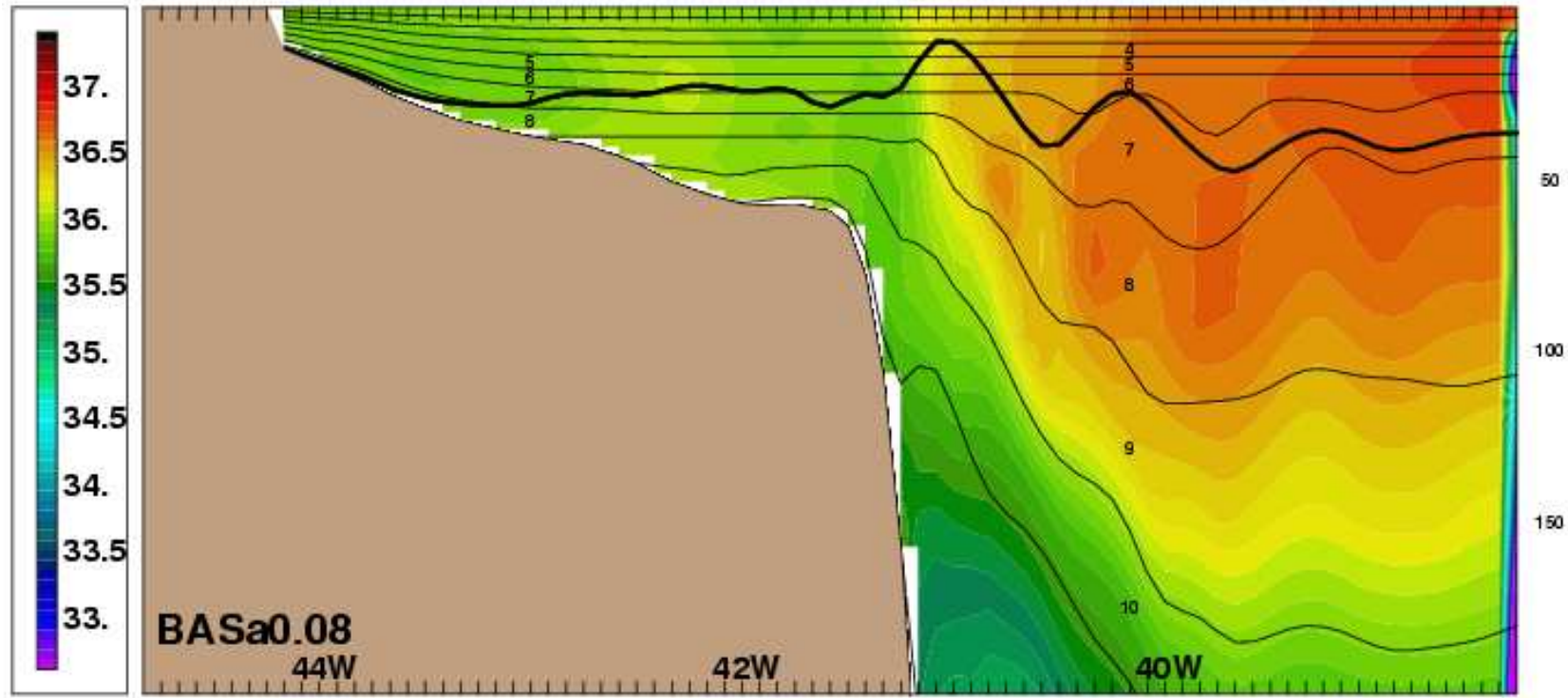

Figura 4.33: Seção zonal de salinidade na latitude $23^{\circ} \mathrm{S} \mathrm{O3Z}$ dia $28 \mathrm{JAN}$ 
Franchito e al., 1998, investigou a atuação da circulação local na ressurgência e vice-versa da ressurgência na circulação local e constatou que, em ambos os casos, um tem o efeito de intensificar o outro. Para investigar o efeito da brisa na ressurgência de Cabo Frio Franchito e al., 1998 usou um modelo oceânico de duas camadas cujo detalhes pode ser encontrado em Lorenzetti et al., 1987. A intensidade da ressurgência neste modelo oceânico é determinada por valores da anomalia de elevação na interface das camadas. Num modelo de duas camadas, a ressurgência é caracterizada por um decréscimo da espessura da camada superior, o que está associada à anomalias positivas de interface. No caso da brisa do mar atuando ao norte de Cabo Frio, onde a orientação da costa é NE-SW, verificou-se que a mudança na direção dos ventos predominantes de NE provocada pela atuação da brisa do mar não contribuía para a intensificação do fenômeno da ressurgência. Isso ocorria pois os vento predominante de NE, paralelo à orientação da linha de costa, caracterizava uma direção favorável ao transporte de Ekman para fora da costa, o que, consequentemente, contribuía para a ocorrência da ressurgência costeira. A atuação da brisa gerava um vento resultante com direção não mais paralelo à costa, não contribuindo assim para a ressurgência. Nas figuras 4.34 e 4.35 temos duas seções meridionais de temperatura na longitude de $41.6^{\circ} \mathrm{W}$, a primeira correspondendo às $03 \mathrm{Z}$ horas e a segunda às $18 \mathrm{Z}$ horas, sendo a figura 4.35 caracterizada com a presença da brisa marinha. Apesar de não ser possível uma conclusão mais definitiva, uma vez que a forçante do vento apresenta oscilações de diferentes freqüências, a modesta diminuição da ressurgência parece estar certa forma de acordo com o enfraquecimento citado no trabalho de Franchito e al., 1998 tendo em vista que as seções foram feitas ao norte de Cabo Frio, onde a orientação da costa é na direção NE-SW. 


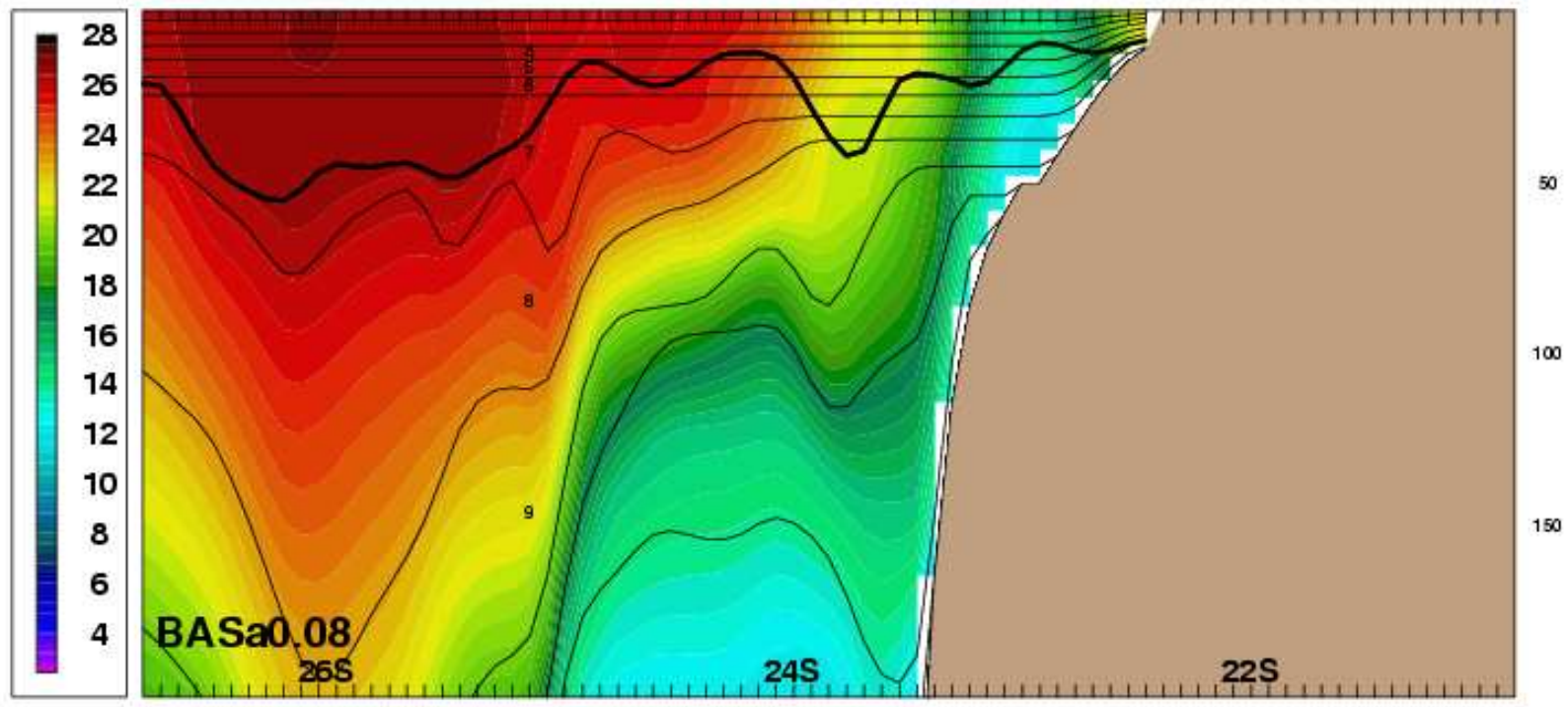

Figura 4.34: Seção meridional de temperatura na longitude $41.6^{\circ} \mathrm{W} 03 \mathrm{Z}$

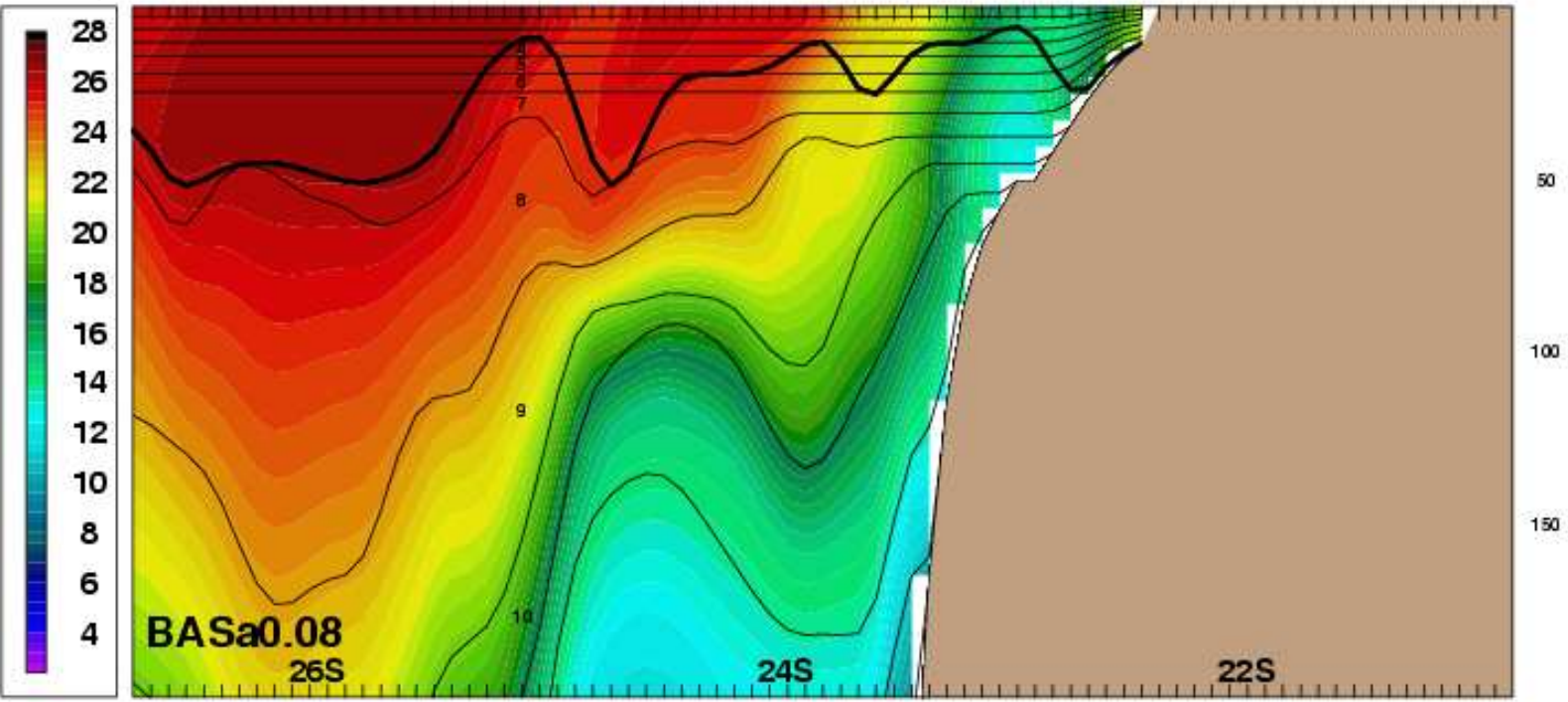

Figura 4.35: Seção meridional de temperatura na longitude $41.6^{\circ} \mathrm{W} \mathbf{1 8 Z}$ 
Nas figuras 4.36 e 4.37 temos as mesmas duas seções meridionais na longitude de $41.6^{\circ} \mathrm{W}$, porém agora para a salinidade sendo a primeira correspondendo às $03 \mathrm{Z}$ horas e a segunda às $18 \mathrm{Z}$ horas, sendo a figura 4.37 caracterizada com a presença da brisa marinha.

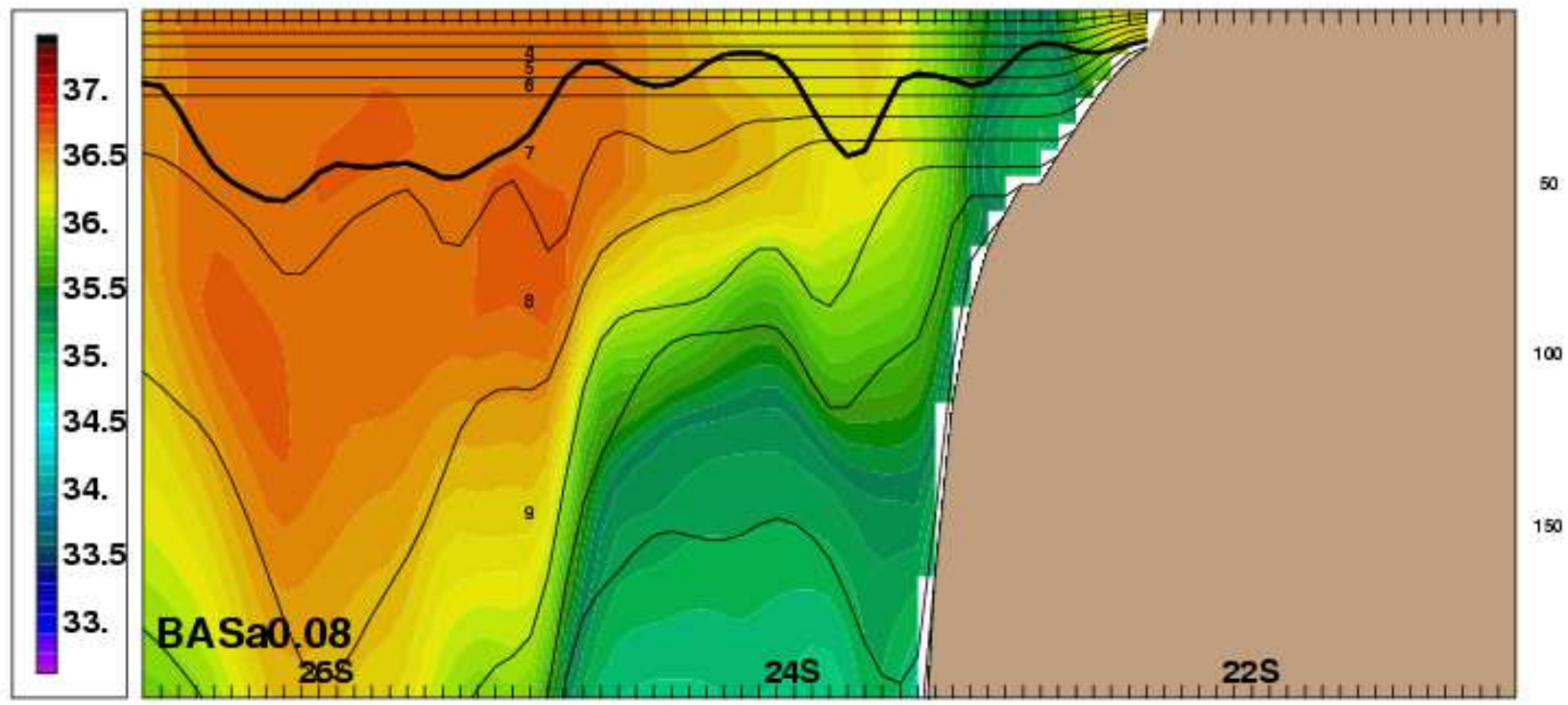

Figura 4.36: Seção meridional de salinidade na longitude $41.6^{\circ} \mathrm{W} 03 \mathrm{Z}$

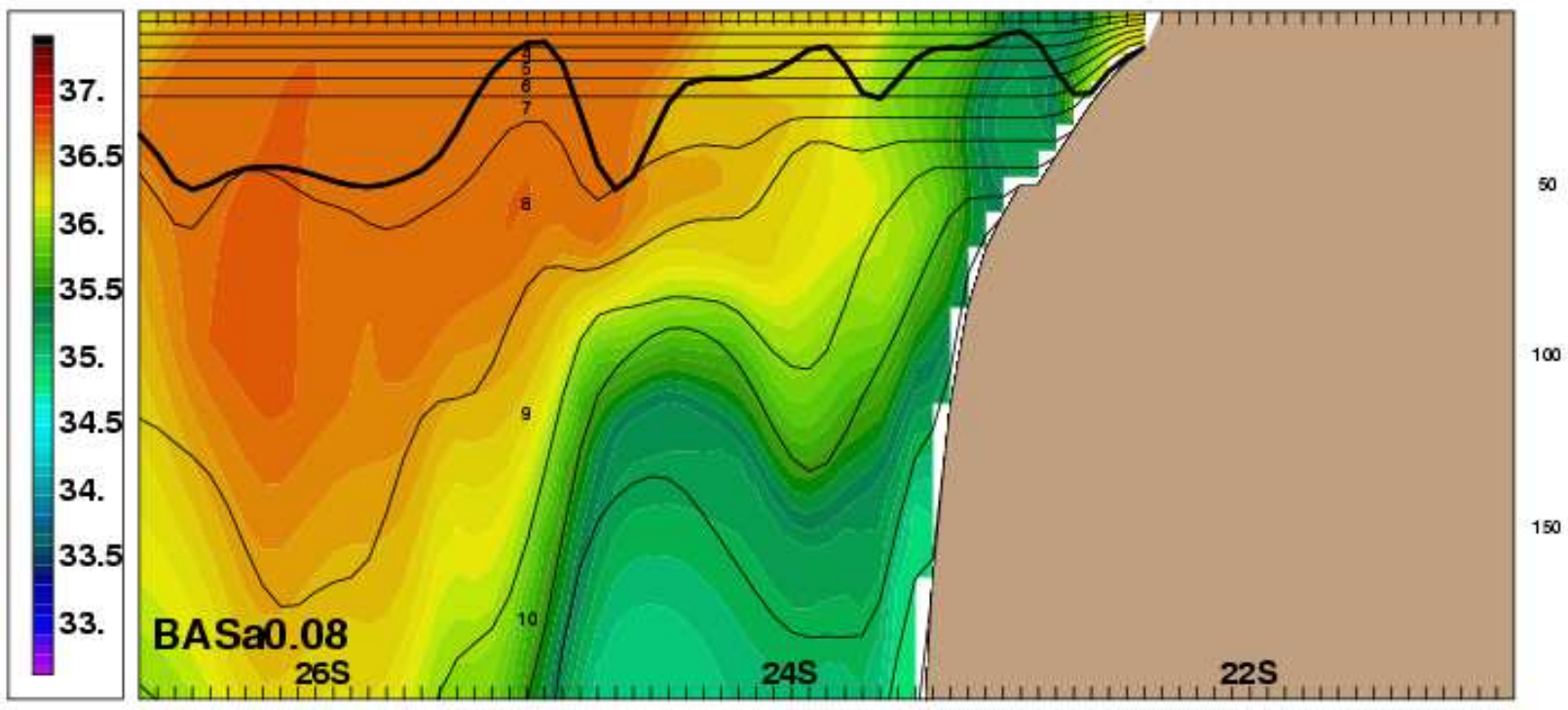

Figura 4.37: Seção meridional de salinidade na longitude $41.6^{\circ} \mathrm{W} \mathbf{1 8 Z}$ 


\section{Capítulo 5}

\section{Conclusão e sugestões para trabalhos futuros}

\subsection{Sumário e Conclusões}

Neste trabalho, com base em análise de dados observacionais e resultados de mo delo numérico, foi realizada uma investigação da influência de transientes de alta frequência do regime de ventos na ressurgência de Cabo Frio, tanto nos meses de verão quanto em época de inverno. Com os dados de final de inverno, referentes à setembro de 1972 , observamos o comportamento da isoterma de $16^{\circ} \mathrm{C}$, que representa de maneira satisfatória o limite superior da ACAS, fria e pouco salina, que penetra na plataforma interna de modo que esta isoterma é um bom indicador da intensidade da ressurgência. Esta mudança de profundidade da isoterma de $16^{\circ} \mathrm{C}$ que afunda de $70 \mathrm{~m}$ para $20 \mathrm{~m}$ e depois retorna novamente para superfície está claramente associada à chegada de um sistema frontal naquela região de acordo com as figuras 4.12 à 4.20 que consistem na evolução sinótica do sistema frontal através das cartas sinóticas obtidas junto à DHN. Esta resposta da isoterma de $16^{\circ} \mathrm{C}$ está coerente com a alteração do vento ocasionada pela passagem da frente fria o que justifica a alteração na sua profundidade. No gráfico apresentado no capítulo 4 observa-se um alteração de $50 \mathrm{~m}$ na profundidade da mesma o que está representado de maneira similar com os dados do modelo HYCOM na figura 4.25.

As séries temporais de dados hidrográficos coletados próximo à Cabo Frio mostram 
que a ACAS é a fonte da ressurgência na região. Esta água fria e pouco salina que aflora à superfície em Cabo Frio vem de profundidades em torno de $100 \mathrm{~m}$ na plataforma continental a partir do sul e sudeste de Cabo Frio, auxiliada pelo intenso gradiente topográfico presente no local. Na seção II da figura 4.10 podemos constatar que o intenso gradiente topográfico próximo à Cabo Frio contribui de maneira significativa para penetração da ACAS na plataforma interna. Pela mesma seção II observamos que a ACAS penetra, preferencialmente, pelo setor sul e sudeste a partir de Cabo Frio.

Com base nas anaálises dos dados observacionais e dos resultados dos experimentos numéricos, foi possível constatar que perturbações de alta freqüência, com períodos respresntativos de efeitos de brisa e passagem de sistemas frontais, podem aftar substancialmente a intensidade da ressurgência, principalmente na região imediatamente ao sul de Cabo Frio. Essa alteração da ressurgência se manifesta pela modificação apreciável observada na isoterma de $16^{\circ} \mathrm{C}$.

\subsection{Sugestão para trabalhos futuros}

Considerando-se que a alteração do campo de temperatura da superfície associada com a modificação do fenômeno da ressurgência pela alta freqüência deve por sua vez alterar o sistema de brisa, é de se esperar que esse tipo de estudo seja melhor realizado considerando-se essas interaçẽs não-lineares. Assim, como sugestão para trabalho futuro, sugere-se a utilização de um modelo acoplado oceano-atmosfera, com o qual se poderia obter melhores resultados. Seria altamente interessante também a obteção de séries de tempo mais longas, tanto da variação da profundidade da isoterma de 16 graus, quanto do sistema de ventos na região. 


\section{Referências Bibliográficas}

Arthur, R. S., On the calculation of vertical motion in eastern boundary currents from determinations of horizontal motion., J. Geophys. Res., 70, 2799-2803, 1965.

Bleck, R., An oceanic general circulation model framed in hybrid isopycnin-cartesian coordinates., Oc. Model, 37, 55-88, 2002.

Campos, E. J. D., J. E. Gonçalves, and Y. Ikeda, Water mass characteristics and geostrophic circulation in the south brazil bight: Summer of 1991, J. Geophys. Res., 100(C9), 18,537-18,550, 1995.

Campos, E. J. D., Y. Ikeda, B. Castro, S. A. Gaeta, L. J. A., and S. M. R., Experiment studies circulation in the western south atlantic., Am. Geophys. Union, r7(27), 253-259, 1996.

Campos, E. J. D., D. Velhote, and I. C. A. Silveira, Shelf break upwelling driven by brazil current cyclonic meanders, Geophys. Res. Lett., 27 NR 6, 751-754, 2000.

Castelão, R. M., E. J. D. Campos, and J. L. Miller, A modelling study of coastal upwelling driven by wind and meanders of the brazil current, J. of Coastal Res., 20(3), 662-671, 2004.

Castro, B. M., Correntes e massas de água da plataforma continental norte de são paulo. tese de livre docência, Instituto Oceanográfico da USP, 1982.

Castro, B. M., and L. B. Miranda, Physical oceanography of the western atlantic continental shelf located between $4^{\circ} \mathrm{n}$ to $34^{\circ} \mathrm{s}$, The sea, 11, 209-251, 1998.

Chen, D., L. Rothstein, and A. Busalacchi, A hybrid vertical mixing scheme and its application to tropical ocean models., J. Phys. Oceanogr., 24, 2156-2179, 1994. 
Crépon, M., and C. Richez, Transient upwelling generated by two-dimensional atmosphericforcing and variability in the coastline., J. Phys. Oceanogr., 12, 1437$1457,1982$.

Emilsson, I., The shelf and coastal waters off southern brazil., Bolm. Inst. Oceanogr., 11(2), 101-112, 1961.

Franchito, S. H., V. B. Rao, J. Stech, and J. A. Lorenzzetti, The effect of coastal upwelling on the sea-breeze circulation at cabo frio, brazil: A numerical experiment, Adv. Geophys., 16, 866-881, 1998.

Halliwell, G. R., Evaluation of vertical coordinate and vertical mixing algorithms in the hybrid-coordinate ocean model (hycom)., Oc. Model, 7, 285-322, 2004.

Hellerman, S., and M. Rosenstein, Normal monthly wind stress over the world ocean with error estimates., J. Phys. Oceanogr., 13, 1093-1104, 1983.

Hua, B. L., and F. Thomasset, A numerical study of the effects of coastline geometry on wind-induced upwelling in the gulf of lions., J. Phys. Oceanogr., 13, 678-694, 1983.

Levitus, S. B., and T. Boyer, World ocean atlas 1994, volume 4: Temperature, in NOAA Atlas NESDIS 4, U.S. Department of Commerce, Washington, D. C., 1994.

Levitus, S. B., R. Burget, and T. Boyer, World ocean atlas 1994, volume 3: Salinity, in NOAA Atlas NESDIS 4, U.S. Department of Commerce, Washington, D. C., 1994.

Mascarenhas, A. S., L. B. Miranda, and N. J. Rock, A study of the oceanographic conditions in the region of cabo frio., In: Costlow Jr., J.D. (Ed.), Fertility of The Sea, 1, 285-308, 1971.

Miranda, L. B., Análise de massas de água da plataforma continental e da região oceânica adjacente: cabo de são tomé (rj) a ilha de são sebastiião. tese de livre docência, Instituto Oceanográfico da USP, 1982. 
Osgood, K. E., J. M. Bane, and W. Dewar, Vertical velocities and dinamical balances in gulf stream meanders, J. Geophys. Res., 92, 13,029-13,040, 1987.

Peffley, M. B., and J. J. O'Brien, A three-dimensional simulation of coastal upwelling off oregon., J. Phys. Oceanogr., 6, 164-180, 1976.

Preller, R., and J. J. O'Brien, The influence of bottom topography on upwelling off peru., J. Phys. Oceanogr., 10, 1377-1398, 1980.

Rodrigues, R. R., and J. A. Lorenzzetti, A numerical study of the effects of bottom topography and coastline geometry on the southeast brazilian coastal upwelling, Continental Shelf Research, 21, 1271-1274, 2001.

Shaji, C., C. Wang, G. H. Jr., and A. Wallcraft, Simulation of tropical pacific and atlantic oceans using a hybrid coordinate ocean model., Oc. Model, 9(3), 253-282, 2005.

Silveira, I. C. A., A. C. K. Schmidt, E. J. D. Campos, S. S. de Godoi, and Y. Ikeda, A corrente do brasil ao largo da costa leste brasileira., Rev. Bras. Oceanogr., 48(2), 171-183, 2000.

Stech, J., and J. A. Lorenzzetti, The response of the south brazil bight to the passage of wintertime colds fronts, J. Geophys. Res., 97(C6), 9507-9520, 1992.

Valentim, J. L., D. L. André, and S. A. Jacob, Hidrobiology in the cabo frio (brazil) upwelling: two-dimensional structure and variability during a wind cicle., Continental Shelf Research, 7(1), 77-88, 1987.

Yoshida, K., Circulation in the eastern tropical oceans with special reference to upwelling and undercurrents, Japanese Journal of Geophysics, 4(2), 1-75, 1967. 